CENTRO UNIVERSITÁRIO DA FEI

DRYELE DANTE SASSO

ELABORAÇÃO DE VIDRO COM ABSORÇÃO DE RAIOS ULTRAVIOLETA POR MEIO DA ADIÇÃO DE FRITAS NOS CANAIS DE ALIMENTAÇÃO DE UM FORNO VIDREIRO

São Bernardo do Campo

2018 


\section{ELABORAÇÃO DE VIDRO COM ABSORÇÃO DE RAIOS ULTRAVIOLETA POR MEIO DA ADIÇÃO DE FRITAS NOS CANAIS DE ALIMENTAÇÃO DE UM FORNO VIDREIRO}

Dissertação de mestrado, apresentada ao Centro Universitário da FEI, como parte dos requisitos necessários para obtenção do título de Mestre em Engenharia de Mecânica com ênfase em Materiais e Processos, orientado pelo Prof. Dr. Fernando dos Santos Ortega.

São Bernardo do Campo 
Dante Sasso, Dryele.

ELABORAÇÃO DE VIDRO COM ABSORÇÃO DE RAIOS ULTRAVIOLETA POR MEIO DA ADIÇÃO DE FRITAS NOS CANAIS DE ALIMENTAÇÃO DE UM FORNO VIDREIRO / Dryele Dante Sasso. São Bernardo do Campo, 2018. 73 f. : il.

Dissertação - Centro Universitário FEI.

Orientador: Prof. Dr. Fernando dos Santos Ortega.

1. âmbar. 2. flint. 3. color-feeder. 4. transmitância. 5. cromaticidade. I. dos Santos Ortega, Fernando, orient. II. Título.

Elaborada pelo sistema de geração automática de ficha catalográfica da FEI com os dados fornecidos pelo(a) autor(a). 
Título do Trabalho: Elaboração de vidro com absorção de raios ultravioleta por meio da adição de fritas nos canais de alimentação de um forno vidreiro.

Área de Concentração: Materiais e Processos

Orientador: Prof. Dr. Fernando dos Santos Ortega

Data da realização da defesa: 29/01/2018

Avaliação da Banca Examinadora:

São Bernardo do Campo, 29 / 01 / 2018.

MEMBROS DA BANCA EXAMINADORA

Prof. Dr. Fernando dos Santos Ortega

Prof. Dr. Mauro Akerman

Prof. Dr. Eduardo Bellini Ferreira
Ass. :

Ass.:

Ass. :

A Banca Julgadora acima-assinada atribuiu ao aluno o seguinte resultado:

APROVADO $\bigotimes$

REPROVADO $\square$

\section{VERSÃO FINAL DA DISSERTAČ̃̃O}

APROVO A VERSÃO FINAL DA DISSERTAÇÃO EM QUE FORAM INCLUÍDAS AS RECOMENDAÇÕES DA BANCA EXAMINADORA
Aprovação do Coordenador do Programa de Pós-graduação 


\section{AGRADECIMENTOS}

Meus sinceros agradecimentos a todas as pessoas que contribuíram para a realização desse projeto, especialmente: Fernando Ortega, Catia Fredericci, Edson Toporcov, João Luis Abel, Mariléia Souza, Antonio Souza, Mauro Akerman, Ricardo Aurélio da Costa e Stephanie Roedel. 


\section{RESUMO}

As embalagens de vidro âmbar retêm parte da radiação ultravioleta não absorvida pela camada de ozônio, por este motivo, são largamente utilizadas no setor farmacêutico, onde a estabilidade do medicamento pode ser afetada pela interação com a luz, implicando na perda do efeito terapêutico ou formação de produtos de degradação tóxicos. A coloração e a retenção de radiação ultravioleta apresentada pelo vidro âmbar se deve à formação do cromóforo $\mathrm{Fe}^{3+}$ $\mathrm{S}^{2-}-\mathrm{O}^{2-}-\mathrm{Na}^{+}$, que se forma em condições redutoras no interior do forno de fusão. O vidro âmbar e o vidro flint são produzidos em fornos de fusão, já o vidro colorido, pode ser produzido por um sistema denominado como color feeder. Nesse sistema, a mistura dos óxidos que irão colorir o vidro ocorre em um dos canais de alimentação, em condições diferentes daquela encontrada no forno de fusão. Este trabalho foi realizado em parceria com uma indústria vidreira, a qual possui pouca demanda de vidro âmbar em relação ao vidro flint, sendo assim, o forno de fusão funciona apenas por alguns meses fabricando vidro âmbar, e então, efetua-se o desligamento do forno ou a transição para vidro flint, gerando custos elevados. Portanto, este trabalho teve por objetivo flexibilizar a produção deste tipo de vidro, determinando uma composição de óxidos que pudessem gerar vidro com retenção de UV pelo processo de color-feeder a partir do vidro flint. Os testes foram efetuados em pequena escala a partir da fusão de cacos de vidro flint de composição conhecida a $1300{ }^{\circ} \mathrm{C}$ por $2 \mathrm{~h}$, em cadinho refratário. Após fusão, foram adicionadas fritas, selecionadas com base na revisão bibliográfica, seguindo um planejamento fatorial $2^{\mathrm{k}}$ tendo como variável de saída a transmitância na faixa de 290 a $450 \mathrm{~nm}$. Tomou-se como referência o limite de $10 \%$ de transmitância na faixa de 290 a $450 \mathrm{~nm}$ estabelecido pela Farmacopeia Americana. Devido ao preparo ser manual, as amostras apresentaram certa variabilidade na espessura, que foi corrigida para $3 \mathrm{~mm}$ utilizando as leis de Fresnel e Lambert Beer, possibilitando as comparações. As coordenadas tricromáticas das amostras foram calculadas de acordo com a CIE (Commission Internationale de l'Eclairage). Foi encontrado assim, que uma composição com teor de fritas de 5\% B674UL (60\% Fe), 5\% 410JS(30,1\% Mn) e 2,5\% G924XP $(0,88 \%$ Se) que pode ser utilizada na fabricação de vidro com retenção de U.V. pelo processo de color-feeder, em frascos com espessura igual ou superior a 1,6 mm.

Palavras chave: Âmbar; Flint; Color-feeder; Transmitância; Cromaticidade 


\begin{abstract}
The stability of a drug is the ability to maintain its properties within the specified limits during the validity period, and it can be affected by several factors, such as interaction with light, a source of energy, that will impact the rate of degradation reactions. To alleviate this problem, amber glass are used as packages to retain part of the ultraviolet radiation (U.V.) that has not been fully retained by the ozone layer. The colouring and retention of ultraviolet radiation is obtained by the chromophore $\mathrm{Fe}^{3+} \mathrm{S}^{2-} \mathrm{O}^{2-} \mathrm{Na}^{+}$formed under reducing conditions inside the melting furnace. Ambar glass and flint glass require furnaces dedicated to their production, which is not the case with colored glass, since it can be produce by a system called color feeder. In this system, the mixture of the oxides that will color the glass are made through feed channels, under different conditions from that found in the melting furnace. However, the industry that requested this research has low demand of ambar in relation to flint glass, so when demand is met, the switch-off or transition to flint glass is effected. Both options will result high costs. Therefore, the objective of this work is to flexibilize the production of this type of glass, producing it by the color-feeder process from the flint glass. The tests were carried out on a small scale by the fusion of cullet flint glass, with known composition, at $1300^{\circ} \mathrm{C}$ for 2 hours in refractory crucible. After fusion, frits were added, selected based by bibliographic review, following a $2^{\mathrm{k}}$ factorial design having as output variable the transmittance in the range of 290 to $450 \mathrm{~nm}$. The $10 \%$ transmittance limit in the 290 to $450 \mathrm{~nm}$ range established by the American Pharmacopoeia was taken as reference. Due to the manual preparation, the samples showed a certain variability in thickness, which was corrected to $3 \mathrm{~mm}$ using the Fresnel and Lambert Beer laws, making comparisons possible. The trichromatic coordinates of the samples were calculated according to the ICD. It was thus found that a composition having 5\% B674UL $(\mathrm{Fe}), 5 \%$ 410JS (Mn) and 2.5\% G924XP (Se) frit content produces glass with U.V. by the colorfeeder process, in bottles with a thickness of 1,6 mm or more.
\end{abstract}

Keywords: Amber; Flint; Color-feeder; Transmittance; Chromaticity 


\section{LISTA DE FIGURAS}

Figura 1 - Volume específico em função da temperatura, sendo a curva ACD, a solidificação de um material cristalino e a curva $\mathrm{ABEF}$, de um material vítreo.

Figura 2 - Efeito do fundente $\left(\mathrm{Na}_{2} \mathrm{O}\right)$ na estrutura do vidro de sílica. $\mathrm{O} \mathrm{Na} 2 \mathrm{O}$ favorece a quebra das ligações entre oxigênio e sílicio, fragmentando a rede tridimensional de átomos de sílica, reduzindo consequentemente a temperatura de fusão.

Figura 3 - Exemplo de mistura de cores (a) Aditiva; (b) Subtrativa.

Figura 4 - Esquema de um forno contínuo a gas/óleo combustível, e o fluxo do processo, desde a adição de matéria prima, até a elaboração do frasco

Figura 5 - Esquema de distribuição da massa vítrea em um forno vidreiro pelos canais de alimentação com sistema color-feeder.

Figura 6 - Gráfico de viscosidade versus temperatura para vidros de composições diferentes, demonstrando a influência da temperatura na viscosidade e sua consequência no processo, desde fusão até a deformação do vidro.

Figura 7 - Curva de concentração de enxofre retido no vidro em função de $\mathrm{Fe}^{2+} / \mathrm{Fe}_{\text {total, }}$, associada ao número redox. 26

Figura 8 - Mudança na intensidade de um feixe de luz ao passar sobre um vidro de espessura d.

Figura 9 - Múltiplas reflexões da luz incidente na superfície de um vidro. 32

Figura 10 - Diagrama de cromaticidade proposto pela CIE, possuindo o espectro de 410 a 780 nm.

Figura 11 - Cadinho refratário com 400g de caco flint, utilizado para simular o processo de color feeder, de modo a obter uma massa vítrea para mistura dos óxidos colorantes e conformação das amostras.

Figura 12 - Forno tipo poço a combustão, utilizado para fusão da massa vítrea, com uma mistura de ar e gás natural, contendo três queimadores laterais, direcionados ao cadinho. . 44

Figura 13 - Visão interna do forno com o cadinho já inserido e posicionado entre os queimadores.

Figura 14 - a) Medição da temperatura da massa vítrea, após o tempo de residência de 2 horas, para fusão do caco; b) Medição da porcentagem de oxigênio na atmosfera do forno.

Figura 15 - Fritas fundindo sobre a massa vítrea após serem inseridas no cadinho. 45

Figura 16 - Processo de agitação da massa vítrea com vareta refratária, simulando os agitadores do processo de color-feeder. 
Figura 17 - a) Processo de vazamento; b) formação da gota; c) corte da gota; e d) prensagem manual para elaboração das amostras.

Figura 18 - Forno utilizado para recozimento das amostras.

Figura 19 - Amostras cortadas e polidas, preparadas para análise de transmitância. (a) Grupo 1;

(b) Grupo 2 .

Figura 20 - (a) Curva de transmitância do bloco 1, corrigida para espessura de 3mm, (b) Curva de transmitância do bloco 2, corrigida espessura para 3mm, (réplica do Bloco 1). As composições idênticas entre os blocos possuem as mesmas cores, por exemplo, $\mathrm{G} 22=\mathrm{G} 26$ (curva em vermelho).

Figura 21 - Resultados do Grupo 1: Coordenadas tricromáticas das amostras para transmitância corrigida espessura para $3 \mathrm{~mm}$. As composições idênticas entre os blocos possuem as mesmas cores, por exemplo, G22=G26 (curva em vermelho). 50

Figura 22 - Gráfico de pareto dos efeitos padronizados para as amostras do grupo 1. .52

Figura 23 - Grafico de pareto dos efeitos padronizados para as amostras do grupo 1, sem o efeito da interação $\mathrm{AB}$. 52

Figura 24- Gráfico de probabilidade normal dos efeitos padronizados para amostra do grupo 1.

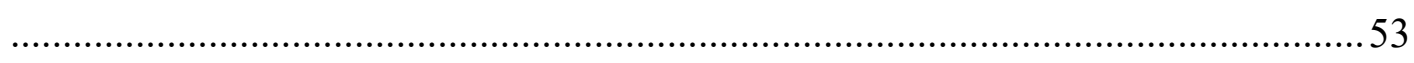

Figura 25 - Gráfico de contorno das amostras do grupo 1. 54

Figura 26 - Curva de concentração de enxofre retido no vidro em função de $\mathrm{Fe}^{2+} / \mathrm{Fe}_{\text {total}}$, associada ao número redox, para determinação do número redox da amostra G26 56

Figura 27 - Curva de transmitância das amostras do grupo 2 corrigidas para a espessura de $3 \mathrm{~mm}$.

Figura 28 - Coordenadas tricromáticas das amostras do grupo 2 para transmitância corrigida na espessura de $3 \mathrm{~mm}$.

Figura 29 - Gráfico de Pareto dos efeitos padronizados das amostras do grupo 2 ....... 61

Figura 30 - Gráfico de Pareto dos efeitos padronizados das amostras do grupo 2, sem o efeito da interação BC. 61

Figura 31 - Gráfico de probabilidade normal dos efeitos padronizados, para o grupo 2. 62

Figura 32 - Gráfico de contorno para as amostras do grupo 2.

Figura 33 - Curva de concentração de enxofre retido no vidro em função de $\mathrm{Fe}^{2+} / \mathrm{Fe}_{\text {total }}$, associada ao número redox, para determinação do número redox da amostra G11 65

Figura 34 - Influência da quantidade de fritas adicionadas sobre a área abaixo da curva de transmitância na faixa de comprimento de onda entre 290 e $450 \mathrm{~nm}$. 66 


\section{LISTA DE TABELAS}

Tabela 1- Regiões do espectro eletromagnético e respectiva frequência, energia e comprimento de onda.

Tabela 2- Concentração do elemento colorante em cada frita utilizada. 40

Tabela 3- Composição química média do caco Flint, analisado por fluorescência de raios-X.

Tabela 4- Planejamento experimental do grupo 1: B674UL (Fe) x G924XP (Se).

Tabela 5- Planejamento experimental do grupo 2: B674UL (Fe) x 410JS (Mn) x G924XP (Se).

Tabela 6- Resultados da integração das curvas das amostras do grupo 1 na faixa de 290 a 450nm com o software Origin. 51

Tabela 7- Análise de variância gerada pelo Minitab® para o grupo 1 54

Tabela 8- Coeficientes gerados pelo Minitab ${ }^{\circledR}$ para o grupo 1 . 54

Tabela 9- Análise química por fluorescência de Raios-X da amostra G26. 55

Tabela 10- Dados para calcular a relação $\mathrm{Fe}^{2+} / \mathrm{Fe}_{\text {total }}$ para inserir na curva de concentração de enxofre retido no vidro em função de $\mathrm{Fe}^{2+} / \mathrm{Fe}_{\text {total }}$, associada ao número redox.......55

Tabela 11- Soma das quantidades adicionadas de fritas para comparação com o resultado da integração das curvas das amostras do grupo 1 na faixa de 290 a $450 \mathrm{~nm}$ com o software Origin.

Tabela 12- Resultados da integração das curvas das amostras do grupo 2 na faixa de 290 a $760 \mathrm{~nm}$ com o software Origin.

Tabela 13- Análise de variância gerada pelo Minitab® para o grupo 2

Tabela 14- Coeficientes gerados pelo Minitab® para o grupo 2 . 63

Tabela 15- Análise química por fluorescência da amostra G11 65

Tabela 16- Dados para calcular a relação $\mathrm{Fe}^{2+} / \mathrm{Fe}_{\text {total }}$ para inserir na curva de concentração de enxofre retido no vidro em função de $\mathrm{Fe}^{2+} / \mathrm{Fe}_{\text {total, }}$ associada ao número redox 65

Tabela 17- Soma das quantidades adicionadas de frita em cada tratamento para comparação com o resultado obtido, no grupo 2 . 


\section{SUMÁRIO}

1. INTRODUÇÃO.......................................................................................... 10

$1.1 \quad$ OBJETIVO

2. REVISÃO BIBLIOGRÁFICA............................................................ 12

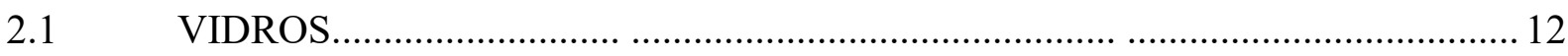

2.1.1 Definição de vidro..................................................................................................12

2.1.2 Composição do vidro.......................................................................................................... 13

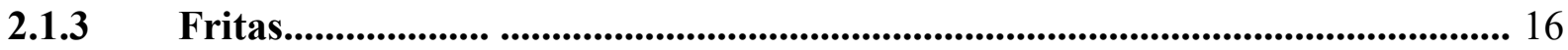

2.1.4 Fabricação do vidro..........................................................................19

2.1.5 Estado de oxidação da massa vítrea... .......................................................... 24

2.1.6 Vidro Flint... ..................................................................................................26

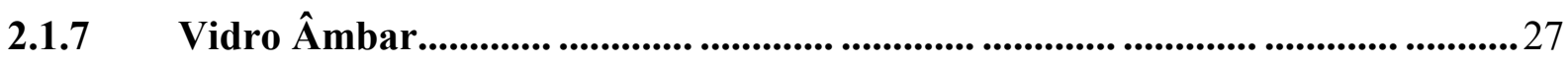

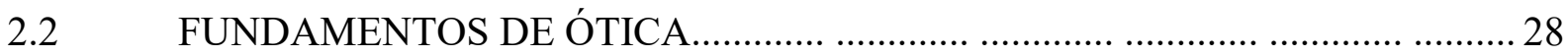

2.2.1 Definição de luz............................................................................................... 28

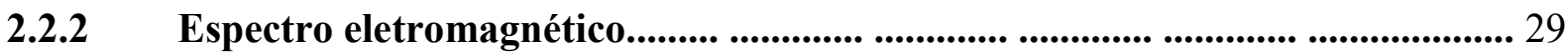

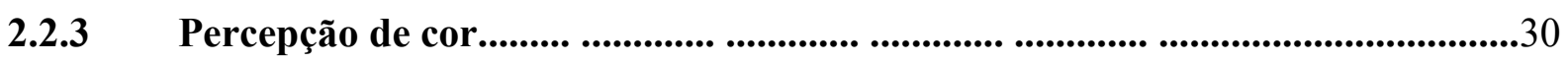

2.2.4 Transmitância em vidros.............................................................................. 30

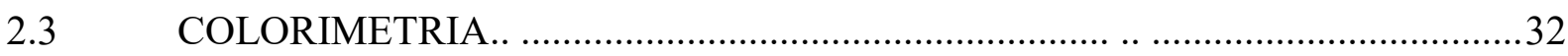

2.3.1 Ensaios para medição de cor.. ….................................................................................... 32

2.3.2 Coordenadas tricromáticas.. ....................................................................................... 33

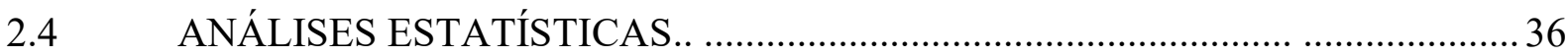

2.4.1 Experimentos com misturas.. _.................................................................... 36

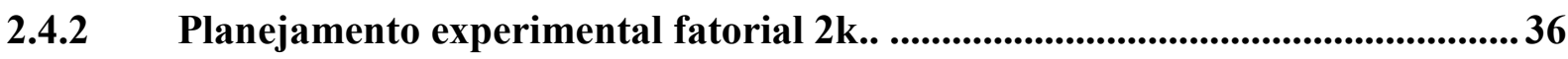

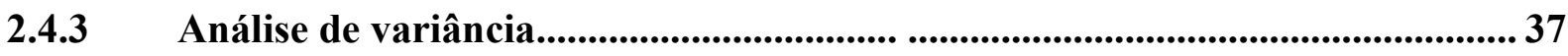

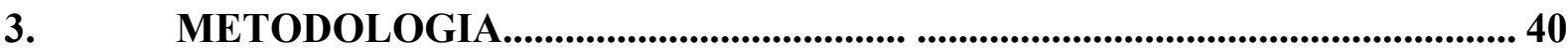

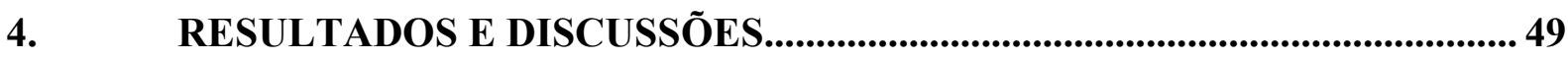

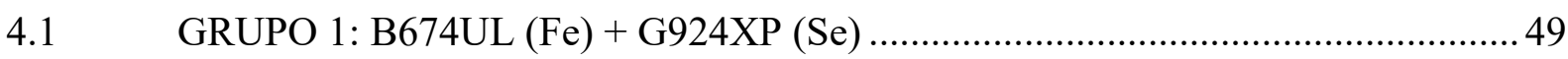

4.2 GRUPO 2: B674UL (Fe) + 410JS (Mn) + G924XP (Se) ................................... 57

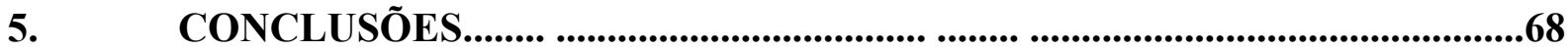

6. SUGESTÃO PARA TRABALHOS FUTUROS.........................................69

REFERÊNCIAS................................................................................................70 



\section{INTRODUÇÃO}

O vidro âmbar é utilizado quando existe a necessidade de reter a radiação ultravioleta, onde a estabilidade do produto pode ser afetada pela interação com a luz, implicando na perda de propriedades do produto ou formação de produtos de degradação tóxicos. Ele é produzido sob condições redutoras e necessita de um forno dedicado à sua produção, bem como o vidro flint, que é produzido em condições oxidantes. Já o vidro colorido não necessita de um forno exclusivo a sua produção, visto que pode ser produzido por sistema denominado como color feeder, onde a mistura dos óxidos que irão dar cor ao vidro acontece em um dos canais de alimentação.

Este trabalho foi desenvolvido em parceria com uma indústria vidreira de grande porte, a qual disponibilizou o acesso às informações, as amostras e aos laboratórios. Na indústria vidreira em que este trabalho foi desenvolvido, a demanda de vidro âmbar é baixa em comparação ao vidro flint, de modo que, ao atingir a quantidade de vidro âmbar solicitada, é efetuada a troca da fabricação de vidro âmbar para flint, pela mudança das matérias-primas adicionadas no forno de fusão, ou o forno poderá ser desligado. Após o desligamento ou a transição, as necessidades pontuais de clientes podem ser atendidas com os frascos em estoque, mas não são atendidas para frascos especiais ou volumes além do estocado até o próximo acionamento ou transição.

Além da falta de flexibilidade, deve-se considerar que sucessivos desligamentos implicam em uma redução de vida útil do forno e aumento de gastos com manutenção, visto que os refratários do forno, com o aquecimento, se dilatam e, com o resfriamento, se contraem, podendo gerar quebras, ou trincas que irão se propagar a cada novo ciclo de temperaturas.

Também é necessário considerar o alto custo devido ao vidro rejeitado na transição e ao vidro que poderia ser produzido neste período, que leva em torno de 20 dias $^{1}$ para transitar de vidro âmbar para flint e 5 dias para transitar de vidro flint para âmbar. Em caso de desligamento, levam-se 20 horas para drenar todo o vidro fundido dentro do forno de fusão, e 8 dias para que seja possível iniciar a produção, na etapa de acionamento.

\subsection{OBJETIVO}

Este trabalho tem como objetivo desenvolver uma composição de vidro com capacidade de reter radiação ultravioleta similar à do vidro âmbar através da adição de fritas contendo

\footnotetext{
${ }^{1} \mathrm{O}$ vidro flint produzido nesta indústria vidreira é do tipo extra branco, no qual limita-se a quantidade de ferro até no máximo 200ppm. Isso aumenta a quantidade de vidro que deverá passar pelo forno para "limpar" o forno e os canais, da coloração âmbar que possui alto teor de Ferro.
} 
óxidos colorantes ao vidro flint, em condição oxidante semelhante à do color-feeder. Os resultados gerados neste trabalho serão posteriormente testados em um canal de alimentação de uma linha de produção da indústria vidreira em que o estudo é desenvolvido. 


\section{REVISÃO BIBLIOGRÁFICA}

Toda a pesquisa elaborada teve como base as seções que serão apresentadas a seguir.

\subsection{VIDROS}

Nesta seção será apresentado o processo envolvido na transformação das matériasprimas em vidro, bem como os fatores que podem afetar a qualidade final do vidro formado.

\subsubsection{Definição de vidro}

Vidros são materiais não se cristalizam durante resfriamento, mas sim, mantêm a estrutura de um líquido, ou seja, amorfa (ZANOTTO; MAURO, 2017). O estado vítreo é melhor explicado pelo gráfico da Figura 1 .

Figura 1- Volume específico em função da temperatura, sendo a curva ACD, a solidificação de um material cristalino e a curva ABEF, de um material vítreo.

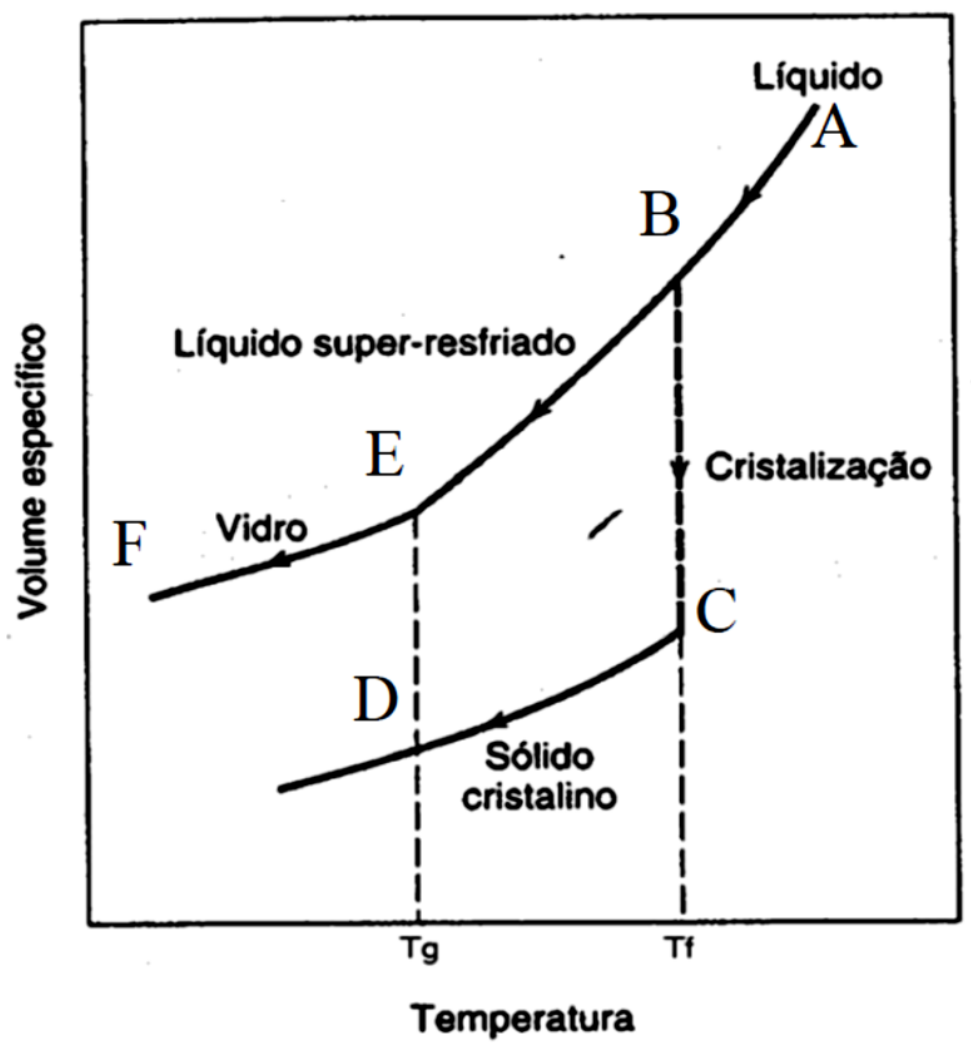

Fonte- Autor, "adaptado de" CALLISTER, 2002

O ponto A representa um material qualquer em estado líquido. Se este material fundido, com alta mobilidade entre seus átomos devido à alta temperatura, sofrer resfriamento, ocorrerá um aumento da viscosidade, visto que os átomos irão perder a mobilidade pelo decréscimo de temperatura, e se esses átomos conseguirem se organizar, eles irão gerar estruturas denominadas como cristalinas. No gráfico, isso é representado pelo ponto B para $\mathrm{C}$, que também indica uma retração volumétrica devido a organização dos átomos, ocupando um volume menor do que 
quando estavam com alta mobilidade ou desorganizados. Materiais metálicos seguem esse tipo de processo durante o resfriamento, por exemplo. Porém, existem materiais que durante o resfriamento, o aumento de viscosidade é tão alto, devido a velocidade de resfriamento, que os átomos não conseguem se organizar e geram uma estrutura denominada amorfa, ou seja, sem forma, sem organização. Isto é o que acontece com os vidros. No gráfico, essa transformação é representada pelo ponto E. O ponto E está num intervalo de transformação que depende da velocidade de resfriamento. Neste intervalo está situado a temperatura de transição vítrea (Tg), que representa o limite entre a forma plástico-viscosa.

\subsubsection{Composição do vidro}

Existem vários óxidos capazes de formar vidros, dentre eles, a sílica é a mais utilizada pelo baixo custo e maior disponibilidade na crosta terrestre. Segundo teoria de Zachariasen, no vidro de sílica são formados tetraedros de sílica, nos quais cada átomo de oxigênio está ligado a dois átomos de silício (RAO, 2002).

Devido à forte energia de ligação Si-Si é mais dispendioso trabalhar apenas com a sílica, pois a energia para romper essas ligações é elevada, ou seja, necessita-se de temperaturas mais altas, então, por este motivo, são adicionados fundentes, que reduzem a temperatura de fusão.

O fundente favorece a formação de oxigênios não ligados, o que deixa o vidro mais vulnerável ao ataque da água, pois facilita a formação de hidróxido por romper as ligações entre oxigênio e silício, conforme ilustrado na Figura 2 (ASKELAND;PHULÉ,2008).

Figura 2- Efeito do fundente $\left(\mathrm{Na}_{2} \mathrm{O}\right)$ na estrutura do vidro de sílica. $\mathrm{O} \mathrm{Na} 2 \mathrm{O}$ favorece a quebra das ligações entre oxigênio e sílicio, fragmentando a rede tridimensional de átomos de sílica, reduzindo consequentemente a temperatura de fusão.

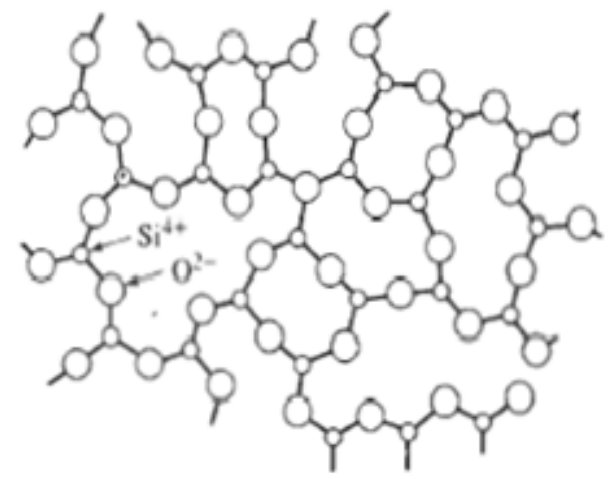

Vidro de $\mathrm{SiO}_{2}$

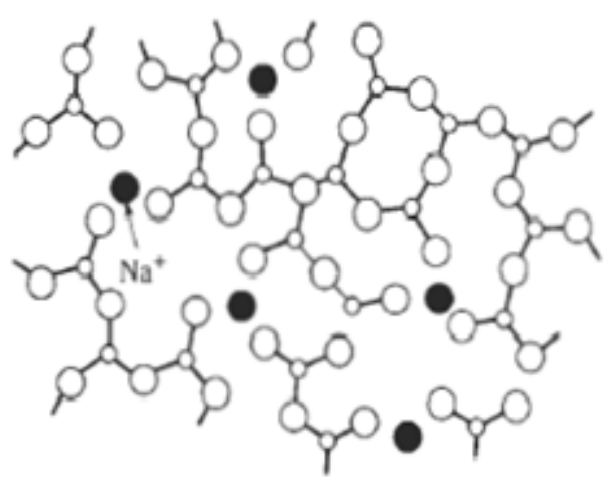

Vidro modificado por $\mathrm{Na}_{2} \mathrm{O}$

Fonte- AKERMAN, 2007

Para atenuar esta vulnerabilidade, são adicionados estabilizantes que também atuam como fundentes, mas que não reduzem a resistência do vidro ao ataque da água. 
Durante a fusão dessas matérias-primas ocorre liberação de gás, e por ser uma massa de alta viscosidade, o gás liberado fica preso na massa fundida em forma de bolhas. Para liberar essas bolhas de forma mais rápida, são adicionados agentes afinantes que formam bolhas ainda maiores e, portanto, com maior força de ascensão, carregam as pequenas bolhas (AKERMAN, 2007).

O estado de oxidação do banho influencia a coloração do vidro, assim como as impurezas que estão contidas na matéria-prima. Por este motivo, são adicionados agentes oxidantes e/ou redutores de acordo com a necessidade, para equilíbrio das reações de oxiredução, e também elementos descolorantes, quando necessário.

As matérias-primas que fornecem esses elementos contêm algumas impurezas, por este motivo, o cálculo percentual da composição não consegue ser preciso, mas deve satisfazer os limites de tolerância. É necessário ter uma análise química das matérias-primas para cálculo da fornada ou da composição do vidro.

As matérias-primas podem ser minerais provenientes da natureza, que são purificados ou beneficiados após extração ou produtos químicos comerciais.

Vidro para embalagem, que é o foco deste trabalho, possui geralmente de 13 a $17 \%$ de $\mathrm{Na}_{2} \mathrm{O} ; 5$ a $10 \%$ de $\mathrm{CaO} ; 70$ a $73 \%$ de $\mathrm{SiO}_{2}$ e o restante é composto por elementos como $\mathrm{MgO}$, $\mathrm{Al}_{2} \mathrm{O}_{3}, \mathrm{Fe}_{2} \mathrm{O}_{3}, \mathrm{~K}_{2} \mathrm{O}$ e $\mathrm{BaO}$ (BAMFORD,1997).

Os principais elementos constituintes do vidro são descritos abaixo:

$\underline{\text { Sílica }}$

A principal fonte de sílica é a areia, que consiste de grãos de quartzo. Geralmente é fornecida em grãos de tamanho maior que 20 mesh. Se os grãos forem muito pequenos, haverá perdas no processo de mistura, além de impactar a etapa de refino. A areia de grau 1 possui 99,6 a 99,8\% de sílica, geralmente com $0,3 \%$ de alumina e $0,025 \%$ de ferro. Os demais graus possuem teores maiores de ferro (NAROTTAM; DOREMUS, 1986).

Alumina

$\mathrm{O}$ feldspato $\left(\mathrm{R}_{2} \mathrm{O} \cdot \mathrm{Al}_{2} \mathrm{O}_{3} \cdot 6 \mathrm{SiO}_{2}\right)$ é a mais importante fonte de alumina. Ele pode ser encontrado livre de ferro e em um estado aceitável de pureza. Funde-se geralmente entre 1110 ${ }^{\circ} \mathrm{C}$ e $1200^{\circ} \mathrm{C}$. Os demais componentes do vidro se dissolvem no líquido formado pela fusão do feldspato. Vem acompanhado de outros óxidos usuais para elaboração do vidro, como $\mathrm{Na}_{2} \mathrm{O}$ ou $\mathrm{K}_{2} \mathrm{O}$ e $\mathrm{SiO}_{2}$. (NAROTTAM; DOREMUS, 1986).

A alumina hidratada $\left(\mathrm{Al}_{2} \mathrm{O}_{3} \cdot \mathrm{H}_{2} \mathrm{O}\right)$ é um produto artificial produzido pela precipitação de materiais como a bauxita. É utilizada no vidro quando não se é desejável adicionar álcalis. 
$\mathrm{O}$ caolin $\left(\mathrm{Al}_{2} \mathrm{O}_{3} .2 \mathrm{SiO}_{2} .2 \mathrm{H}_{2} \mathrm{O}\right)$ também pode ser utilizado, porém o teor de ferro é muito alto (NAROTTAM; DOREMUS, 1986).

Bário

O sulfato de bário é encontrado como mineral na natureza e é utilizado como fonte de óxido de bário. Reage com o carbonato de sódio gerando sulfato de sódio e carbonato de bário. Ele ajuda a remover bolhas da massa vítrea devido a decomposição do carbonato em altas temperaturas (NAROTTAM; DOREMUS, 1986).

\section{Cálcio}

É fornecido pelo carbonato de cálcio $\left(\mathrm{CaCO}_{3}\right)$ disponível no calcário ou precipitado como carbonato de cálcio.

O cálcio inserido como carbonato tem a vantagem de ter baixo custo, uniformidade de composição e vantagens na fusão do vidro devido a liberação de $\mathrm{CO}_{2}$ durante o processo de fusão. É estável em sua composição e fácil de ser armazenado. Os limites recomendados de ferro e alumina no calcário é $0,1 \%$ de $\mathrm{Fe}_{2} \mathrm{O}_{3}$ e $0,2 \%$ a $0,4 \%$ de alumina. Se for um calcário com alto teor de cálcio, deverá ter $56 \%$ de $\mathrm{CaO}$, se for um calcário dolomítico, irá conter $30 \%$ de $\mathrm{CaO}$ e $21 \%$ de $\mathrm{MgO}$.

O carbonato ou a dolomita calcinada, reagem facilmente com a sílica, com liberação de calor, porém pode se hidratar facilmente durante armazenamento (NAROTTAM; DOREMUS, 1986).

\section{Ferro}

O ferro é um contaminante inevitável na fusão do vidro flint. Os teores de ferro, bem como a composição base, influenciam a cor do vidro. Ele pode ser utilizado para fazer vidros cinza, bronze e verde.

O óxido de ferro é utilizado com principal fonte de ferro em vidros esverdeados ou para fabricação de vidros que retém o ultravioleta, como o vidro âmbar.

Para produção de vidros que absorvem o infravermelho, uma alta quantidade de $\mathrm{FeO}$ é utilizada, bem como materiais redutores como: $\mathrm{Fe}_{3} \mathrm{O}_{4}$ (Magnetita), $\mathrm{FeCO}_{3}$ (Siderita) ou $\mathrm{FeC}_{2} \mathrm{O}_{4}$ (Oxalato de Ferro) (NAROTTAM; DOREMUS, 1986).

\section{Magnésio}

A principal fonte de magnésio é o calcário dolomítico, entrando na composição do vidro sempre em quantidades equivalentes ao Cálcio (NAROTTAM; DOREMUS, 1986).

$\underline{\text { Sódio }}$ 
A principal fonte de sódio é o carbonato de sódio $\left(\mathrm{Na}_{2} \mathrm{CO}_{3}\right)$. O método usual para sua obtenção é o processo Solvay, no qual a reação entre cloreto de sódio com amônia e dióxido de carbono formam o bicarbonato de sódio, que é aquecido para formar o carbonato de sódio.

O sódio também pode ser fornecido pelo sulfato de sódio que é produzido como subproduto do ácido hidroclorídrico. O principal efeito do sulfato é prevenir a espuma ou a camada de sílica sobrenadante no banho (NAROTTAM; DOREMUS, 1986).

\section{Carbono}

É geralmente utilizado o coque, em maior quantidade nos vidros reduzidos.

\subsubsection{Fritas}

Algumas das cores em vidros são obtidas por misturas de cores, conforme figura 3, pela adição de fritas de cor resultante conhecida em relação a composição do vidro base, constituídas de íons metálicos tais como V, Cr, Mn, $\mathrm{Fe}, \mathrm{Co}, \mathrm{Ni}, \mathrm{Cu}$ e terras raras.

Figura 3- Exemplo de mistura de cores (a) Aditiva; (b) Subtrativa.

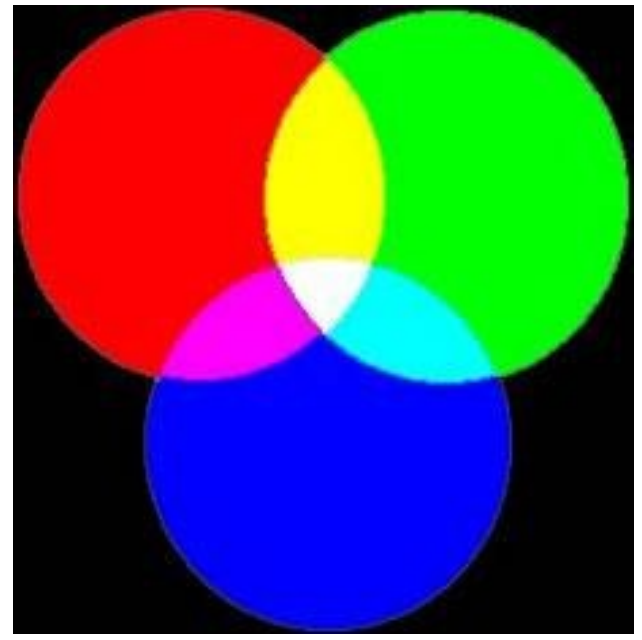

(a)

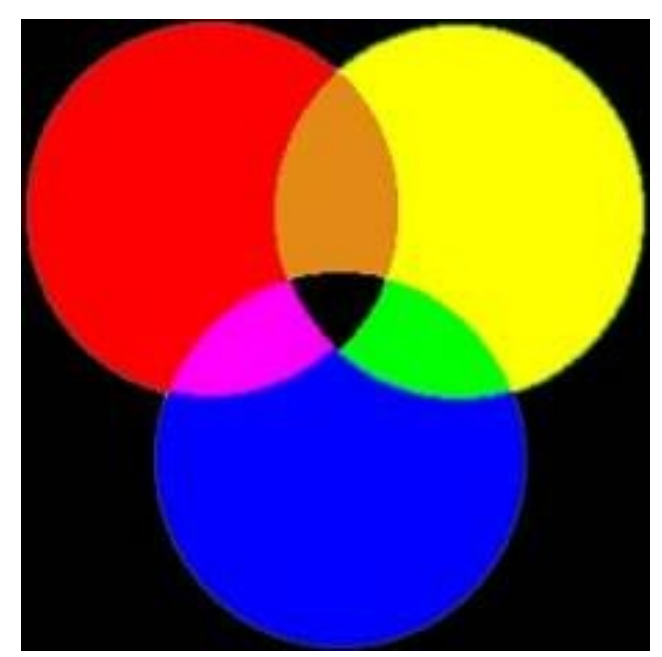

(b)

Fonte- AKERMAN, 2007

A frita é composta por um ou mais elementos colorantes, geralmente um metal ou terrarara, sendo que o resto da composição é basicamente a mesma que o vidro na qual será adicionada, com exceção do alto teor de fundente para que possa fundir rapidamente, de preferência assim que entram em contato com a massa vítrea, já que o tempo disponível para fusão e homogeneização é limitado, dependente da extração do vidro na produção.

Fritas são fundidas em fornos dedicados, depois resfriadas e moídas. A função dessa pré-fusão é transformar quaisquer componentes insolúveis ou tóxicos em componentes solúveis, através da sua combinação com a sílica e outros óxidos adicionados.

Os óxidos presentes nas fritas que foram utilizadas nesse trabalho são: 


\section{$\underline{\text { Ferro }}$}

O íon de ferro pode ocorrer em três valências: $\mathrm{Fe}^{6+}$, que é extremamente instável; $\mathrm{Fe}^{3+}$, que é um formador de rede, gera cor marrom-clara ou verde amarelada no vidro com forte absorção no ultravioleta, é pouco estável, e seu espectro de absorção possui três picos localizados em 380, 420 e 435nm; e $\mathrm{Fe}^{2+}$, que apresenta absorção em uma banda intensa centralizada em 1050nm; a cor resultante do mesmo é azul; e somente é estável se considerarem que suas cargas elétricas são neutralizadas (BAMFORD, 1977). Em vidros de sílica soda-cal, o ferro está presente como íon ferroso $\left(\mathrm{Fe}^{2+}\right)$ e férrico $\left(\mathrm{Fe}^{3+}\right)$.

A absorção no ultravioleta é intensificada pela proporção de $\mathrm{Fe}_{2} \mathrm{O}_{3}$, e a absorção no infravermelho é influenciada pela proporção de FeO. Devido à sua forte absorção no infravermelho, vidros com alto teor de $\mathrm{FeO}$ são adequados para uso como protetores de calor. A banda de absorção no infravermelho do ferro é afetada pela composição do vidro de base, bem como pelo seu estado de oxi-redução.

$\mathrm{Na}$ fusão, o ferro parcialmente se decompõe em $\mathrm{Fe}^{3+}$ e $\mathrm{Fe}^{+2}$. Esta é a explicação para o fato de que nenhum vidro de sílica pode ser fundido sem formar $\mathrm{Fe}^{3+}$, mesmo com uma forte redução (BAMFORD, 1977).

$\mathrm{O}$ equilíbrio entre $\mathrm{Fe}^{2+}$ e $\mathrm{Fe}^{3+}$ depende da concentração, composição do vidro e atmosfera. No vidro em altas temperaturas, ainda viscoso, é pouco provável que se alcance o equilíbrio em condições operacionais. (BAMFORD, 1977).

\section{$\underline{\text { Selênio }}$}

Em vidros soda-cal-sílica oxidados, o selênio gera a cor rosa amarelado ou salmão. Em vidros potássicos, gera a cor rosa. Pode ser utilizado como descolorante, pois complementa o verde gerado pelo ferro.

O selênio, assim como o enxofre, forma espécies $\mathrm{Se}^{6+}, \mathrm{Se}^{4+}, \mathrm{Se}^{0}, \mathrm{Se}^{2-}$. Somente o $\mathrm{Se}^{0}$ irá gerar a cor rosa complementar desejada; $\mathrm{Se}^{6+} \mathrm{e} \mathrm{Se}^{4+}$ são incolores. Os selenatos $\left(\mathrm{Se}^{6+}\right)$ são raros no vidro, uma vez que requerem uma oxidação muito forte (BAMFORD, 1977). Selenitos $\left(\mathrm{Se}^{4+}\right)$ se formam no vidro sob condições oxidantes, geralmente devido aos agentes oxidantes, tais como nitrato e arsênio ou antimônio, que aumentam a basicidade do vidro. $\mathrm{Se}^{2-}$ formamse especialmente sob condições levemente redutoras e na presença de ferro geram um marrom avermelhado, análogo à coloração âmbar, chamado seleneto ferroso (FeSe). A formação de FeSe é devido à substituição de $\mathrm{Se}^{2-}$ por $\mathrm{O}^{2-}$ em um tetraedro de $\mathrm{Fe}-\mathrm{O}$, semelhante ao enxofre no cromofóro âmbar. O estado de oxidação do selênio é fortemente influenciado pela presença de ferro e enxofre, e pela quantidade total de selênio. O selênio é extremamente volátil, acreditase que a espécie mais volátil seja $\mathrm{Se}^{4+}($ JITWATCHARAKOMOL, 2005) 
Uma grande desvantagem do selênio é sua dissolução relativamente baixa no vidro fundido. Apenas 10 a $20 \%$ do selênio total adicionado à massa vítrea permanece no vidro, isto é, boa parte é vaporizada. O selênio começa a volatilizar a $200^{\circ} \mathrm{C}$, abaixo do seu ponto de fusão de $217^{\circ} \mathrm{C}$. Sua volatilização é significativa acima de $300^{\circ} \mathrm{C}$. O selênio elementar volatiliza mais do que compostos de selênio em uma atmosfera neutra. Todos os compostos de selênio presentes no vidro são decompostos pela interação com o enxofre dissolvido no vidro.

O estado redox e a atmosfera do forno têm uma influência considerável na retenção de selênio, condições extremamente redutoras ou oxidantes proporcionam a melhor retenção, enquanto em condições ligeiramente reduzidas, a evaporação aumenta.

O selênio é utilizado geralmente junto com cobalto como descolorante em indústrias vidreiras que utilizam areia com impurezas como ferro. Ou pode ser utilizado sozinho como colorante na produção de vidro de cor rosa (JITWATCHARAKOMOL, 2005).

Em vidro contendo óxido de ferro, o equilíbrio da reação pode ser apresentado segundo (1.

$$
4 \mathrm{Fe}^{3+}+2 \mathrm{O}^{2-} \leftrightarrow 4 \mathrm{Fe}^{2+}+\mathrm{O}_{2}
$$

A cor residual e a tonalidade amarelada de $\mathrm{Fe}^{3+}$ são normalmente neutralizadas pela utilização de uma pequena quantidade de cobalto, ou por meio de selênio elementar (que possui coloração rosa) ou pelo cromóforo Fe-Se (de coloração castanho avermelhado) (JITWATCHARAKOMOL, 2005).

O efeito da cor não é função apenas dos teores dos elementos, mas também do estado de oxidação do íon e da sua competição com outras espécies redox.

$\mathrm{Se}^{2-}$ e $\mathrm{Se}^{4+}$ não coexistem em fusões acima de $1000{ }^{\circ} \mathrm{C}$. Em temperaturas mais baixas, o sulfato tem um efeito oxidante no Se. Na interação de Fe-Se, primeiro o Se é reduzido por $\mathrm{Fe}^{2+}$ até $\mathrm{Se}^{2-}$, em seguida, $\mathrm{FeO}$ e $\mathrm{Na}_{2} \mathrm{Se}$ formam FeSe (BAMFORD, 1977).

A decomposição do selenito de sódio ocorre novamente no tratamento térmico ou no recozimento longo. $\mathrm{O} \mathrm{Na} 2 \mathrm{Se}$ reage com o resto de $\mathrm{FeO}$ e cria o chamado FeSe secundário, onde obtêm-se o vidro de cor amarelada (JITWATCHARAKOMOL, 2005).

Existe ainda outra interação entre as espécies selênio e enxofre no vidro: o $\mathrm{SeO}_{2}$ pode ser reabsorvido por bolhas contendo $\mathrm{SO}_{3}$. Deste modo, quanto maior o teor de sulfato na massa fundida maior a retenção do selênio na massa fundida. O selênio tem dois picos de absorção no visível, um pico a $500 \mathrm{~nm}$ e outro a $750 \mathrm{~nm}$, enquanto que o seleneto ferroso tem um pico a $490 \mathrm{~nm}$ (BAMFORD, 1977). 


\section{Manganês}

No vidro oxidado, o manganês pode dar a cor ametista a purpura, e no vidro reduzido é incolor. Em altas concentrações pode gerar o vidro preto.

$\mathrm{O}$ óxido de manganês é rico em oxigênio, podendo atuar como oxidante de $\mathrm{FeO}$ a $\mathrm{Fe}_{2} \mathrm{O}_{3}$ durante a fusão e agir como agente de refino devido a liberação de $\mathrm{O}_{2}$ em altas temperaturas. Somente quando todo o $\mathrm{Fe}^{2+}$ é oxidado para $\mathrm{Fe}^{3+}$ é iniciado a formação de $\mathrm{Mn}^{3+}$ no vidro. (SALMANG,2013)

Os vidros que contém $\mathrm{Mn}^{3+}$ são roxos e os que contém $\mathrm{Mn}^{2+}$ são incolores, dependente da basicidade. A medida que a basicidade da fusão aumenta, os íons $\mathrm{Mn}^{2+}$, que são incolores, apresentam coloração verde. Por exemplo, no vidro $2 \mathrm{Na}_{2} \mathrm{O} \cdot \mathrm{B}_{2} \mathrm{O}_{3}$ o manganês gera coloração verde, mas caso a massa fundida se torne ácida pela adição de sílica, a cor verde desaparece. A presença de álcali leva à oxidação $\mathrm{Mn}^{3+}$ que tem uma banda de absorção no visível a 470 a 520 nm, cuja posição depende da composição química do vidro. (SALMANG,2013)

\subsubsection{Fabricação do vidro}

Para obter vidro é necessário fundir a matéria prima em altas temperaturas, para isto, é necessário ter um forno bem dimensionado e bem isolado termicamente para evitar perdas térmicas. Esses fornos são chamados de fornos vidreiros. Os fornos vidreiros são dimensionados em relação à quantidade e ao tipo de vidro a ser produzido, podendo ser diários ou contínuos; quanto ao tipo de aquecimento, pode ser elétrico, a combustão, oxi-combustão; e quanto ao reaproveitamento de energia, regenerador ou recuperador.

O forno vidreiro utilizado na indústria de vidro que possibilitou este trabalho é um forno contínuo à gás/óleo combustível com regenerador e sete canais de alimentação. Uma representação simplificada deste forno pode ser visualizada na Figura 4, onde temos:
a) Entrada e saída de gases (Regenerador)
b) Entrada de matéria (Enfornadora)
c) Fusão
d) Afinagem
e) Estabilização da temperatura e fluxo (Zona de trabalho)
f) Canal de alimentação (Feeder)
g) Conformação da massa vítrea (Máquinas I.S.) 
Figura 4- Esquema de um forno contínuo a gas/óleo combustível, e o fluxo do processo, desde a adição de matéria prima, até a elaboração do frasco.

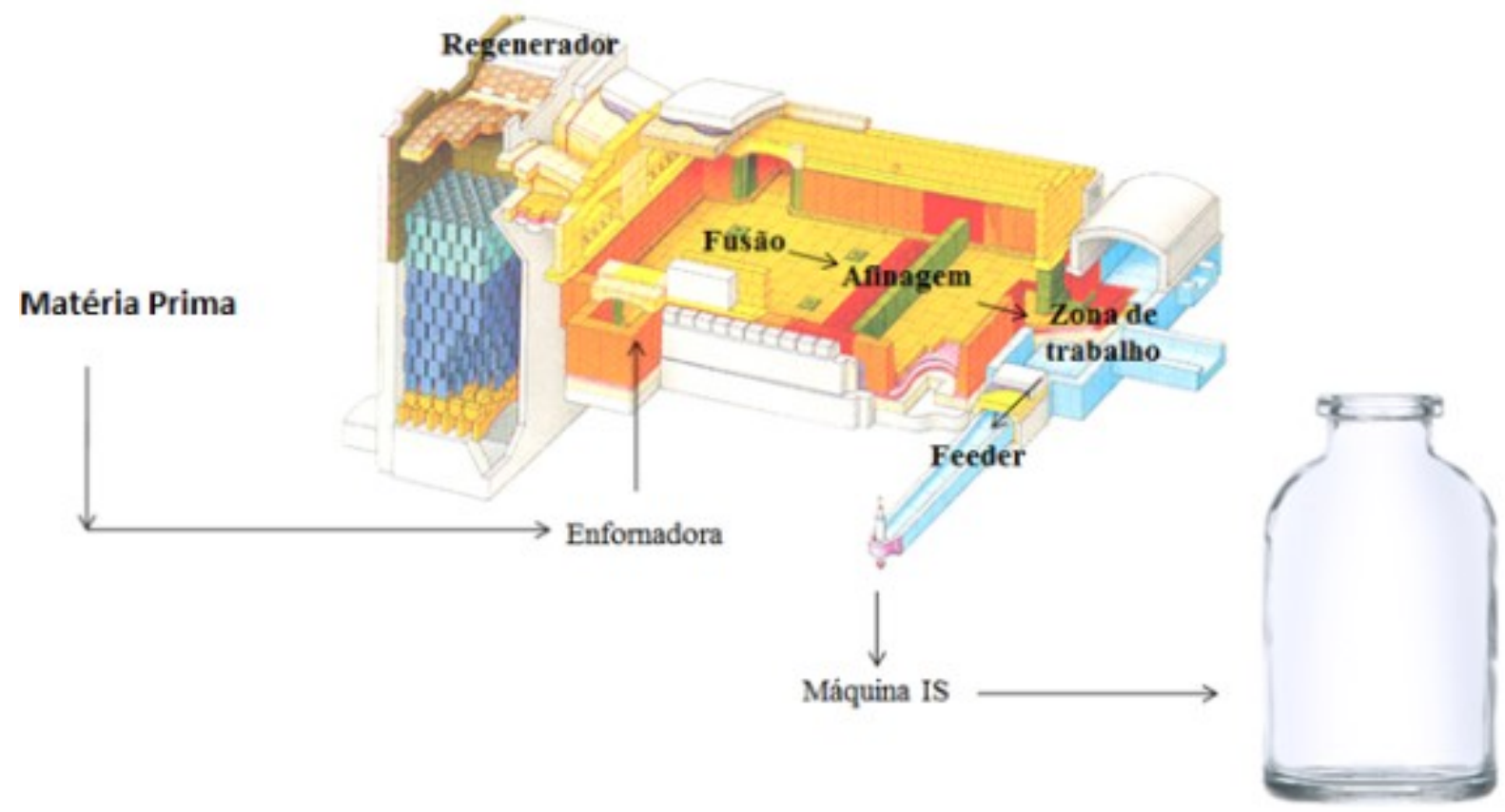

Fonte- Autor "Adaptado de "Glass global consulting GmbH

Após a entrada das matérias-primas pela enfornadora, ocorrem as seguintes etapas:

Fusão:

Com o aumento de temperatura, as seguintes reações químicas e físicas ocorrem

a) Evaporação da água livre da matéria prima adicionada;

b) Formação e perda de gases como $\mathrm{CO}_{2}, \mathrm{SO}_{3}, \mathrm{SO}_{2}, \mathrm{H}_{2} \mathrm{O}$ estrutural e etc, provenientes da decomposição das matérias-primas;

c) Formação de fases líquidas da fusão de algumas matérias-primas e misturas eutéticas inerentes da mistura ou de segregações localizadas;

d) Dissolução das segregações e misturas eutéticas produzindo uma massa vítrea livre de materiais cristalinos;

e) Volatilização de componentes do vidro $\mathrm{Na}_{2} \mathrm{O}, \mathrm{K}_{2} \mathrm{O}, \mathrm{B}_{2} \mathrm{O}_{3}, \mathrm{PbO}, \mathrm{SiF}_{4}, \mathrm{BF}_{3}, \mathrm{~F}_{2}$, etc;

f) Dissolução de fases gasosas provenientes do combustível, ar, produtos de combustão, $\mathrm{CO}_{2}, \mathrm{SO}_{2}$ etc) na massa vítrea, podendo levar a uma supersaturação na qual resultará num equilíbrio metaestável e liberação de gases na forma de pequenas bolhas, denominadas como "seeds". 
As reações se iniciam na superfície, onde surgem os primeiros eutéticos ${ }^{2}$ (SHELBY, 2005). As matérias-primas não fundidas flutuam sobre o vidro já fundido por diferença de densidade.

As reações exotérmicas que ocorrem durante a fusão do vidro envolvem a formação de novas fases cristalinas, como por exemplo, na reação de $\mathrm{SiO}_{2}$ com $\mathrm{CaO}$ para a forma $\mathrm{CaSiO}_{3}$ durante processo de fusão (NAROTTAM; DOREMUS, 1986). Essas reações não ocorrem de forma ordenada, podendo acontecer de forma sobreposta em regiões localizadas do forno.

O tempo de fusão é considerado como sendo o tempo em que não existem mais fases cristalinas. Aumentar a temperatura não é uma solução eficiente para garantir a fusão da matéria prima na zona de fusão, pois pode favorecer a segregação e diminuir a vida útil do refratário. É mais eficiente melhorar a preparação da mistura, a alimentação da fornada, o design e a uniformidade da chama.

Os fatores que mais influenciam a taxa de fusão:
a) Composição do vidro
b) Temperatura de fusão
c) Tamanho de grão dos constituintes da fornada
d) Quantidade e tamanho do caco
e) Formulação da mistura
f) Homogeneidade da mistura

Quanto maior o tamanho de grão das matérias-primas, maior o tempo de fusão. No entanto, para o caco, é efeito é o inverso.

Quando o tamanho de grão de todas as matérias-primas é o mesmo, o tempo de fusão do vidro diminui conforme menor for o tamanho de grão. Se o tamanho de grão for diferente, o tempo aumenta. A adição de caco minimiza essa separação e reduz o tempo de fusão.

\section{Afinagem:}

O processo de afinagem começa no mesmo momento do início da fusão e vai além da completa dissolução dos materiais cristalinos, que caracterizam o final da fusão. É a etapa em que a massa vítrea fundida libera os gases em forma de bolhas. O tempo de afinagem é dependente do nível de qualidade do vidro a ser produzido. Aumentar a temperatura é uma maneira eficaz de reduzir o tempo de afinagem.

A afinagem tem por objetivo a eliminação de bolhas na massa vítrea. Isto é feito pela adição de substâncias que liberam $\mathrm{O}_{2}$ ou $\mathrm{SO}_{2}$, agitação do banho, aumento da temperatura e

\footnotetext{
${ }^{2}$ Reações via fase líquida
} 
injeção de gases. A composição dos gases eliminados é $\mathrm{CO}_{2}, \mathrm{~N}_{2}, \mathrm{H}_{2}$ e CO. O excesso de $\mathrm{Na}_{2} \mathrm{SO}_{4}$ pode gerar bolhas de $\mathrm{SO}_{3}$ que são difíceis de serem eliminadas (SHELBY, 2005).

O processo de afinagem é químico devido ao conceito de acidez relativa ou potencial negativo devido a presença de certos íons, mas também é físico, pois envolve viscosidade, tensãoo superficial e diferenças de densidade.

Os agentes afinantes mais importantes são sulfatos, arsênio e antimônio. Cloretos, brometos e iodetos são utilizados em vidros reduzidos (NAROTTAM; DOREMUS, 1986).

A efetividade dos agentes afinantes aumenta com o decréscimo do teor de álcalis ou aumento do teor de sílica. Os sulfatos são muito eficazes para vidros oxidados mas não para vidros reduzidos (NAROTTAM; DOREMUS, 1986).

\section{Homogeneização:}

O vidro é considerado homogêneo quando não tem apresenta variações de propriedade, principalmente em sua composição química. A homogeneização começa junto com a fusão, terminando em função da qualidade do vidro a ser produzido (NAROTTAM; DOREMUS, 1986).

Os principais fatores que afetam a homogeneidade do vidro são:

a) Temperatura

b) Tempo

c) Formulação da fornada ou combinação das matérias-primas empregadas

d) Nível de homogeneidade da mistura

e) Tendência de segregação no transporte e fusão

f) Natureza e nível da convecção e agitação mecânica

g) Reações físico químicas com os refratários

Zona de trabalho:

O condicionamento térmico é a etapa em que o vidro estabiliza sua temperatura e fluxo para permitir a conformação, e isto ocorre na zona de trabalho.

A massa vítrea após fusão, afinagem, homogeneização e estabilização do fluxo na zona de trabalho flui pelos canais de alimentação até as máquinas de conformação.

Quando se tem demanda para produção de vidro colorido, utiliza-se o sistema de coloração da massa vítrea em um dos canais de alimentação do forno (processo mais conhecido como "color-feeder") que estiver produzindo vidro incolor. Este sistema consiste em um dosador fixado acima do canal de alimentação, que a cada período de tempo, despeja certa quantidade de fritas sobre o fluxo de massa vítrea, e efetua a mistura dessas fritas na massa por 
meio de um conjunto de pás cerâmicas giratórias, denominada como "conjunto de agitadores", conforme demonstrado na figura 5 .

Figura 5- Esquema de distribuição da massa vítrea em um forno vidreiro pelos canais de alimentação com sistema color-feeder.

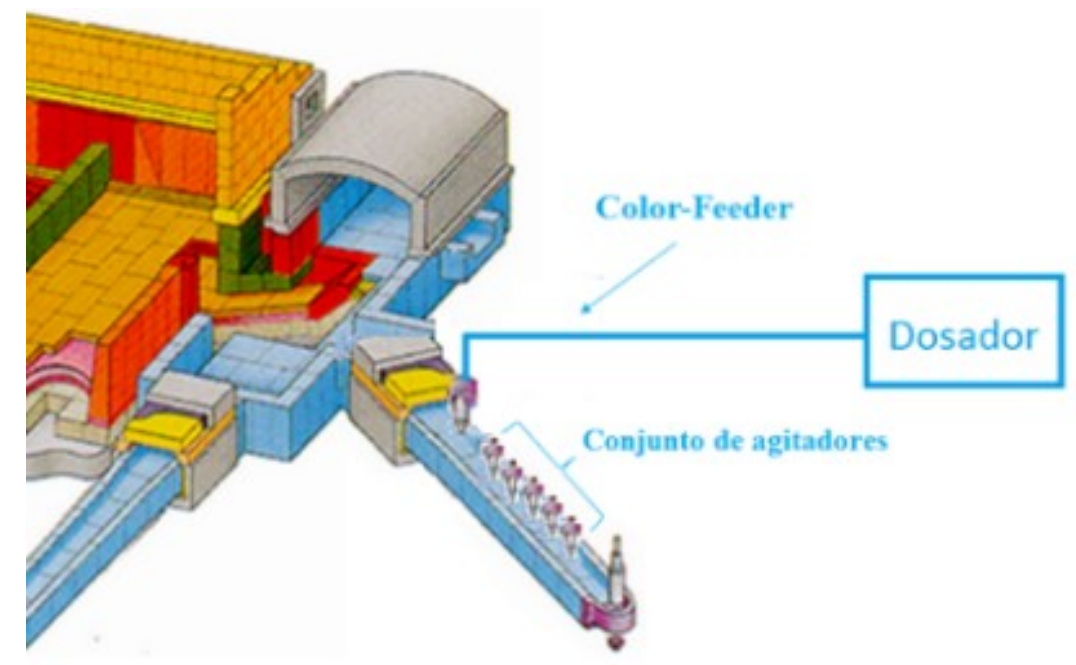

Fonte- Autor “adaptado de" Glass Global

Após passagem por todas as zonas do forno, o vidro pode ser conformado e recozido. O estado viscoso entre o ponto de trabalho e o amolecimento é a faixa de trabalho, conforme indicado na figura 6 , ou seja, a faixa onde é possível dar forma ao vidro.

Figura 6- Gráfico de viscosidade versus temperatura para vidros de composições diferentes, demonstrando a influência da temperatura na viscosidade e sua consequência no processo, desde fusão até a deformação do vidro.

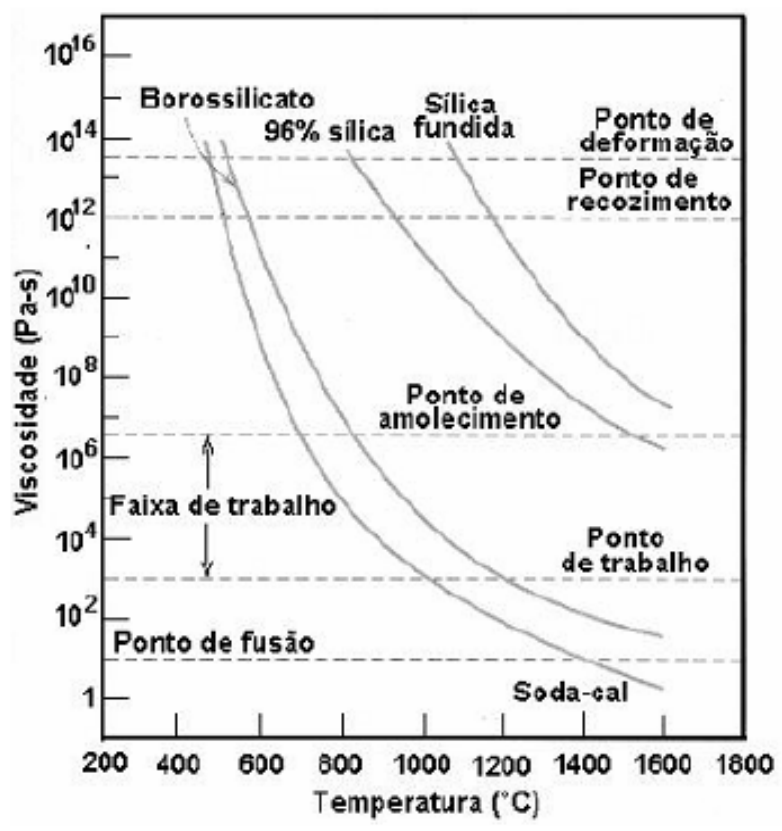

Fonte- Adaptado de CALLISTER, 2002 


\subsubsection{Estado de oxidação da massa vítrea}

O estado de oxidação da massa vítrea tem uma influência significativa na etapa de fusão. Determinar o estado, mesmo que empiricamente, ajuda a avaliar a otimização da afinagem, a cor do vidro e possibilita o ajuste na prática industrial, pela alteração da quantidade das matérias-primas adicionadas, tais como, por exemplo: sulfatos, que são oxidantes; carbono, enxofre ou qualquer forma de sulfitos, que são redutores.

O estado de oxidação é influenciado pelo teor e tipo de elemento polivalente (DUFFY, 1996), a concentração e tipo de elemento redutor; parâmetros de processo como a composição da atmosfera do forno, a taxa de aquecimento e a máxima temperatura de fusão (MAGNIEN, et al, 2008).

Para esclarecer a importância do estado de oxidação da massa vítrea, note as reações que podem acontecer em cada estado: entre temperaturas de 600 a $900{ }^{\circ} \mathrm{C}$, os carbonatos irão liberar $\mathrm{CO}_{2}$, que por sua vez, irão reagir com o carbono até estabelecer um equilibrio de acordo com a reação de Boudouard, demonstrada na equação 2.

$$
\mathrm{C}+\mathrm{CO}_{2} \leftrightarrow 2 \mathrm{CO}
$$

Em atmosferas com baixa atividade de oxigênio, grande parte do carbono irá reagir com $\mathrm{CO}_{2}$ formando $\mathrm{CO}$ e irá reagir com os sulfatos $\left(\mathrm{SO}_{4}{ }^{2-}\right)$ gerando sulfitos $\left(\mathrm{SO}_{3}{ }^{2-}\right)$, gás $\mathrm{SO}_{2}, \mathrm{~S}_{2}$ ou sulfetos $\left(\mathrm{S}^{2-}\right)$ em temperaturas acima de $700-800^{\circ} \mathrm{C}$. A equação 3 demonstra a reação em massa vítrea levemente reduzida; a equação 4 , em massa vítrea fortemente reduzida; e a equação 5 , em massa vítrea extremamente reduzida.

$$
\begin{aligned}
& \mathrm{SO}_{4}{ }^{2-}+\mathrm{CO} \leftrightarrow \mathrm{SO}_{2}+\mathrm{CO}_{2}+\mathrm{O}^{2-} \\
& 2 \mathrm{SO}_{4}{ }^{2-}+6 \mathrm{CO} \leftrightarrow \mathrm{S}_{2}+6 \mathrm{CO}_{2}+2 \mathrm{O}^{2-} \\
& \mathrm{SO}_{4}{ }^{2-}+4 \mathrm{CO} \leftrightarrow \mathrm{S}^{2-}+4 \mathrm{CO}_{2}
\end{aligned}
$$

Ocorre também que parte do sulfato não irá reagir com $\mathrm{CO}$ e irá se decompor na massa em temperaturas mais altas, conforme desmonstra a equação 6, e parte do sulfato também poderá reagir com sulfeto de acordo com a reação demonstrada na equação 7, ou em condições extremamente redutoras, irá reagir conforme demonstra a equação 8.

$$
\begin{aligned}
& \mathrm{SO}_{4}{ }^{2-} \leftrightarrow \mathrm{SO}_{2}+1 / 2 \mathrm{O}_{2}+\mathrm{O}^{2-} \\
& \mathrm{S}^{2-}+3 \mathrm{SO}_{4}^{2-} \leftrightarrow 4 \mathrm{SO}_{2}+4 \mathrm{O}^{2-} \\
& 3 \mathrm{~S}^{2-}+\mathrm{SO}_{4}^{2-} \leftrightarrow 2 \mathrm{~S}_{2}+4 \mathrm{O}^{2-}
\end{aligned}
$$

Com o aumento da pressão parcial de $\mathrm{SO}_{2}$ durante afinagem, sulfito $\left(\mathrm{SO}_{3}{ }^{2-}\right)$ poderá ser formado no vidro em concentrações na faixa de 0,02-0,05\% em massa (BEERKENS, 2002). 
A concentração de sulfetos $\left(\mathrm{S}^{2-}\right)$, sulfatos $\left(\mathrm{SO}_{4}{ }^{2-}\right)$ e óxidos de ferro $\left(\mathrm{Fe}^{2+}\right.$ e $\left.\mathrm{Fe}^{3+}\right)$ irão influenciar a cor do vidro, e a concentração depende do estado de oxidação, que por sua vez, está relacionado com a adição de Carbono (DUFFY, 1996); (MORSI,2015). Quanto maior o teor de carbono, maior o aumento da pressão parcial de $\mathrm{CO}$, o que aumenta as reações dos componentes com carbono, e geram um equilíbrio entre estado oxidado e reduzido dos elementos polivalentes, tendendo na direção do estado mais reduzido, conforme demonstra a equação 9. Em atmosfera oxidante, parte do carbono irá reagir com o oxigênio e a redução pelo carbono terá menor eficiencia, a formação de CO será limitada, conforme indica a equação 10 (BEERKENS, 2002).

$$
\begin{aligned}
& 2 \mathrm{Fe}^{3+}+\mathrm{CO} \leftrightarrow 2 \mathrm{Fe}^{2+}+\mathrm{CO}_{2} \\
& \mathrm{C}+\mathrm{O}_{2} \leftrightarrow \mathrm{CO}_{2}
\end{aligned}
$$

Dada a importância do estado de oxidação, vários métodos foram elaborados para estimar o estado de oxidação do banho, e o mais bem aceito foi o método de Simpson, no qual para cada matéria prima introduzida no banho é atribuido um fator positivo, quando oxidante; e negativo, quando redutor, resultando no "número redox", conforme desmonstra a equação 11.

$$
\mathrm{NR}=\sum \mathrm{C}_{\mathrm{i}} \times \mathrm{F}_{\mathrm{i}, \mathrm{x}}-\sum \mathrm{C}_{\mathrm{j}} \times \mathrm{F}_{\mathrm{j}, \mathrm{red}}
$$

O número redox, além de estimar o estado de oxidação do vidro, ainda fornece a tendência de coloração do vidro de forma rápida, como pode ser visualizado na figura 7 . O número redox pode ser descrito no gráfico com o teor de enxofre retido no vidro, pois a condição oxidada ou reduzida irá determinar o teor de enxofre retido no vidro, bem como a relação $\mathrm{Fe}^{2+} / \mathrm{Fe}_{2} \mathrm{O}_{3}$. 
Figura 7- Curva de concentração de enxofre retido no vidro em função de $\mathrm{Fe}^{2+} / \mathrm{Fe}_{\text {total, }}$ associada ao número redox.

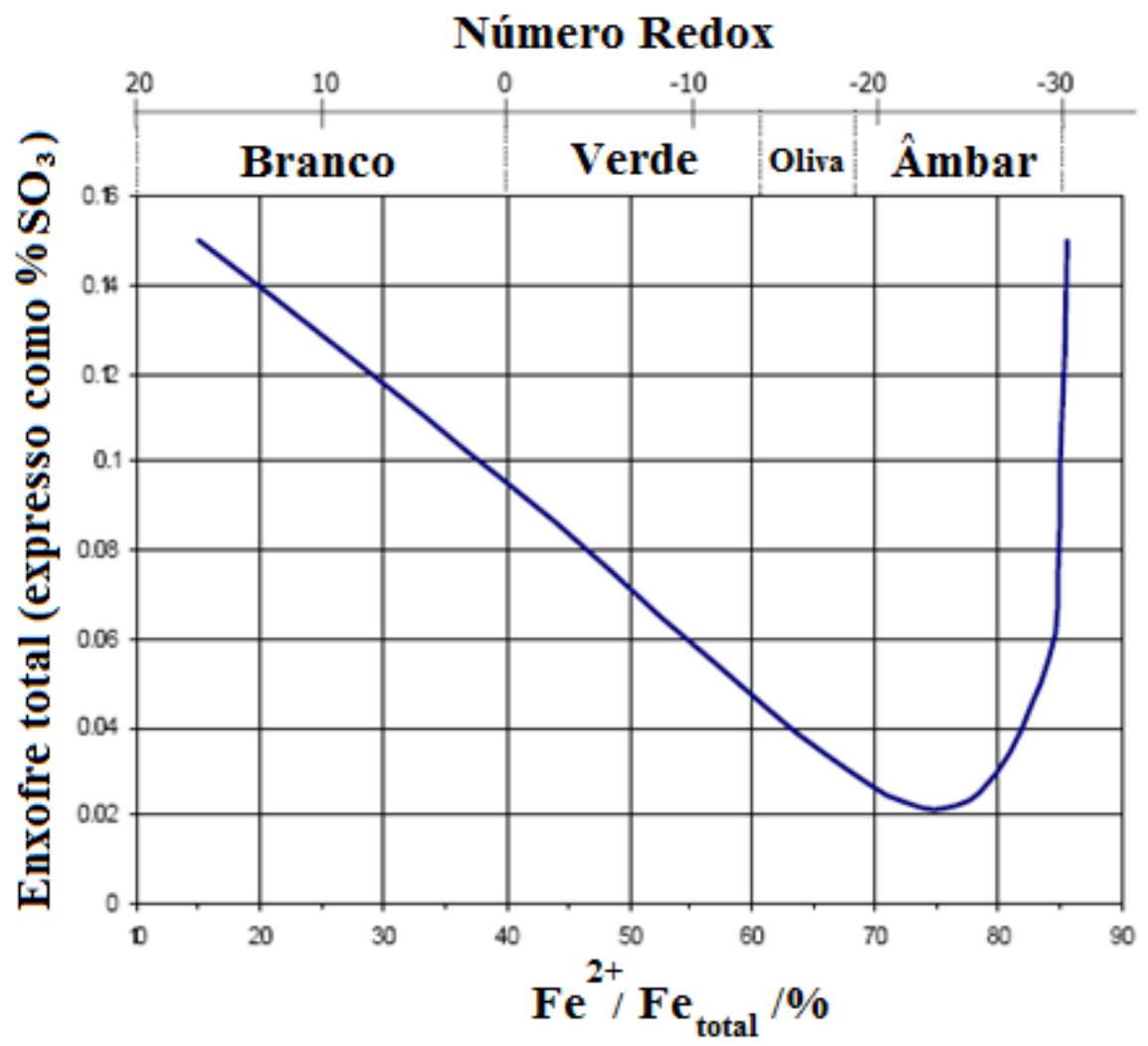

Fonte- Adaptado de DIBELLO, 1989.

Vidros incolores ou brancos, têm, usualmente, um número positivo na faixa de $+1.0 \mathrm{a}$ +22.0. Vidros âmbar contém sulfitos e possuem números negativos em uma faixa de $-10,0$ até -60.0. Quanto maior o valor negativo mais intensa a coloração âmbar. Os fatores de cada ingrediente são encontrados pela estequiometria de reações químicas de oxi-redução.

No entanto, também é usual que o estado de oxidação do banho seja estimado após a obtenção do produto final pela medição de suas propriedades, tais como: retenção de enxofre e análise dos óxidos de ferro, que se apresentam no estado $\mathrm{Fe}^{2+}$ ou $\mathrm{Fe}^{3+}$, resultando em uma relação iônica do ferro $\left(\mathrm{Fe}^{2+} / \mathrm{Fe}^{3+}\right)$ ou na relação de seus óxidos $\left(\mathrm{FeO} / \mathrm{Fe}_{2} \mathrm{O}_{3}\right)$, conforme mostra ; pela análise do espectro ou medindo o estado de oxidação no feeder, o que gera um delay entre o estado corrigido e o estado desviado em todos esses casos (BEERKENS, 2002). Podem ser utilizados todos os óxidos de coloração do vidro, não somente $\mathrm{Fe}^{2+}$ e $\mathrm{Fe}^{3+}$, mas sim todos aqueles os quais podem ocorrer em diferentes estados de oxidação (AKERMAN, 2007).

\subsubsection{Vidro Flint}

O termo "flint" refere-se a um tipo de quartzo denominado sílex. O vidro flint é um vidro de sílica soda-cal com alta transmitância. O vidro flint, embora considerado por alguns como incolor, possui coloração, no entanto, esta é mascarada até atingir o mais próximo do branco, 
por meio de sobreposição de cores. Este tipo de vidro é produzido em condições oxidantes e é essencial o controle do estado de oxidação do banho e da quantidade de impurezas, visto que os óxidos de metais de transição presentes na matéria prima podem ter diferentes valências dependendo do estado de oxidação do banho, o que por sua vez poderá afetar a transmitância deste vidro. Para isto, são adicionados elementos oxidantes e redutores afim de se obter um equilíbrio quando as impurezas na matéria prima são conhecidas e controladas, para resultar no estado de oxidação desejado, e ainda, quando necessário, adicionam-se os elementos denominados "descolorantes", mas que tem função contrária, ou seja, colorir o vidro para assim mascarar a cor dada por tal impureza (AKERMAN, 2007).

\subsubsection{Vidro Âmbar}

O vidro âmbar também é um vidro de sílica soda-cal assim como o vidro flint, no entanto, este tipo de vidro tem como principal propriedade a retenção de radiação ultravioleta, devido a formação de um cromóforo específico, denominado cromóforo âmbar.

$\mathrm{O}$ cromóforo é constituído por um íon $\mathrm{Fe}^{3+}$ rodeado por quatro ânions, ao menos um $\mathrm{S}^{2-}$ e três $\mathrm{O}^{2-}$, formando o complexo $\mathrm{Fe}^{3+}-\mathrm{S}^{2-}-3 \mathrm{O}^{2-}-n \mathrm{Na}^{+}$que é responsável pela coloração âmbar.

A formação deste cromóforo depende fortemente da concentração de íon ferroso $\left(\mathrm{Fe}^{2+}\right)$, e sulfito $\left(\mathrm{SO}_{3}{ }^{2-}\right)$, que se ligam ao álcali para preservar a eletroneutralidade. Quanto maior o teor de álcali, geralmente sódio $(\mathrm{Na})$, maior a intensidade âmbar, pois o álcali promove a estabilidade do cromóforo (BEERKENS, 2003).

Durante resfriamento da massa vítrea reduzida abaixo de $1000 \mathrm{~K}$, o íon ferroso $\left(\mathrm{Fe}^{2+}\right)$ reage com o sulfito $\left(\mathrm{SO}_{3}{ }^{2-}\right)$, fazendo a concentração dos íons férricos $\left(\mathrm{Fe}^{3+}\right)$ e sulfuretos $\left(\mathrm{S}^{2-}\right)$ aumentarem conforme equação 12 .

$$
6 \mathrm{Fe}^{2+}+\mathrm{SO}_{3}^{2-} \leftrightarrow 6 \mathrm{Fe}^{3+}+\mathrm{S}^{2-}+3 \mathrm{O}^{2-}
$$

A formação de $\mathrm{Fe}^{3+}$ e $\mathrm{S}^{2-}$ é favorecida por baixas temperaturas, ou seja, a reação demonstrada na equação 12 tende ao lado direito durante o resfriamento, então o $\mathrm{SO}_{2}$ ou $\mathrm{SO}_{3}{ }^{2-}$ converterá o íon $\mathrm{Fe}^{2+}$ em íon $\mathrm{Fe}^{3+}$ (BEERKENS, 2003).

Outras espécies que serão formadas no vidro em estado de oxidação baixo $\left(p \mathrm{O}_{2}<10^{-9}\right.$ bar a $1673 \mathrm{~K}$ ), são: $\mathrm{S}_{0}$ e $\mathrm{S}_{2}$, que serão dissolvidos fisicamente em níveis de solubilidade baixos. A solubilidade do $\mathrm{S}_{2}$ no vidro é estimada em valores abaixo de $0,02 \mathrm{~mol} /\left(\mathrm{m}^{3}\right.$.bar). Assim, devido a concentração baixa de $S_{2}$, a reação irá ocorrer conforme equação 13 .

$$
4 \mathrm{Fe}^{2+}+\mathrm{S}_{2} \leftrightarrow 4 \mathrm{Fe}^{3+}+2 \mathrm{~S}^{2-}
$$


Sulfetos $\left(\mathrm{S}^{2-}\right)$ e íons férricos $\left(\mathrm{Fe}^{3+}\right)$ serão formados por ambas as reações. A presença de sulfito $\left(\mathrm{SO}_{3}{ }^{2-}\right)$ ou $\mathrm{SO}_{2}$ dissolvido em alta temperatura é essencial para formação do íon férrico durante resfriamento da massa vítrea reduzida (BEERKENS, 2003).

A intensidade da cor âmbar depende da temperatura de fusão e estado de oxidação do vidro. Em condições redutoras $\mathrm{S}^{2-}$ será formado. Em condições menos redutoras, $\mathrm{S}^{2-}$ começa a se tornar menos estável e a concentração total de enxofre retido na massa vítrea é mais baixa. Em condições altamente redutoras, nenhum $\mathrm{S}^{2-}$ é formado durante resfriamento e a formação da cor âmbar é limitada (BEERKENS, 2002).

A cor âmbar é estavel nas faixas de $\mathrm{pO}_{2} 10^{-5}$ a $10^{-9}$ bar, medida a $1400{ }^{\circ} \mathrm{C}$. Quando $\mathrm{pO}_{2}$ está acima de $10^{-9}$, a cor some, e abaixo decresce em intensidade. A intensidade da cor âmbar descrece com o descréscimo do teor de óxido de Sódio (MORSI, 2015).

\subsection{FUNDAMENTOS DE ÓTICA}

Para melhor entendimento da análise de transmitância efetuada neste trabalho, serão apresentados conceitos fundamentais de ótica nas próximas seções.

\subsubsection{Definição de luz}

Luz é a energia radiante avaliada de acordo com a capacidade de produzir sensações visuais. As teorias sobre a natureza da energia radiante, conforme o Illuminating Engineering Society (IES) descreve, são:

Teoria corpuscular:

a) Corpos luminosos emitem energia radiante em partículas.

b) Estas partículas são intermitentemente ejetadas em linhas retas

c) A ação das partículas na retina estimula o nervo ótico produzindo a sensação de luz

\section{Teoria ondulatória:}

a) Luz é resultante da vibração molecular do objeto luminoso

b) As vibrações são transmitidas em movimentos ondulatórios

c) A ação das vibrações transmitidas na retina estimula o nervo óptico para produzir a sensação de luz.

d) A teoria ondulatória permite efetuar uma representação gráfica da energia radiante de acordo com o comprimento de onda, ao qual pode ser chamado de espectro.

Teoria eletromagnética:

a) O corpo luminoso emite luz como forma de energia radiante

b) A energia radiante é transmitida na forma de onda eletromagnética 
c) A ação das ondas eletromagnéticas na retina estimula os nervos óticos produzindo a sensação de luz

Teoria do quantum:

a) A energia é emitida e absorvida em quanta discretizados

b) A magnitude de cada quanta é h.v (constante de Planck versus frequência)

Teoria das ondas mecânicas:

a) Relaciona a teoria do quantum e ondulatória

\subsubsection{Espectro eletromagnético}

O espectro eletromagnético completo situa-se dentro do comprimento de onda de 10 a $10^{-9} \mathrm{~cm}$, e pode ser subdivido em regiões (não de modo preciso), conforme Tabela 1.

Tabela 1- Regiões do espectro eletromagnético e respectiva frequência, energia e comprimento de onda.

\begin{tabular}{cccc}
\hline Região & $\begin{array}{c}\boldsymbol{\lambda} \\
(\mathbf{c e n t i ́ m e t r o s )}\end{array}$ & $\begin{array}{c}\mathbf{f} \\
\mathbf{( H z )}\end{array}$ & $\begin{array}{c}\mathbf{E} \\
(\mathbf{e V})\end{array}$ \\
\hline Rádio & $>10$ & $<3 \times 10^{9}$ & $<10^{-5}$ \\
Micro-ondas & $10-0.01$ & $3 \times 10^{9}-3 \times 10^{12}$ & $10^{-5}-0.01$ \\
Infra- & $0.01-7 \times 10^{-5}$ & $3 \times 10^{12}-4.3 \times 10^{14}$ & $0.01-2$ \\
vermelho & $7 \times 10^{-5}-4 \times 10^{-5}$ & $4.3 \times 10^{14}-7.5 \times 10^{14}$ & $2-3$ \\
Visível & $4 \times 10^{-5}-10^{-7}$ & $7.5 \times 10^{14}-3 \times 10^{17}$ & $3-10^{3}$ \\
Ultravioleta & $10^{-7}-10^{-9}$ & $3 \times 10^{17}-3 \times 10^{19}$ & $10^{3}-10^{5}$ \\
Raios-X & $<10^{-9}$ & $>3 \times 10^{19}$ & $>10^{5}$ \\
Raios Gama & & &
\end{tabular}

Fonte- Autor

A energia $(E)$ é diretamente proporcional à velocidade do elétron $(v)$ vezes a constante de Planck (h), como demonstra a equação 14.

$$
E=h v
$$

E, sendo a velocidade do elétron o inverso da frequência do mesmo, resultará na equação 15.

$$
v=\frac{1}{f}
$$

Então temos que, quanto menor a frequência, maior a velocidade e maior a energia e, portanto, maior o poder nocivo da radiação. Por este motivo, os raios ultravioleta não bloqueados pela camada de ozônio são tão prejudiciais.

O espectro eletromagnético visível está na faixa de 380 a $780 \mathrm{~nm}$. A radiação ultravioleta está na faixa de 100 a 400 nm, sendo dividida em U.V.A (400 a 320 nm), U.V.B 
(320-280 nm) e U.V.C (280-100 nm). U.V.A é a radição que efetivamente chega a terra; a U.V.B é parcialmente retida na camada de ozônio e a U.V.C é totalmente retida na camada de ozônio (DE ARAUJO, 2008).

\subsubsection{Percepção de cor}

A cor é percebida quando a luz interage com o objeto e dependendo da maneira com que o objeto reage com a luz poderá ser classificado como (CHOUDHURY, 2014):

a) Não Metálico: quando a luz incide sobre um objeto e a superfície desse objeto reflete a luz para todos os lados.

b) Metálico: quando boa parte da luz é refletida especularmente ${ }^{3}$ e há pouca reflexão difusa.

c) Translúcido: quando parte da luz passa através do objeto, mas também reflete difusa e especularmente a luz. A cor, neste caso, pode ser percebida tanto pela reflexão difusa quanto pela luz transmitida.

d) Transparente: quando a luz atravessa o objeto e tem parte de seu espectro absorvido, gerando a percepção de cor.

\subsubsection{Transmitância em vidros}

A figura 8 ilustra a transmitância em vidros, que pode ser descrita matematicamente da seguinte maneira: quando um feixe com intensidade $\mathrm{I}_{0}$, incide sobre um vidro de espessura $\mathrm{d}$, a intensidade de entrada, $\mathrm{I}_{e}$, passa a ser descrita conforme equação 16.

$$
\mathrm{I}_{\mathrm{e}}=\mathrm{I}_{0} \cdot(1-\mathrm{r})
$$

sendo $r$, a refletividade do vidro.

Dentro do vidro, o feixe é atenuado de acordo com uma função exponencial, sendo assim, a intensidade na saída, $\mathrm{I}_{\mathrm{d}}$, ficará conforme equação 17.

$$
I_{d}=I_{e} \cdot \exp (-k \cdot d)
$$

onde $\mathrm{k}$, é o coeficiente de absorção.

Na superfície de saída também ocorre reflexão, portanto, a intensidade do feixe será descrita conforme equação 18 .

$$
\mathrm{It}=\mathrm{Id} .(1-\mathrm{r})
$$

\footnotetext{
${ }^{3}$ É o reflexo espelhado da luz em uma superfície, no qual há uma única direção de entrada e uma única direção de saída.
} 
Figura 8- Mudança na intensidade de um feixe de luz ao passar sobre um vidro de espessura d.

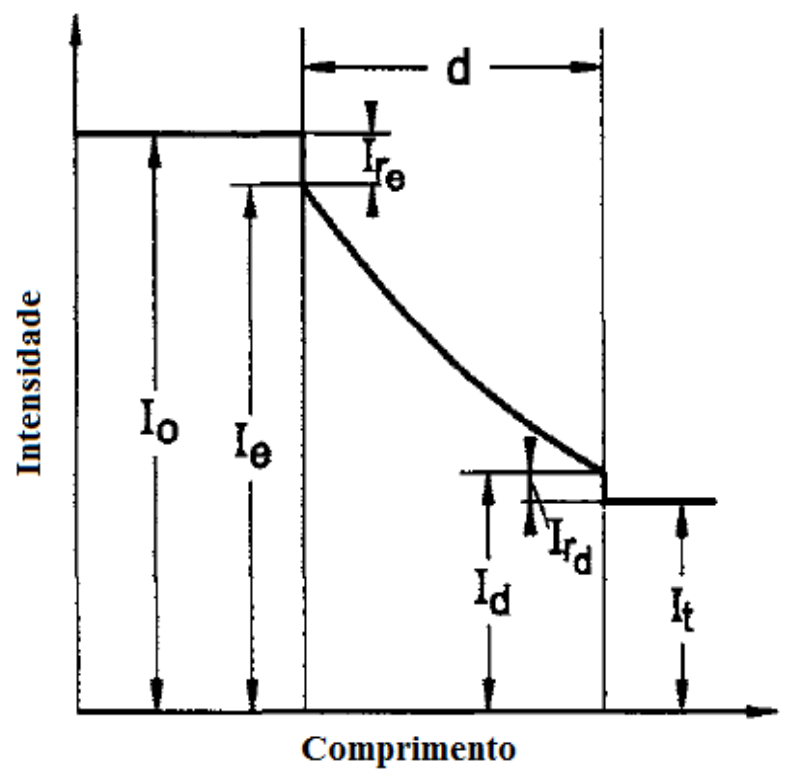

$\mathrm{I}_{0}:$ Intensidade incidente

$I_{\mathrm{re}}:$ Intensidade refletida na face frontal

$\mathrm{I}_{\mathrm{e}}:$ Intensidade de entrada

$\mathrm{I}_{\mathrm{d}}:$ Intensidade de saída

$\mathrm{I}_{\mathrm{rd}}$ : Intensidade refletida na face de saída

$\mathrm{I}_{\mathrm{t}}:$ Intensidade transmitida

$\mathrm{d}:$ Espessura

Fonte- Adaptado de BACH; NEUROTH, 2013

Dando origem a equação 19:

$$
I_{t}=I_{e}(1-r) \exp (-k d)=I_{0}(1-r)^{2} \exp (-k d)
$$

Parte do feixe refletido na saída retorna para superfície de entrada e é dividido em parte refletida e parte transmitida. Este processo ocorre infinitamente, conforme ilustra a figura 9. Com múltiplas reflexões a transmissão será dada pela equação 20.

$$
T=\frac{I_{t}}{I_{0}}=P T_{i}
$$

sendo, $T_{i}=\frac{I_{d}}{I_{e}}$. 
Figura 9- Múltiplas reflexões da luz incidente na superfície de um vidro.

Fonte- Adaptado de BACH; NEUROTH, 2013

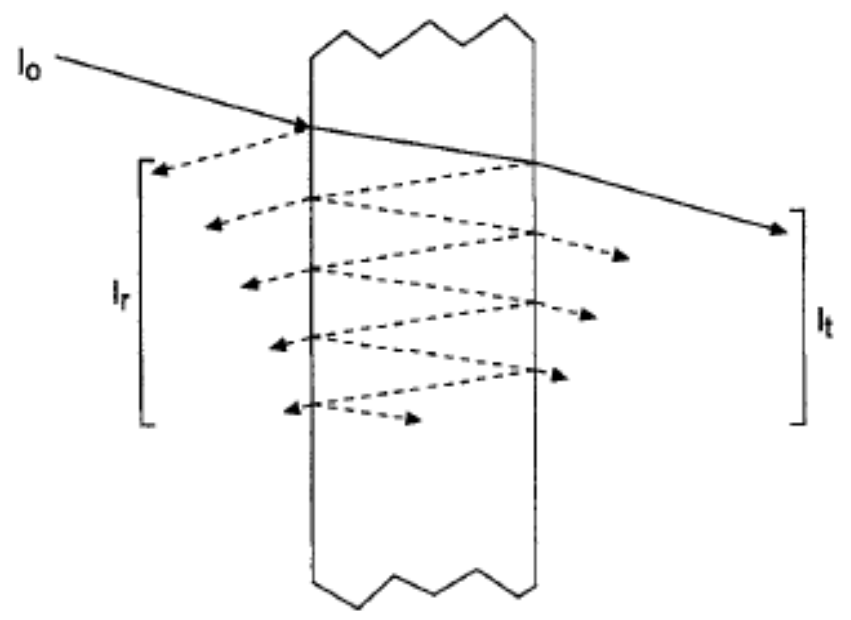

O fator de reflexão, $\mathrm{P}$, é derivado da equação de Fresnel e descreve a relação entre reflexividade $r$ e índice de refração n, descrito na equação 21 .

$$
P \approx \frac{(1-r)^{2}}{1-r^{2}}=\frac{2 n}{n^{2}+1}
$$

A transmissão interna é a parte do feixe atenuada pelo próprio vidro nas regiões em que o fator de reflexão gera as reflexões (BACH; NEUROTH, 2013).

\subsection{COLORIMETRIA}

Para melhor entendimento da medição de cor em vidros, será apresentados nas próximas seções, conceitos de colorimetria.

\subsubsection{Ensaios para medição de cor}

A cor em vidros pode ser quantitativamente determinada medindo a transmitância em vários comprimentos de onda. O método mais recomendado é a espectrofotometria. A espectrofotometria mede a quantidade de luz absorvida ou transmitida por um meio pela diferença entre a intensidade luminosa inicial de um feixe de luz e sua intensidade após passar através do meio.

Geralmente o resultado é demonstrado graficamente com (I / $\left.\mathrm{I}_{0}\right) * 100$ ou $\log \left(\mathrm{I} / \mathrm{I}_{0}\right)$ em y e o comprimento de onda em x. A determinação da cor pode ser feita então pelas coordenadas tricromáticas seguindo o sistema de coordenadas tricromáticas da CIE (Commission Internationale de l'Eclairage). 


\subsubsection{Coordenadas tricromáticas}

Uma superfície não pode emitir mais do que nela incide, por este motivo, a refletância4 varia de 0 a 1 . O valor exato pode ser mensurado por um equipamento denominado espectrofotômetro e este valor é uma propriedade inerente do material. A especificação de cor de uma superfície pode ser feita em termos de refletância para cada componente espectral. A curva de refletância de um material constitui um registro permanente que não requer o armazenamento de uma amostra da cor.

A estimulação visual de uma superfície colorida depende da caracterização da luz pela qual a superfície foi iluminada. A fonte de luz mais comum é a luz do dia. Ela consiste de uma mistura de todos os componentes do espectro em proporções aproximadamente iguais. Investigações da distribuição de energia no espectro da luz do dia foram realizadas por longos períodos de tempo para estimar a média do efeito do estado do clima e da altitude do sol, utilizando uma lâmpada de tungstênio, que reproduz aproximadamente a luz do dia (HARDY, 1936).

O método empregado na determinação da distribuição espectral de energia em uma fonte de luz consistiu em dispersar a luz por um prisma gerando um espectro. Cada região espectral foi isolada e a quantidade de energia presente em cada espectro foi mensurada por meio de um dispositivo sensível de medição de temperatura ao qual um corpo negro convertia a energia da luz em calor.

A Comissão Internacional de Iluminação em 1931 adotou uma fonte de luz que possui uma distribuição de energia como um padrão internacional de iluminação para ser utilizado na colorimetria exceto em condições especiais regidas pelo uso de outras fontes. Este padrão é conhecido como ICI iluminante $\mathrm{C}$.

Dois outros padrões foram adotados na mesma reunião, designados como iluminante A e B. O iluminante A representa uma fonte de luz que possui distribuição similar a uma lâmpada de tungstênio preenchida com gás, e B representa a luz solar do meio dia e é levemente mais amarelada que o iluminante $\mathrm{C}$, sendo um intermediário entre A e C. O iluminante C é um o melhor representante da luz do dia (HARDY, 1936).

O princípio é multiplicar cada comprimento de onda da energia incidente por um fator de reflexão da superfície resultando na distribuição de energia da luz refletida pela superfície (HARDY, 1936). O problema seria estabelecer como a luz com distribuição de energia

\footnotetext{
${ }^{4}$ É a proporção entre o fluxo incidente e o fluxo refletido
} 
conhecida poderia estimular o olho de um observador. Dois observadores não reagem precisamente da mesma maneira, mas as diferenças são notavelmente pequenas, com exceção aos que são daltônicos.

Para que um observador descreva a sensação produzida por uma luz espectralmente conhecida, de maneira que esta informação possa ser útil, ele deverá possuir padrões ou estímulos primários. Um observador normal pode reproduzir o efeito de qualquer estimulo de cor por misturar a luz em 3 fontes primárias em proporções apropriadas. O experimento mais simples para isto é: o observador olha para dentro de um instrumento ótico contendo um aceitável campo fotométrico. A cor que necessita ser encontrada é introduzida dentro de uma parte do campo e a luz das três primeiras fontes é introduzida em outra parte do campo onde é possível controlá-los. Com uma manipulação dos controles, a configuração pode ser encontrada onde a exata cor procurada entre as duas partes do campo é obtida. Existe somente uma configuração para cada um dos três controles que irão produzir a cor procurada. Calibrando esses controles, as quantidades de cada primário podem ser registradas. Uma cor desconhecida pode então ser especificada por três números: X, Y e Z. Esses são conhecidos como "valores tristímulus", cada um representando uma quantidade de um dos estímulos primários (HARDY, 1936).

Instrumentos com esse tipo de princípio são denominados “colorímetros". Antes de 1922, um espectrofotômetro era utilizado para análise de comprimento de onda e um colorímetro para avaliação de um estímulo equivalente.

No entanto, fizeram um experimento, colocando um comprimento de onda de $400 \mathrm{~nm}$ e solicitaram que o observador determinasse a proporção dos três primários, e assim para $410 \mathrm{~nm}$ e assim por diante, conseguindo determinar a proporção dos três primários para cada comprimento de onda. Esses dados foram publicados e então, um espectrômetro era capaz de fazer a função dos dois equipamentos. Os valores tristímulos foram adotados pela ICI para várias cores do espectro. Os valores de $\mathrm{x}, \mathrm{y}$ e $\mathrm{z}$ indicam a quantidade de cada primário requerido para corresponder uma quantidade unitária de energia radiante dos vários comprimentos de onda (HARDY, 1936).

Para a representação gráfica desse sistema, a CIE propôs um diagrama de cromaticidade utilizando os valores x e y como eixos, conforme figura 10 . 
Figura 10- Diagrama de cromaticidade proposto pela CIE, possuindo o espectro de 410 a 780 nm.

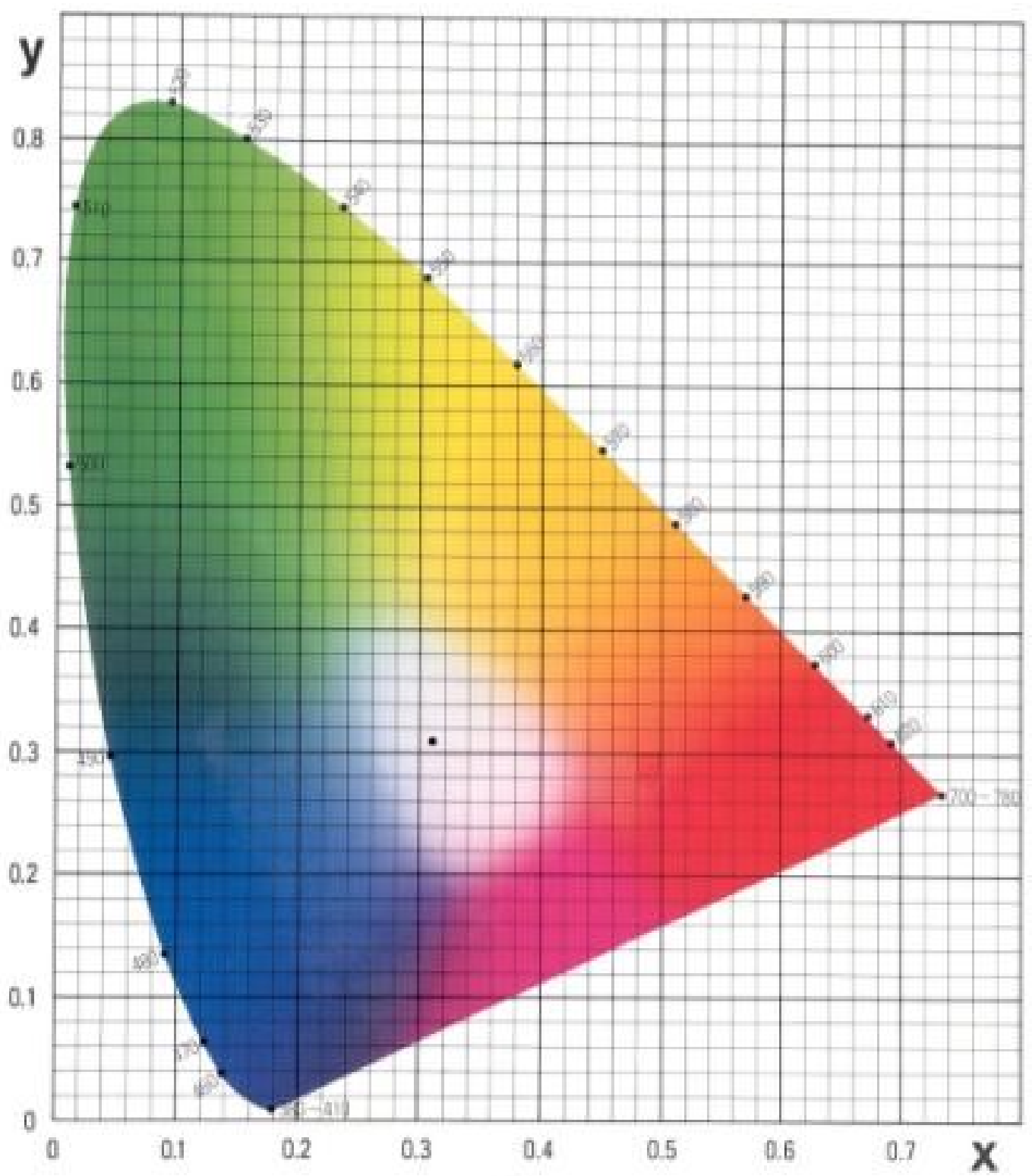

Fonte- HARDY, 1936

O diagrama de cromaticidade pode indicar a proporção com que cada cor primária deve ser misturada para obter qualquer outra cor. Na região central do diagrama encontramos o ponto branco da fonte de energia. O comprimento de onda dominante será aquele correspondente à mistura aditiva da cor da amostra, que é obtido da interseção da reta que passa pelo ponto do iluminante e da amostra com o limite do diagrama. A pureza colorimétrica é o percentual de contribuição da cor na mistura. Uma pureza de $100 \%$ corresponde à cor do espectro e $0 \%$ corresponde ao Iluminante (REA, 2000). 


\subsection{ANÁLISES ESTATÍSTICAS}

Para melhor entendimento das análises realizadas, será apresentado nas próximas seções, conceitos básicos de estatística.

\subsubsection{Experimentos com misturas}

Experimentos com misturas são aqueles em que as propriedades variam com a proporção de cada componente, sendo assim, as variáveis são dependentes, pois a alteração na quantidade de um componente irá a afetar a quantidade do outro, pois devem totalizar 100\%.

As propriedades de uma mistura são determinadas por meio de: modelo; planejamento experimental para validar esse modelo; e ajuste desse modelo aos dados experimentais. $\mathrm{O}$ modelo mais simples é o aditivo, exposto na equação 22.

$$
y=b_{0}+\sum b_{i} \times x_{i}
$$

Para facilitar a análise das variáveis que otimizam a resposta desejada, é utilizado a metodologia de superfície de resposta, podendo ser descrita pelo modelo linear (que possui apenas o efeito principal), quadrático (efeito de interação binaria), cúbico completo (efeito de interação ternaria) e cúbico especial (MONTGOMERY, 2009).

Os coeficientes são encontrados por meio de regressão linear múltipla, que consiste em ajustar o modelo aos dados, verificando a precisão do modelo em representar a variável de resposta.

O ajuste do modelo aos dados consiste em estimar os parâmetros desconhecidos por meio da aplicação do método de mínimos quadrados. A significância estatística desses modelos deve ser avaliada com uma análise de variância.

\subsubsection{Planejamento experimental fatorial $2 \mathrm{k}$}

O planejamento experimental é uma técnica para estudar o comportamento de uma variável de resposta em função da interação entre as variáveis de influência em níveis préestabelecidos por meio da execução de experimentos, cada qual denominado como tratamento (MONTGOMERY, 2009).

Permite obter um modelo matemático para se prever um fenômeno utilizando o mínimo possível de experimentos por meio de uma análise estatística dos resultados dos experimentos.

Planejar um experimento reduz tempo, custo operacional, variação e rendimento do processo. Envolve definir um objetivo claro a fim de definir as variáveis e seus níveis, o tamanho da amostra e o método de análise.

Para efetuar esse tipo de planejamento, é elaborada uma matriz onde são incluídas as todas as variáveis de influência a serem analisadas e seus níveis, gerando em cada linha um tratamento. 
Existem variáveis, conhecidas ou não, denominadas também como fatores de ruído, que podem mascarar os resultados dos efeitos principais. Cuidados devem ser tomados para evitar esse tipo de mascaramento, como por exemplo, a aleatorização dos tratamentos na realização do experimento. A aleatorização consiste em definir a ordem dos tratamentos de forma não sequenciada. Isso também é feito em atendimento a uma das exigências do método estatístico no qual pede que os erros experimentais sejam variáveis aleatórias independentes. Quando o valor de uma variável não pode ser determinado antes da realização do experimento, é denominada como variável aleatória (BORTOLINI, 2012).

O erro experimental pode ser estimado por meio da replicação dos experimentos, ou seja, repetir todos os tratamentos executados sob as mesmas condições de experimentação. Isso permite avaliar se os dados são estatisticamente significativos.

No caso de não ser possível a replicação do experimento, pode-se realizar a inclusão de um ponto central no experimento. Pontos centrais são ensaios em que as variáveis de influência são testadas entre os níveis baixos e altos. Os pontos centrais podem detectar curvaturas na resposta e estimar a variabilidade sem ter de replicar todos os pontos de extremidade (TEÓFILO, 2006).

Para grupos experimentais heterogêneos pode-se fazer blocagem. A blocagem consiste em subdividir os grupos heterogêneos formando grupos mais homogêneos, e assim aumentar a precisão da resposta (BORTOLINI, 2012).

Os efeitos principais são as diferenças médias observadas na resposta quando se muda os níveis das variáveis de influência. Como os experimentos tem mais de uma variável, temos os efeitos de interação entre essas variáveis, que são a metade da diferença entre os efeitos principais de uma variável de influência nos níveis de outra variável de influência.

\subsubsection{Análise de variância}

A análise de variância resume o modelo de regressão linear através da decomposição da variação total da resposta em variação atribuída ao tratamento e variação atribuída ao erro experimental, e utilizando o teste $\mathrm{F}$, testa a hipótese de que qualquer fonte de variação no modelo é igual a zero (TEÓFILO, 2006).

Os resultados da análise de variância são demonstrados em tabela, onde são apresentados os graus de liberdade, a soma de quadrados, o quadrado médio, a estatística $\mathrm{F}$ e o valor-p.

Os graus de liberdade são a quantidade de informação fornecida para estimar os valores de variáveis não conhecidas e calcular a variabilidade dessas estimativas. Esse valor é determinado pelo número de observações da amostra e o número de variáveis do modelo. 
A soma de quadrados mede a variação dos dados, e o quadrado médio mede o quanto os tratamentos afetam o resultado.

A estatística de teste é uma variável aleatória, calculada a partir dos dados da amostra e mede o grau de concordância entre amostra e hipótese nula. A estatística de teste é utilizada para calcular o valor-p.

\section{$\underline{\text { Valor-p }}$}

O valor-p é uma probabilidade que mensura a validade da hipótese nula. A hipótese nula é inexistência de uma relação entre a variável e a resposta, portanto, o coeficiente seria igual a zero. Geralmente, escolhe-se um nível de significância de 0,05 , que indica um risco de $5 \%$ de se concluir que existe uma relação quando não existe uma.

Para efetuar essa validação da hipótese nula e determinar se a relação entre resposta e variável no modelo é estatisticamente significativa, o valor-p deve ser comparado com o seu nível de significância $(\alpha)$. Se o valor-p $\leq \alpha$, a relação é estatisticamente significativa e se o valor-p $>\alpha$, a relação não é estatisticamente significativa

Se houver variáveis sem relação estatisticamente significativa com a resposta, podemos reduzir o modelo removendo os termos um de cada vez.

\section{Análise dos coeficientes}

$\mathrm{Na}$ tabela de coeficientes gerada pelo Minitab®, software de análises estatísticas utilizado neste trabalho, é demonstrado o efeito, o coeficiente, o erro padrão do coeficiente, Valor-T, Valor-P:

a) O efeito mostra a dimensão e a direção da relação entre a variável de influência e a variável de resposta.

b) O coeficiente representa o quanto a resposta será alterada quando é alterado uma unidade da variável de influência a qual ele pertence. O sinal do coeficiente indica a direção da relação entre a variável de influência e a resposta.

c) O erro padrão do coeficiente estima a precisão do coeficiente.

d) $\mathrm{O}$ valor-t pode determinar se a hipótese nula deve ser rejeitada, pois mede a razão entre o coeficiente e seu erro padrão. O Minitab® usa o valor-t para calcular o valor-p, que é mais utilizado frequentemente.

\section{Falta de ajuste}

O Minitab ${ }^{\circledR}$ executa o teste da falta de ajuste quando o experimento possui réplicas. Para determinar se o modelo ajusta os dados com precisão, comparamos o valor-p ao nível de 
significância $(\alpha)$. Se o valor-p $<\alpha$, o modelo não se ajusta aos dados e se for $>\alpha$, não existe evidência de que o modelo não se ajusta aos dados.

Gráfico de Pareto dos efeitos padronizados

O gráfico de Pareto dos efeitos padronizados indica os valores absolutos dos efeitos padronizados em ordem decrescente e serve para determinar a magnitude e importância desses efeitos, no entanto, não é possível determinar a direção, ou seja, se as variáveis influenciam positiva ou negativamente a resposta. No gráfico de Pareto, há uma linha de referência que indica os efeitos que são estatisticamente significativos. Os valores que ultrapassam a linha de referência são estatisticamente significativos e quanto maior for o seu valor, mais impacta na variável de resposta.

\section{Gráfico de probabilidade normal de efeitos}

O gráfico de probabilidade normal dos efeitos indica os valores dos efeitos padronizados em relação a uma linha de ajuste de distribuição que considera que todos efeitos são iguais a zero. Os efeitos positivos ficam do lado direto da linha de ajuste e indicam que a resposta varia de forma diretamente proporcional a variável de influência. Os efeitos negativos ficam do lado esquerdo da linha de ajuste e indicam que a resposta varia de forma indiretamente proporcional a variável de influência. Quanto mais os efeitos estiverem afastados de zero, eles são estatisticamente mais significativos.

\section{Gráfico de contorno}

O gráfico de contorno mostra bidimensionalmente a relação entre uma resposta e duas variáveis contínuas. 


\section{METODOLOGIA}

O estudo consistiu na análise das amostras obtidas pela fusão de caco de vidro flint com adição de fritas, seguindo um planejamento fatorial $2^{\mathrm{k}}$, tendo como variáveis, os percentuais de fritas de B674UL (Ferro), G924XP (Selênio) e 410JS (Manganês), providas por um fornecedor da indústria onde foi desenvolvido este trabalho, cujo nome será mantido em sigilo, bem como os nomes reais das fritas. Foram feitas análises com base nos resultados de transmitância, diagrama de cromaticidade, análise química e análise da oxi-redução.

A frita tem composição química próxima do caco de vidro flint, com teor elevado de fundente e elemento colorante, e não será exposta devido ao sigilo exigido pelo fornecedor, mas será apresentada na Tabela 2 a concentração do elemento colorante presente na frita.

Tabela 2- Concentração do elemento colorante em cada frita utilizada.

\begin{tabular}{ccc}
\hline \multicolumn{2}{c}{ Nomenclatura da frita } & \% Elemento colorante presente nas fritas \\
\hline B 674 UL & $60,0 \%$ Ferro \\
& G 924 XP & $0,88 \%$ Selênio \\
\hline Fonte- Autor & 410 JS & $30,1 \%$ Manganês
\end{tabular}

A composição química do caco de vidro é mostrada na Tabela 3:

Tabela 3- Composição química média do caco Flint, analisado por fluorescência de raios-X.

\begin{tabular}{cccccccc}
\hline Composto & $\mathrm{SiO}_{2}$ & $\mathrm{Na}_{2} \mathrm{O}$ & $\mathrm{CaO}$ & $\mathrm{SO}_{3}$ & $\mathrm{MgO}$ & $\mathrm{Al}_{2} \mathrm{O}_{3}$ & $\mathrm{Fe}_{2} \mathrm{O}_{3}$ \\
\% massa & 71,6 & 14,36 & 11,1 & 0,22 & 0,77 & 1,94 & 0,021 \\
\hline
\end{tabular}

Fonte- Autor

O objetivo do trabalho é atingir uma composição de fritas a serem adicionadas por meio do processo de color-feeder, que possa resultar na retenção de raios ultravioleta, assim como o vidro âmbar. Sendo assim, o vidro âmbar foi utilizado como referência para análise do gráfico de transmitância e diagrama de cromaticidade. No entanto, o vidro âmbar não possui transmitância na faixa de 280 a $450 \mathrm{~nm}$, que é a faixa utilizada para análise, visto que é o valor utilizado na indústria vidreira que possibilitou este trabalho, referenciados pela Farmacopeia Americana. E, como foi escolhida a área abaixo da curva de transmitância para análise comparativa e estatística dos dados, utilizando a ferramenta de integração do software Origin ${ }^{\circledR}$, a área ideal seria aquela mais próxima de zero.

JITWATCHARAKOMOL (2005), observou que o ferro e o selênio resultam em uma cor análoga ao âmbar. Por este motivo foi feito o primeiro conjunto de testes com as amostras 
do grupo 1, contendo fritas de B674UL(Fe) e G924XP(Se). O planejamento foi executado com apenas uma duplicata.

Em uma mistura a soma dos componentes deve ser igual a 1, portanto quando se altera um dos componentes, os outros também serão alterados proporcionalmente:

$$
B 674 U L+G 924 X P+\text { Vidro }=1
$$

Sendo B674UL a fração mássica adicionada da frita de ferro; G924XP, a fração mássica adicionada da frita de selênio e vidro, a fração mássica de caco de vidro adicionada no cadinho.

Para efetuar o planejamento experimental é necessário fixar valores mínimos e máximos para cada variável. Neste caso os coeficientes descritos como R1 e R2 na Tabela 4, definem a fração mássica mínima e máxima de cada frita a ser testada, sendo:

$$
R 1=\frac{\mathrm{B} 674 \mathrm{UL}}{\text { Vidro }} \quad \text { e } 2=\frac{\mathrm{G} 924 \mathrm{XP}}{\text { Vidro }}
$$

A quantidade de vidro presente na composição irá variar conforme variar a quantidade de fritas adicionadas, portanto:

$$
\begin{gathered}
\text { Vidro } * R 1+\text { Vidro } * R 2+\text { Vidro }=1 \\
\text { Vidro } *(R 1+R 2+1)=1 \quad \rightarrow \quad \text { Vidro }=\frac{1}{(R 1+R 2+1)}
\end{gathered}
$$

Determinando a fração de vidro adicionado, encontram-se as respectivas frações de fritas adicionadas, resultando nos valores apresentados na Tabela 4.

Tabela 4- Planejamento experimental do grupo 1: B674UL (Fe) x G924XP (Se).

\begin{tabular}{cccccc} 
Amostra & $R 1$ & $R 2$ & Vidro & B674UL $(\mathrm{Fe})$ & $G 924 X P(\mathrm{Se})$ \\
\hline G21 & 0,00825 & 0,02300 & 0,96970 & 0,00800 & 0,02230 \\
G22 & 0,01650 & 0,04600 & 0,94118 & 0,01553 & 0,04329 \\
G23 & 0,01650 & 0,02300 & 0,96200 & 0,01587 & 0,02213 \\
G24 & 0,00825 & 0,04600 & 0,94854 & 0,00783 & 0,04363 \\
\hline G25 & 0,01650 & 0,02300 & 0,96200 & 0,01587 & 0,02213 \\
G26 & 0,01650 & 0,04600 & 0,94118 & 0,01553 & 0,04329 \\
G27 & 0,00825 & 0,04600 & 0,94854 & 0,00783 & 0,04363 \\
G28 & 0,00825 & 0,02300 & 0,96970 & 0,00800 & 0,02230
\end{tabular}

Fonte- Autor

SALMANG (2013) observou que o óxido de manganês pode atuar como oxidante do Ferro, transformando $\mathrm{Fe}^{2+}$ em $\mathrm{Fe}^{3+}$, o qual possui forte absorção dos raios ultravioleta. Então, 
efetuou-se a segunda tentativa com as amostras do grupo 2, que continham fritas de B674UL(Fe), G924XP(Se) e 410JS(Mn).

Diferentemente do planejamento experimental do grupo 1, o grupo 2 é composto por quatro elementos. Então, como mistura devemos observar que a soma destes seja igual a 1:

$$
B 674 U L+G 924 X P+410 J S+\text { Vidro }=1
$$

Não houve nenhum critério para estabelecer os limites mínimos e máximos. Os coeficientes R1, R2 e R3 apresentados na Tabela 5, definem a fração mássica mínima e máxima de cada frita a ser testada, sendo:

$$
R 1=\frac{\mathrm{B} 674 \mathrm{UL}}{\text { Vidro }} \quad ; \quad R 2=\frac{410 \mathrm{JS}}{\text { Vidro }} \quad ; \quad R 3=\frac{\mathrm{G} 924 \mathrm{XP}}{\text { Vidro }}
$$

A quantidade de vidro presente na composição irá variar conforme variar a quantidade de fritas adicionadas, portanto:

$$
\operatorname{Vidro} * R 1+\operatorname{Vidro} * R 2+\operatorname{Vidro} * R 3+\operatorname{Vidro}=1 \rightarrow \operatorname{Vidro}=\frac{1}{(R 1+R 2+R 3+1)}
$$

Determinando a fração de vidro adicionado, encontram-se as respectivas frações de fritas adicionadas, resultando nos valores apresentados na Tabela 5.

Não foram feitas duplicatas, pois havia uma restrição de custo para o projeto, que se executado a duplicata poderia ser extrapolado. Sendo assim, foi executado um experimento no ponto central, aumentando a confiança nos resultados estatísticos.

Tabela 5- Planejamento experimental do grupo 2: B674UL (Fe) x 410JS (Mn) x G924XP (Se).

\begin{tabular}{cccccccc}
\hline Amostra & $R 1$ & $R 2$ & $R 3$ & Vidro & $\begin{array}{c}\text { B674UL } \\
(\mathrm{Fe})\end{array}$ & $\begin{array}{c}410 J \mathrm{~J} \\
(\mathrm{Mn})\end{array}$ & $\begin{array}{c}G 924 X P \\
(\mathrm{Se})\end{array}$ \\
\hline G10 & 0,0250 & 0,0250 & 0,0250 & 0,9302 & 0,0233 & 0,0233 & 0,0233 \\
G11 & 0,0500 & 0,0500 & 0,0250 & 0,8889 & 0,0444 & 0,0444 & 0,0222 \\
G12 & 0,0250 & 0,0500 & 0,0125 & 0,9195 & 0,0230 & 0,0460 & 0,0115 \\
G13 & 0,0500 & 0,0250 & 0,0125 & 0,9195 & 0,0460 & 0,0230 & 0,0115 \\
G14 & 0,0250 & 0,0250 & 0,0125 & 0,9412 & 0,0235 & 0,0235 & 0,0118 \\
G15 & 0,0500 & 0,0250 & 0,0250 & 0,9091 & 0,0455 & 0,0227 & 0,0227 \\
G16 & 0,0250 & 0,0500 & 0,0250 & 0,9091 & 0,0227 & 0,0455 & 0,0227 \\
G17 & 0,0500 & 0,0500 & 0,0125 & 0,8989 & 0,0449 & 0,0449 & 0,0112 \\
\hline $\begin{array}{c}\text { G18 } \\
\text { (P.central) }\end{array}$ & 0,0375 & 0,0375 & 0,0188 & 0,9143 & 0,0343 & 0,0343 & 0,0171 \\
\hline
\end{tabular}

Fonte- Autor

Para orientar os experimentos de desenvolvimento de cores em vidros é usual que as coordenadas tricromáticas de todas as amostras sejam calculadas de acordo com o CIE, permitindo analisar o elemento responsável por aquela coloração. Sendo assim, os resultados 
de transmitância de todas as amostras foram utilizados para calcular as coordenadas tricromáticas e inseri-las no digrama de cromaticidade.

Os valores triestímulus $\mathrm{X}, \mathrm{Y}, \mathrm{Z}$, foram encontrados multiplicando a transmitância pelos coeficientes tricromáticos $\mathrm{x}, \mathrm{y}$ e $\mathrm{z}$ do iluminante $\mathrm{C}$ para cada comprimento de onda (HARDY, 1936):

$$
X=\sum_{380}^{760} T * x \quad Y=\sum_{380}^{760} T * y \quad ; \quad Z=\sum_{380}^{760} T * Z
$$

As proporções dos valores triestímulos irão gerar coordenadas tricromáticas $\mathrm{x}, \mathrm{y}, \mathrm{z}$ da amostra:

$$
x=\frac{X}{X+Y+Z} \quad ; \quad y=\frac{Y}{X+Y+Z} \quad ; \quad z=\frac{Z}{X+Y+Z}
$$

Como o diagrama é bidimensional e não representa a luminância (coordenada $\mathrm{z}$ ), apenas as coordenadas x e y são utilizadas para encontrar a posição no diagrama de cromaticidade.

No processo de color-feeder, a massa vítrea já homogeneizada que passa pelo canal recebe a adição das fritas que são misturadas por pás giratórias até a homogeneização da cor. Para simular esse processo, $400 \mathrm{~g}$ de caco flint foram adicionados em um cadinho refratário para fusão, conforme figura 11.

Figura 11- Cadinho refratário com 400g de caco flint, utilizado para simular o processo de color feeder, de modo a obter uma massa vítrea para mistura dos óxidos colorantes e conformação das amostras.

Fonte- Autor

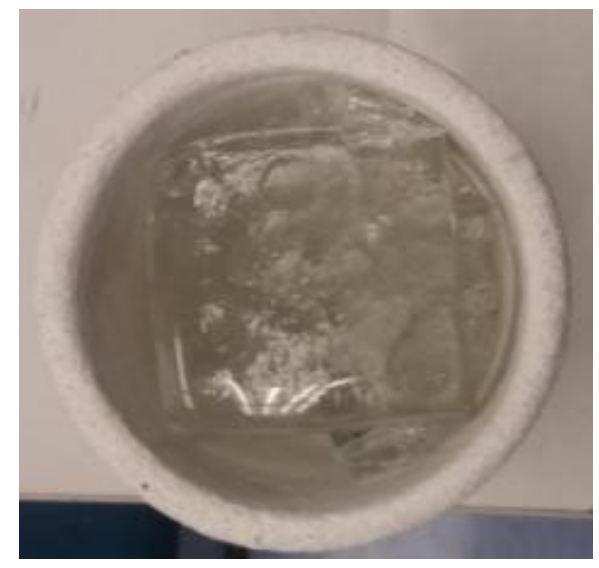

O cadinho foi inserido dentro de um forno tipo poço a combustão, utilizando uma mistura de ar e gás natural, com três queimadores direcionados ao cadinho, conforme ilustram as figura 12 e 13. 
Figura 12- Forno tipo poço a combustão, utilizado para fusão da massa vítrea, com uma mistura de ar e gás natural, contendo três queimadores laterais, direcionados ao cadinho.

Fonte- Autor

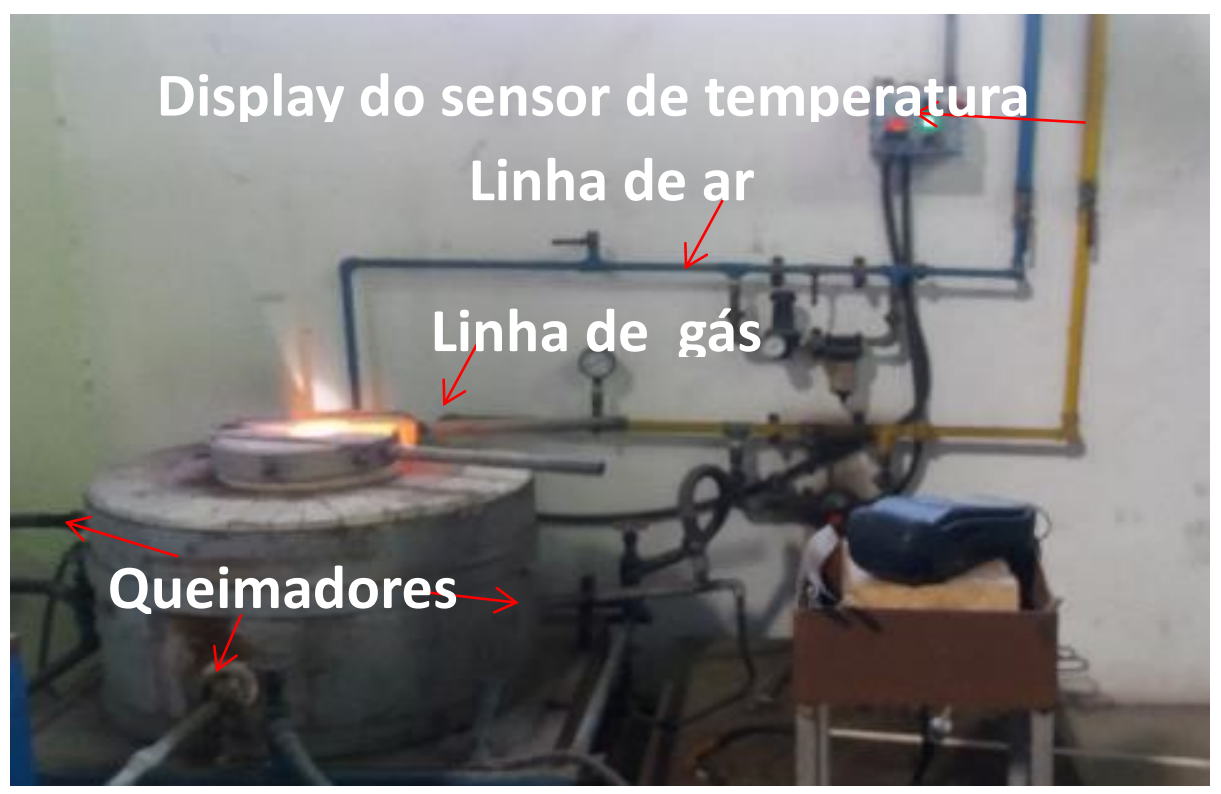

Figura 13- Visão interna do forno com o cadinho já inserido e posicionado entre os queimadores.

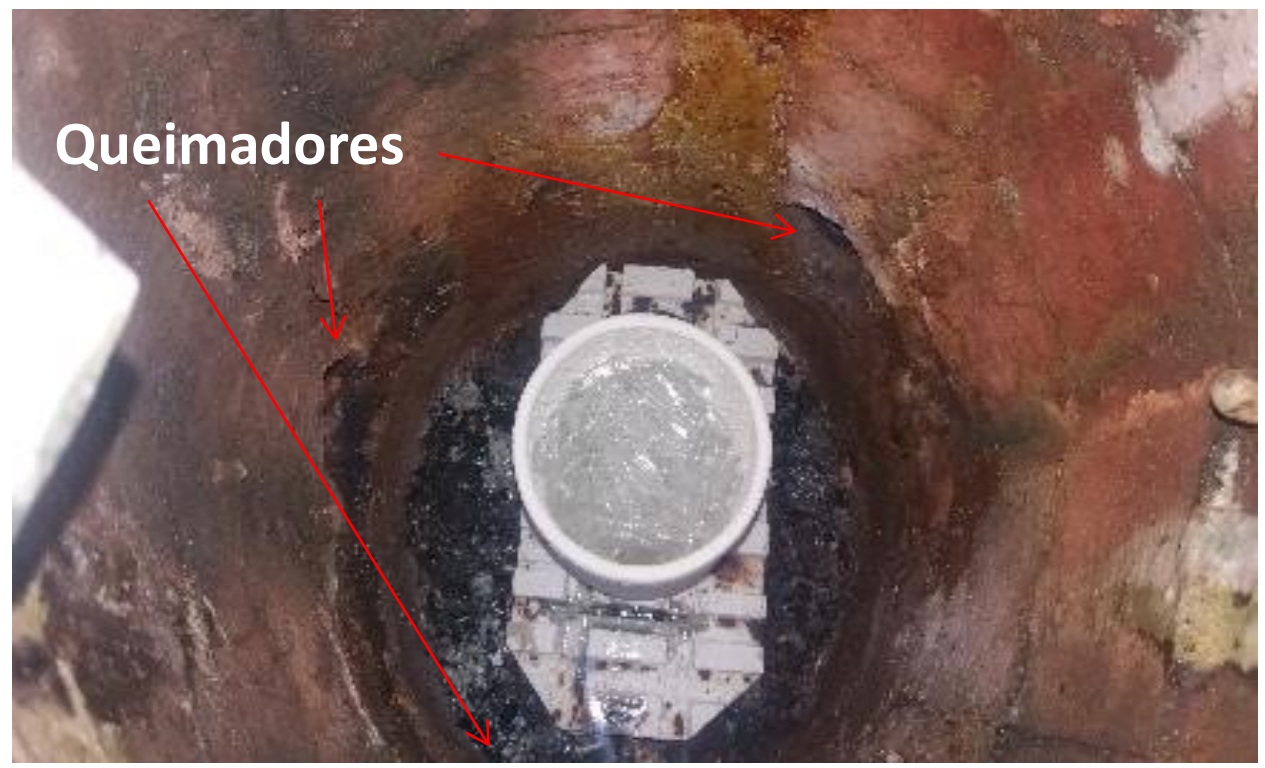

Fonte- Autor

Após posicionar o cadinho, liga-se o forno, ajustando a vazão de ar e gás de forma a obter-se um chama estável, e então, segundo procedimento interno da empresa, aguarda-se cerca de 2 horas para fusão do caco. Após as 2 horas, a temperatura da massa vítrea é medida com pirômetro ótico de marca Ecil, modelo Ciclops 100L, conforme ilustra a figura 14a. Se na medição de temperatura a massa vítrea estiver a cerca de $1300{ }^{\circ} \mathrm{C}$, e estando a atmosfera com 
oxigênio até 2,5\%, pode-se inserir as fritas. A medição da atmosfera do forno é feita com um analisador de gases de marca Ecil, modelo Chemist 402, ilustrado na figura $14 \mathrm{~b}$.

Figura 14- a) Medição da temperatura da massa vítrea, após o tempo de residência de 2 horas, para fusão do caco; b) Medição da porcentagem de oxigênio na atmosfera do forno.
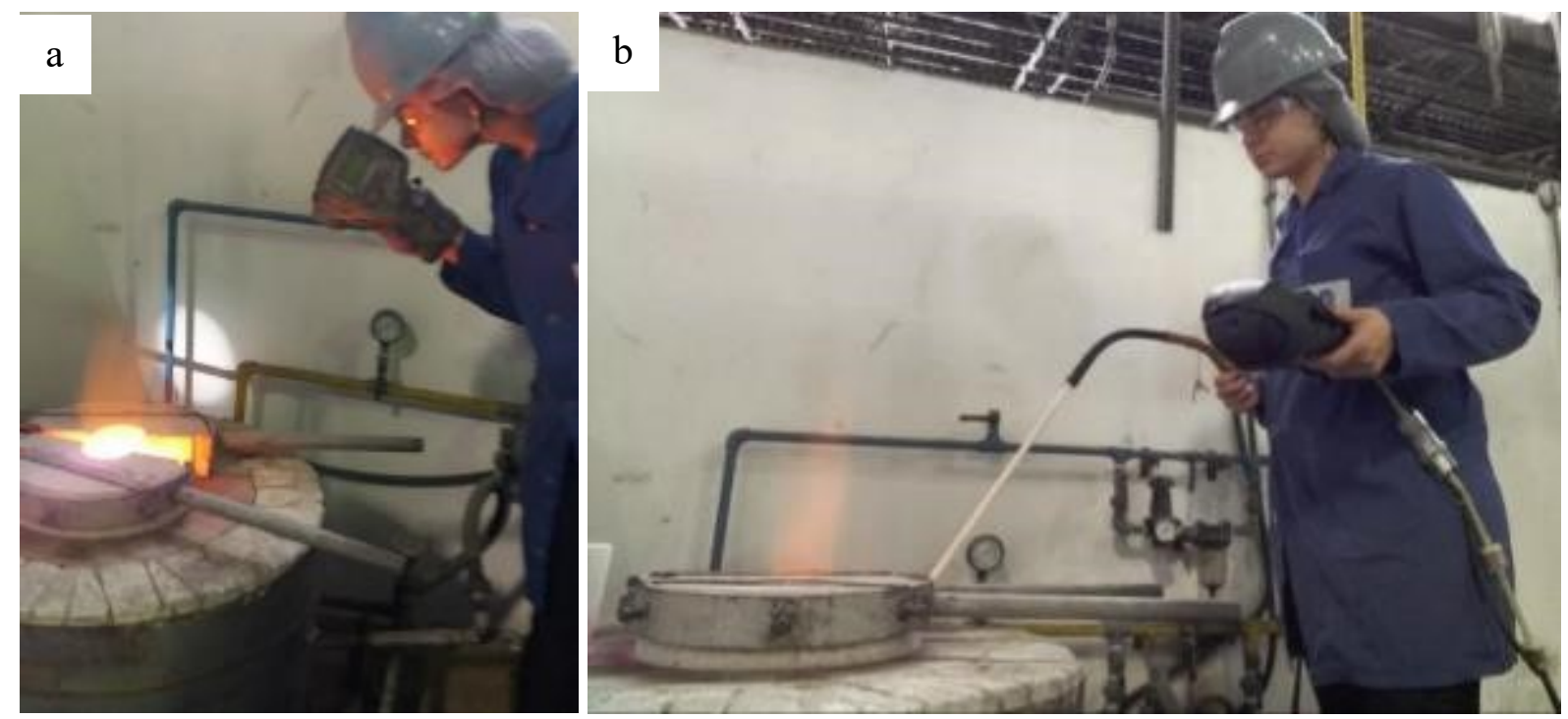

Fonte- Autor

Para inserir as fritas, o cadinho é retirado de dentro do forno. As fritas devem fundir rapidamente sobre a massa vítrea e deve-se retornar o cadinho ao forno imediatamente após inserir as fritas, conforme apresentado na .

Figura 15- Fritas fundindo sobre a massa vítrea após serem inseridas no cadinho.

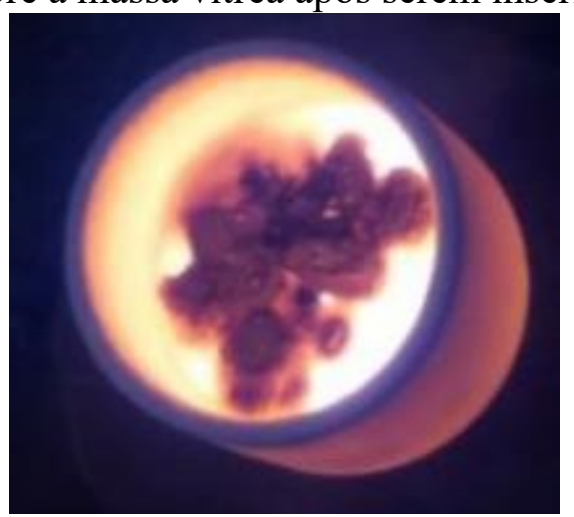

Fonte- Autor

A agitação é feita manualmente com vareta refratária de alumina, conforme ilustra a figura 16, devendo ser pré-aquecida para evitar que quebra por choque térmico quando em contato com o vidro. 
Figura 16- Processo de agitação da massa vítrea com vareta refratária, simulando os agitadores do processo de color-feeder.

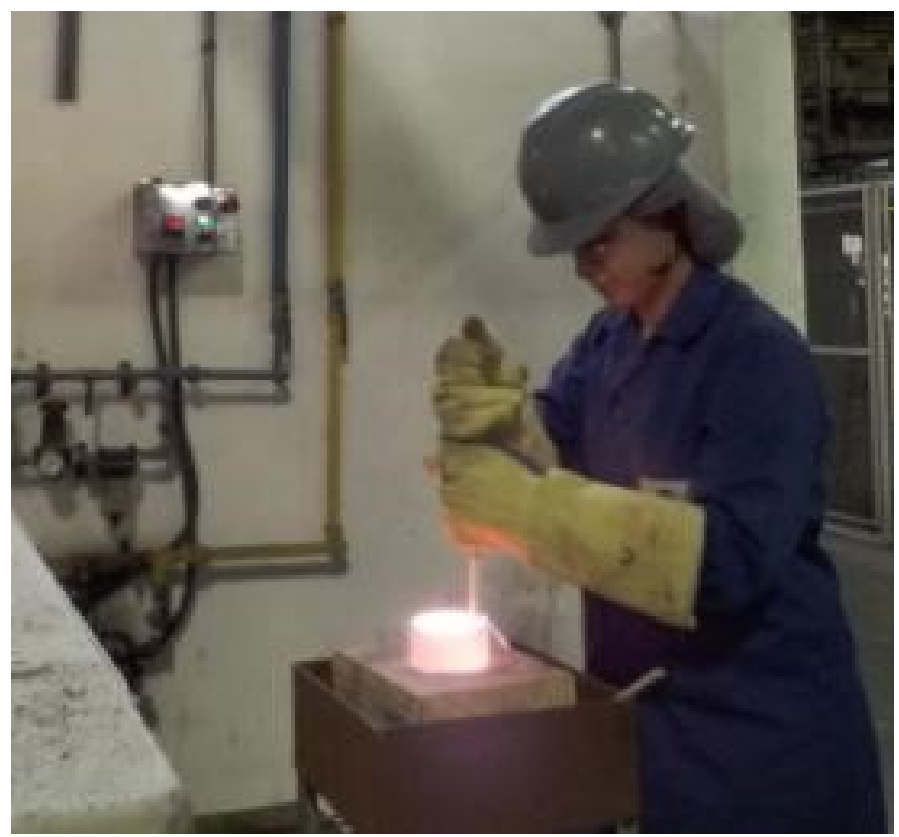

Fonte- Autor.

O processo de agitação é realizado de 3 a 4 vezes, até que visualmente não se observe diferenças de coloração na massa. Quando isso ocorre, o cadinho é inserido pela última vez no forno, onde é contabilizado um tempo de residência de 30 minutos ou mais, para remoção das bolhas geradas pela agitação. Feito isso, pode-se efetuar o vazamento da massa vítrea nos moldes de ferro fundido, com posterior prensagem manual. A figura 17 ilustra o processo de vazamento, corte da gota e prensagem manual.

Figura 17- a) Processo de vazamento; b) formação da gota; c) corte da gota; e d) prensagem manual para elaboração das amostras.

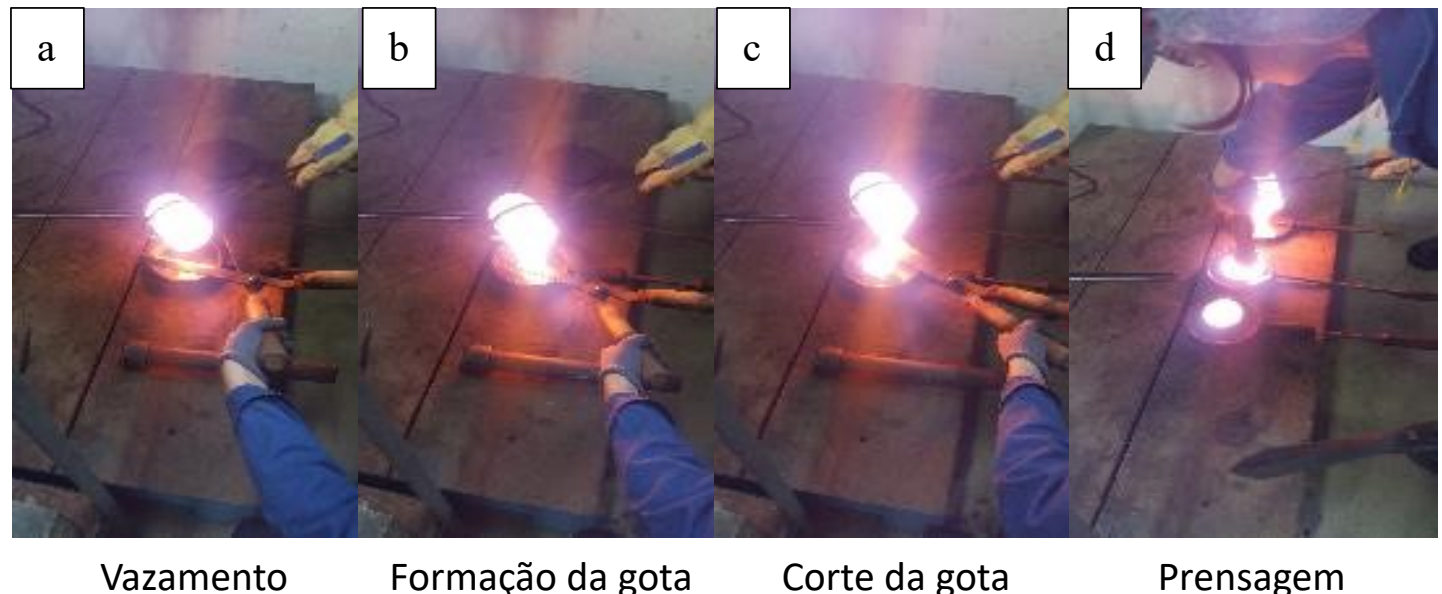

Fonte- Autor. 
Após a prensagem, as amostras são inseridas em forno de recozimento, pré-aquecido a cerca de $550{ }^{\circ} \mathrm{C}$, o qual é desligado logo em seguida, permitindo que as amostras resfriem lentamente, por cerca de 24 horas. Este forno é ilustrado na figura 18 .

Figura 18- Forno utilizado para recozimento das amostras.

Fonte- Autor.

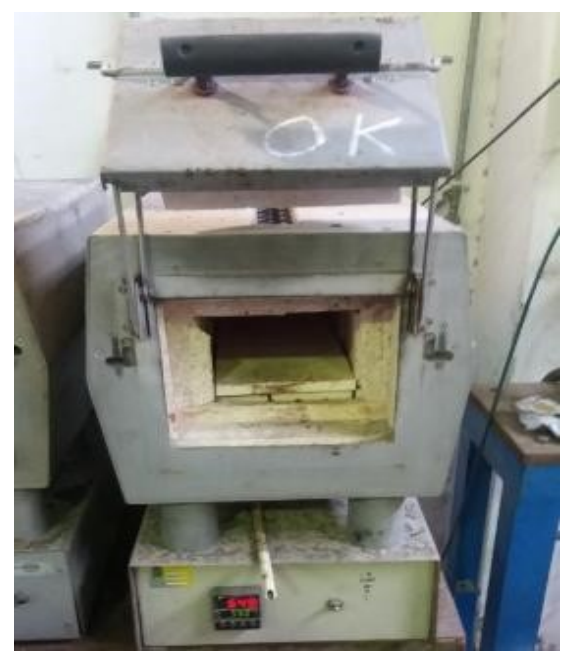

Após elaboração, as amostras foram enviadas ao laboratório para análise química e de transmitância. A preparação das amostras foi feita por meio de corte com serra copo, e polimento até atingir uma espessura próxima de $3 \mathrm{~mm}$. As amostras preparadas podem ser visualizadas na figura 19.

Figura 19- Amostras cortadas e polidas, preparadas para análise de transmitância. (a) Grupo 1; (b) Grupo 2.

a)

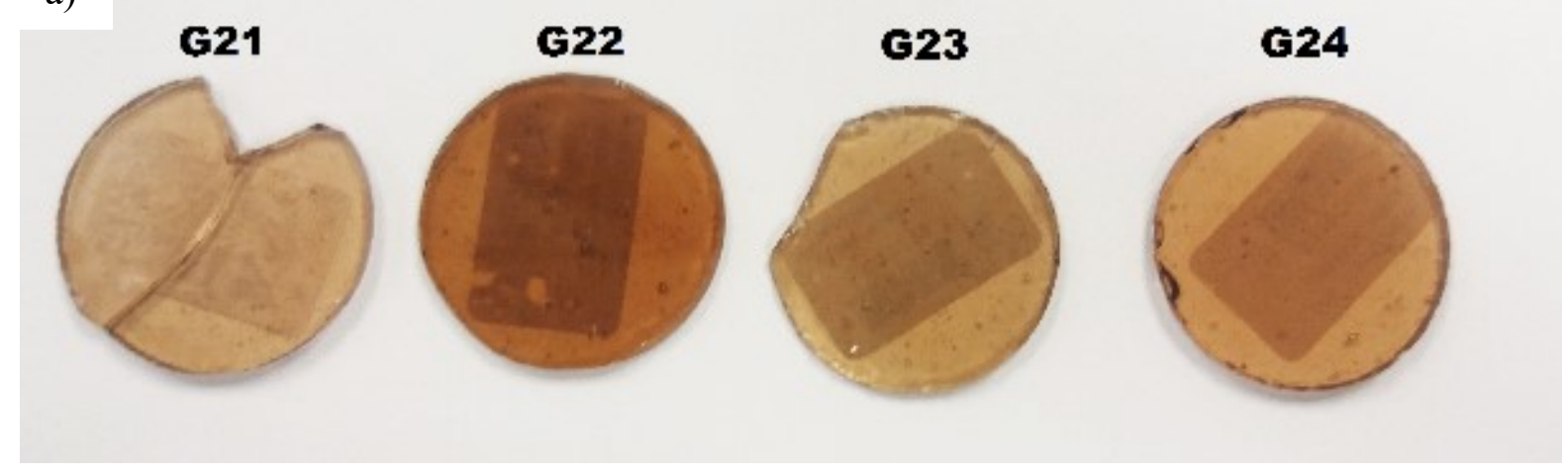




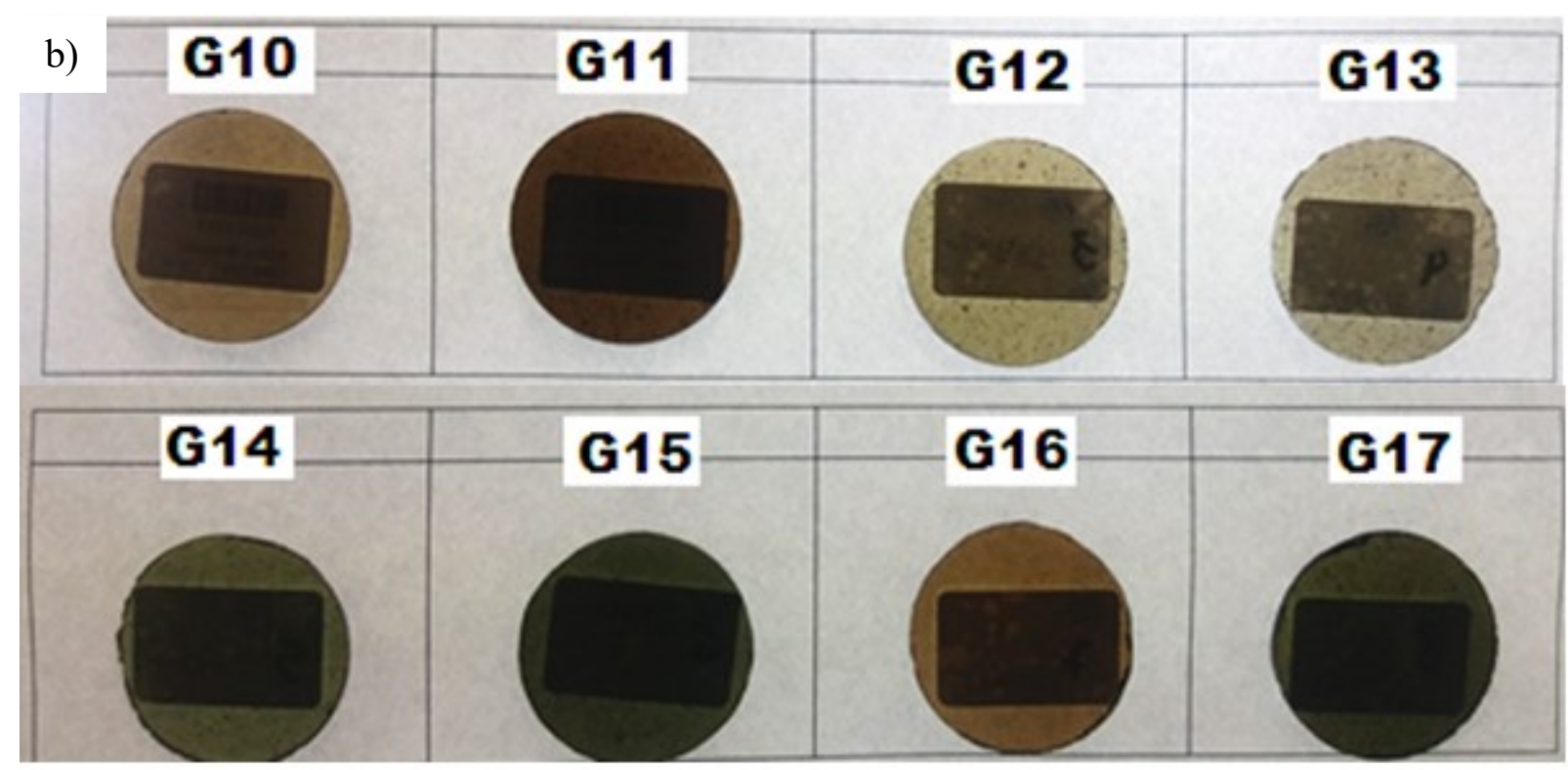

Fonte- Autor.

$\mathrm{O}$ equipamento utilizado para análise química via fluorescência de raios $\mathrm{X}$ foi um espectrômetro da marca Axios, modelo Panalytical. O equipamento utilizado para análise de transmitância foi um Lambda 750 S Perkim Elmer. Esta análise foi realizada com iluminante C e observador a $2^{\circ}$, varrendo a faixa de 280 a $760 \mathrm{~nm}$. Apenas as amostras com melhores resultados foram varridas até $1000 \mathrm{~nm}$, bem como o vidro flint e âmbar.

O procedimento, por ser manual, não possibilita a uniformidade de espessura, e como a transmitância é dependente da espessura do meio, ao variar-se a espessura, varia-se também a transmitância. Para possibilitar uma análise comparativa, foi necessário realizar a correção de espessura da amostra para a espessura desejada. Esta correção foi feita utilizando as leis de Fresnel e Lambert Beer para a espessura de 3 mm, conforme equação 23 (BACH; NEUROTH, 2013), (AKERMAN, 2007).

$$
T c=e^{\ln \left(\frac{T m}{P}\right) \times \frac{e_{c}}{e_{r}} \times P}
$$

Onde:

$\mathrm{T}_{\mathrm{m}}$ é a transmitância medida;

$\mathrm{T}_{\mathrm{c}}$ é a transmitância corrigida;

$\mathrm{e}_{\mathrm{c}}$ é a espessura corrigida;

$\mathrm{e}_{\mathrm{r}}$ é a espessura real

P é o fator de transmitância do vidro, derivado da equação de Fresnel e descreve a relação entre reflexividade $\mathrm{r}$ e índice de refração $\mathrm{n}$, descrito na seção 2.2.4. 


\section{RESULTADOS E DISCUSSÕES}

Para facilitar a compreensão e a análise dos resultados, esta seção foi dividida em duas partes, em que se analisam separadamente o Grupo 1: B674UL (Fe) + G924XP (Se) e o Grupo 2: B674UL (Fe) + G924XP (Se) + 410JS (Mn).

\subsection{GRUPO 1: B674UL (Fe) + G924XP (Se)}

As curvas de transmitância do Grupo 1 obtidas para os comprimentos de onda de 290 a $760 \mathrm{~nm}$ podem ser visualizadas na figura 20. O experimento foi replicado, portanto, para facilitar a visualização de cada amostra no gráfico, os resultados foram separados como Bloco 1, e sua réplica como Bloco 2.

Figura 20- (a) Curva de transmitância do bloco 1, corrigida para espessura de 3mm, (b) Curva de transmitância do bloco 2, corrigida espessura para 3mm, (réplica do Bloco 1). As composições idênticas entre os blocos possuem as mesmas cores, por exemplo, G22=G26 (curva em vermelho).

a

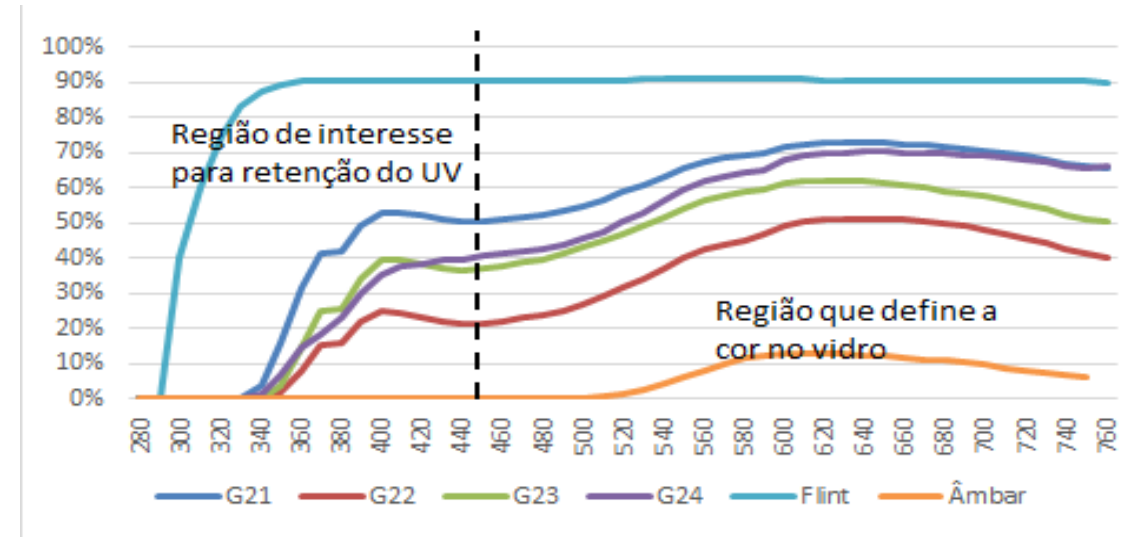

b

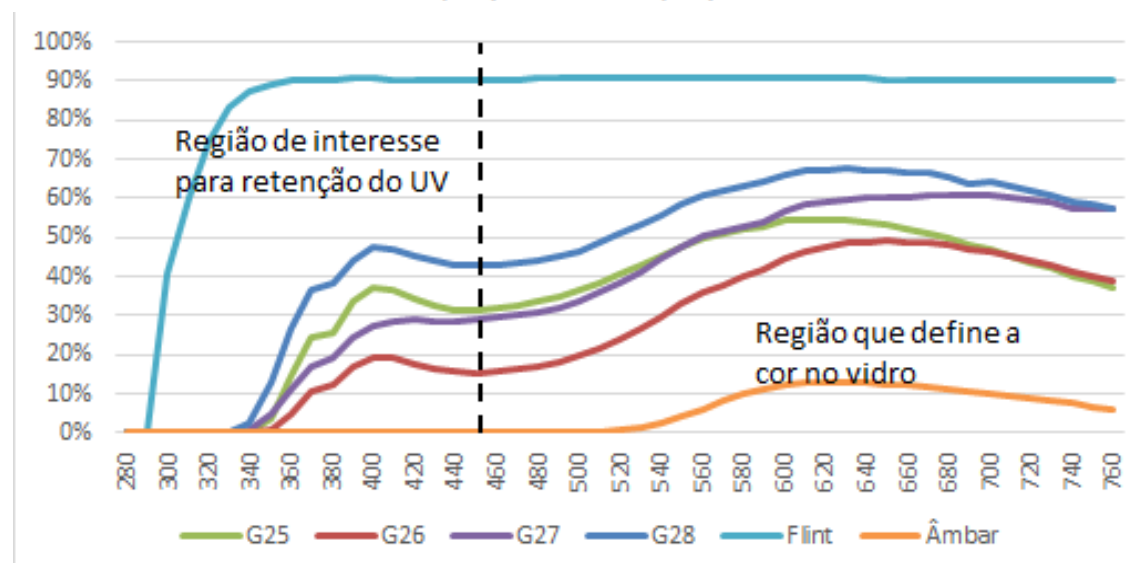


Verifica-se, pela comparação entre os dois gráficos que, houve uma repetitividade dos valores encontrados no primeiro bloco, visto que as curvas de transmitância para cada amostra de mesma composição entre os blocos são bem similares.

É possível observar também que, nenhuma das amostras estaria aprovada pela Farmacopéia americana, visto que nenhuma apresentou transmitância até $10 \%$ no comprimento de onda de 290 a $450 \mathrm{~nm}$. A amostra que mais se aproximou da transmitância exigida pela Farmacopeia foi a G22/G26, a qual possui os níveis máximos das variáveis estudadas, e a que mais se afastou foi a G21/G28, a qual possui os níveis mínimos das variáveis estudadas.

A posição de cada composição no diagrama de cromaticidade é apresentada na figura 21.

Figura 21- Resultados do Grupo 1: Coordenadas tricromáticas das amostras para transmitância corrigida espessura para $3 \mathrm{~mm}$. As composições idênticas entre os blocos possuem as mesmas cores, por exemplo, G22=G26 (curva em vermelho).

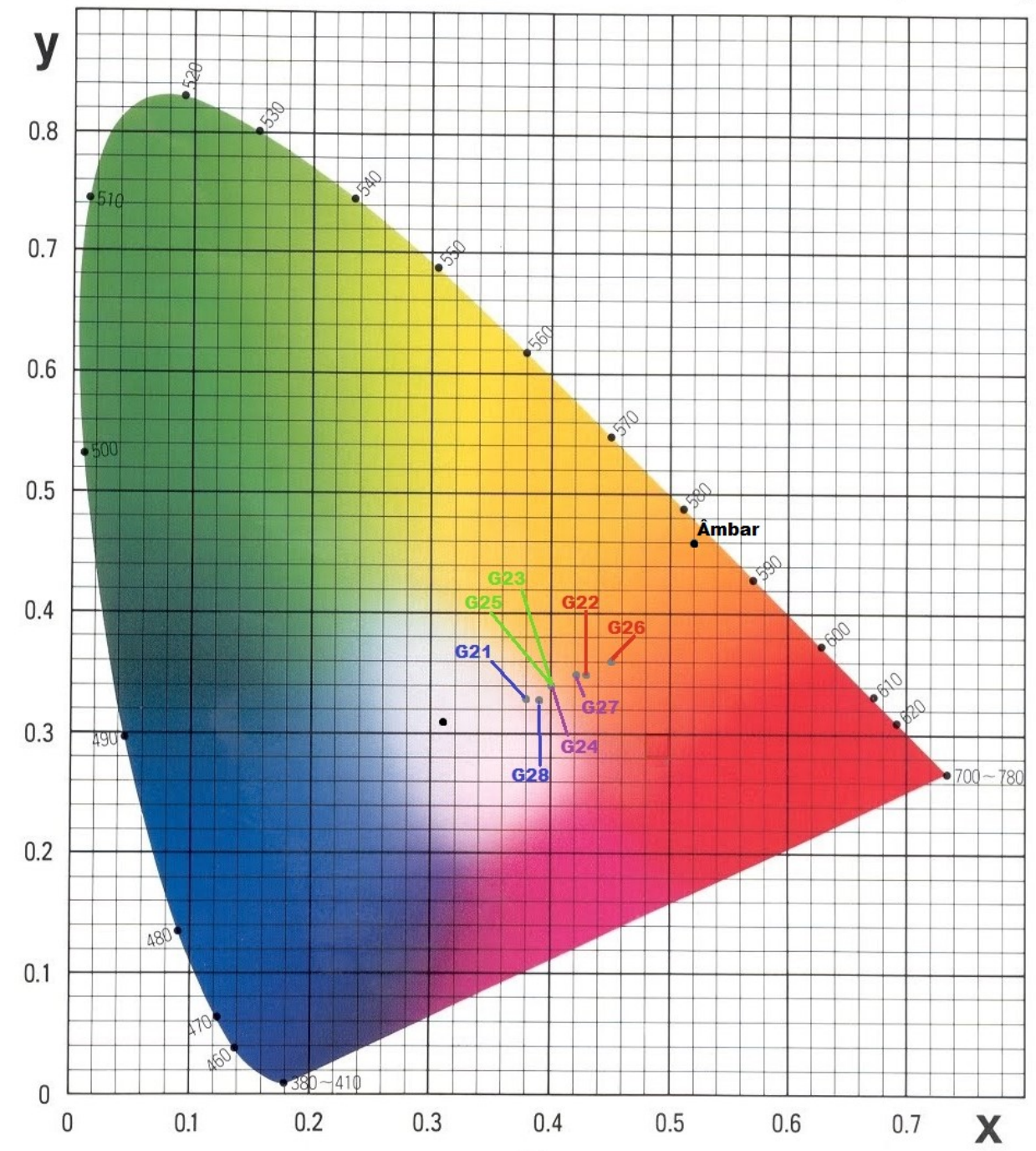

Fonte- Adaptado de HARDY, 1936 
Observa-se que a amostra com menor transmitância na faixa de 290 a $450 \mathrm{~nm}$ é a mesma que apresentou maior proximidade com o ponto âmbar no diagrama de cromaticidade, sendo ela a que possui composição máxima das fritas utilizadas.

Para análise comparativa e estatística dos dados, foi calculada a área abaixo de cada curva na faixa de 290 a $450 \mathrm{~nm}$, utilizando a ferramenta de integração do software Origin ${ }^{\circledR}$. Os resultados podem ser visualizados na última coluna da Tabela 6 .

Tabela 6- Resultados da integração das curvas das amostras do grupo 1 na faixa de 290 a 450nm com o software Origin.

\begin{tabular}{ccccccc}
\hline Amostra & $R 1$ & $R 2$ & Vidro & B674UL & G924XP & $\begin{array}{c}\text { Resultado } \\
\text { (Área) }\end{array}$ \\
\hline G21 & 0,00825 & 0,02300 & 0,96970 & 0,00800 & 0,02230 & 4684,15 \\
G28 & 0,00825 & 0,02300 & 0,96970 & 0,00800 & 0,02230 & 4081,88 \\
Média & & & & & & $\mathbf{4 3 8 3 , 0 2}$ \\
G22 & 0,01650 & 0,04600 & 0,94118 & 0,01553 & 0,04329 & 1906,81 \\
G26 & 0,01650 & 0,04600 & 0,94118 & 0,01553 & 0,04329 & 1418,28 \\
Média & & & & & & $\mathbf{1 6 6 2 , 5 5}$ \\
G23 & 0,01650 & 0,02300 & 0,96200 & 0,01587 & 0,02213 & 3136,99 \\
G25 & 0,01650 & 0,02300 & 0,96200 & 0,01587 & 0,02213 & 2899,83 \\
Média & & & & & & $\mathbf{3 0 1 8 , 4 1}$ \\
G24 & 0,00825 & 0,04600 & 0,94854 & 0,00783 & 0,04363 & 3049,62 \\
G27 & 0,00825 & 0,04600 & 0,94854 & 0,00783 & 0,04363 & 2340,23 \\
Média & & & & & & $\mathbf{2 6 9 4 , 9 3}$ \\
Fonte- Minitab ${ }^{2}$ & & & & &
\end{tabular}

O vidro âmbar não possui nenhum pico até $520 \mathrm{~nm}$, portanto, a área abaixo da curva de transmitância é zero, por este motivo, para comparação, determinamos que o melhor resultado seria aquele em que a área abaixo da curva de transmitância fosse a menor possível, já que não havia nenhum valor limite de área que pudéssemos comparar.

A melhor amostra foi a $\mathrm{G} 22 / \mathrm{G} 26$, a qual possui os níveis máximos das variáveis estudadas: 1,65\% B674UL (Fe) e 4,6\%, G924XP (Se). A pior amostra foi a G21/G28, ao qual possui níveis mínimos das variáveis estudadas: 0,825\% de B674UL (Fe) e 2,3\% de G924XP (Se). 
Com as áreas obtidas na Tabela 6, foi possível a análise no Minitab®, por meio da análise de experimento fatorial $2^{2}$ com réplicas, gerando o gráfico de pareto apresentado na figura 22 .

Figura 22- Gráfico de pareto dos efeitos padronizados para as amostras do grupo 1.

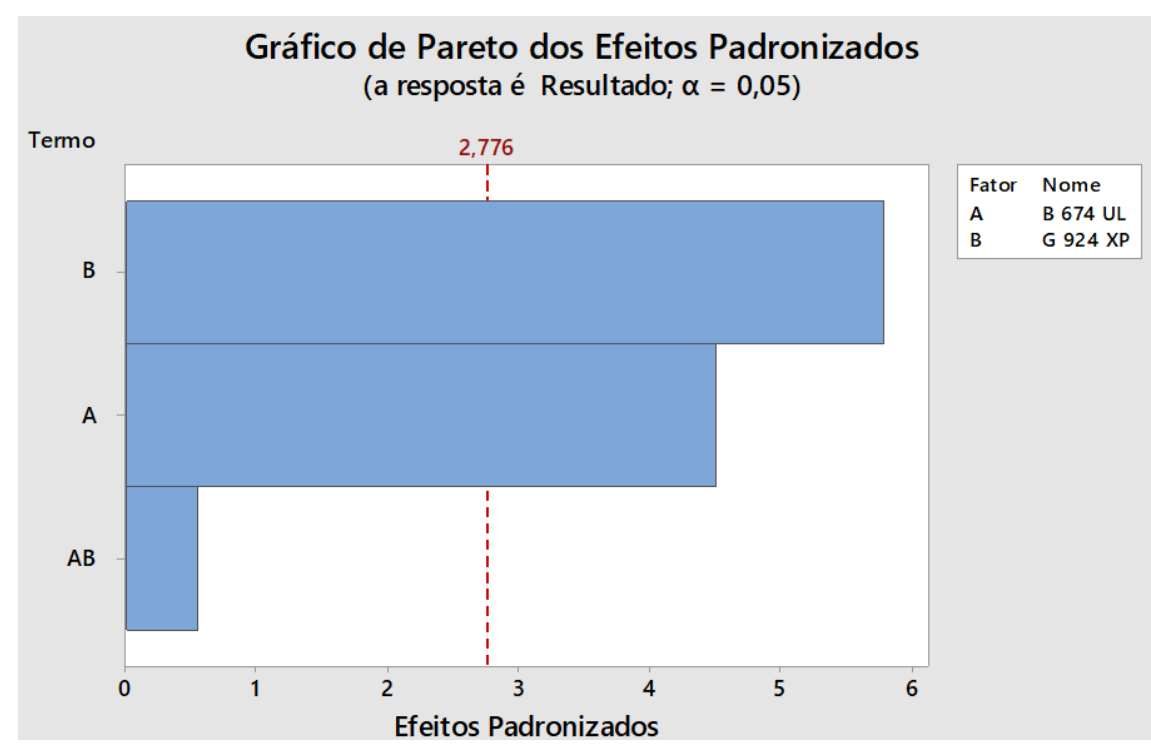

Fonte- Minitab®

O gráfico de Pareto determina a importância dos efeitos de cada variável. Verifica-se com o gráfico de pareto gerado, que a interação entre B674UL(Fe) e G924XP(Se), indicado como termo $\mathrm{AB}$, não é significativa, pois não ultrapassa a linha de referência para ser estatisticamente significativa, por este motivo, pode ser retirada do modelo, gerando um grau de liberdade para o cálculo do erro experimento. O novo gráfico de pareto gerado é apresentado na figura 23 .

Figura 23- Grafico de pareto dos efeitos padronizados para as amostras do grupo 1, sem o efeito da interação AB.

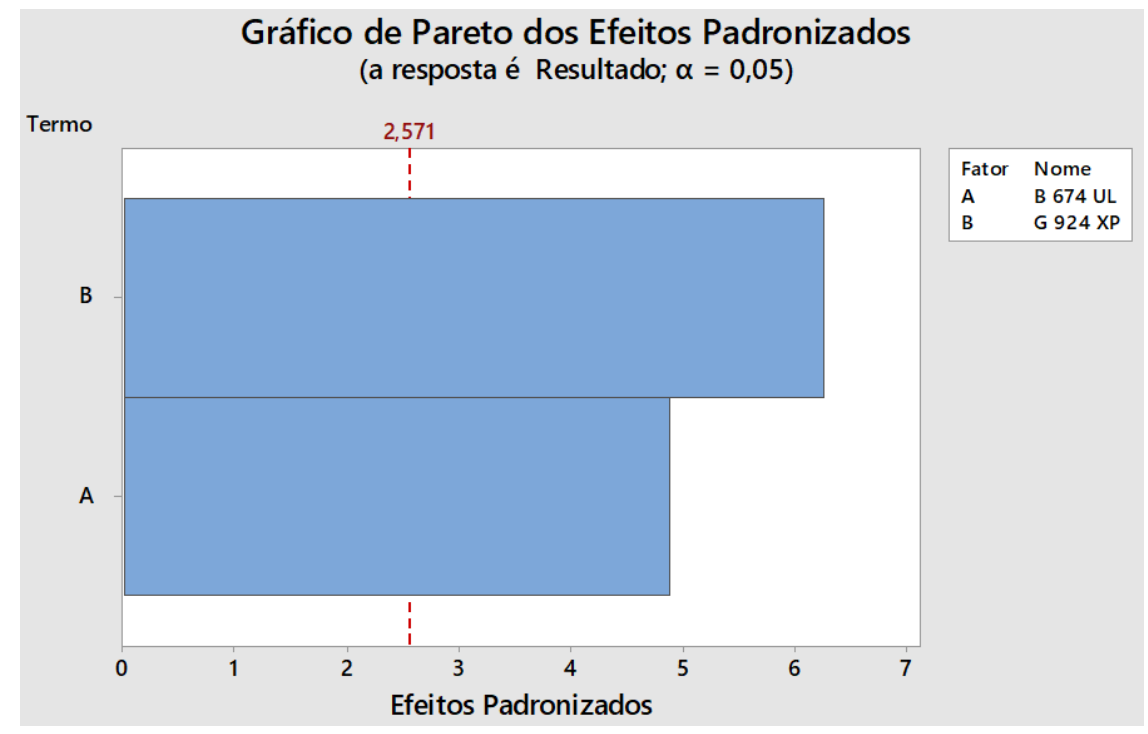


As barras que ultrapassam a linha de referência são estatisticamente significativas, portanto, as variáveis que são apresentadas no gráfico da são estatisticamente significativas. Ainda, observa-se que o teor de G924XP tem maior importância na resposta, mas não é possível determinar como essa variável age sobre a resposta, ou seja, se aumenta ou diminui a área sob a curva de transmitância. Esta análise pode ser feita através do Gráfico Normal dos Efeitos Padronizados, como mostra a figura 24.

Figura 24- Gráfico de probabilidade normal dos efeitos padronizados para amostra do grupo 1.

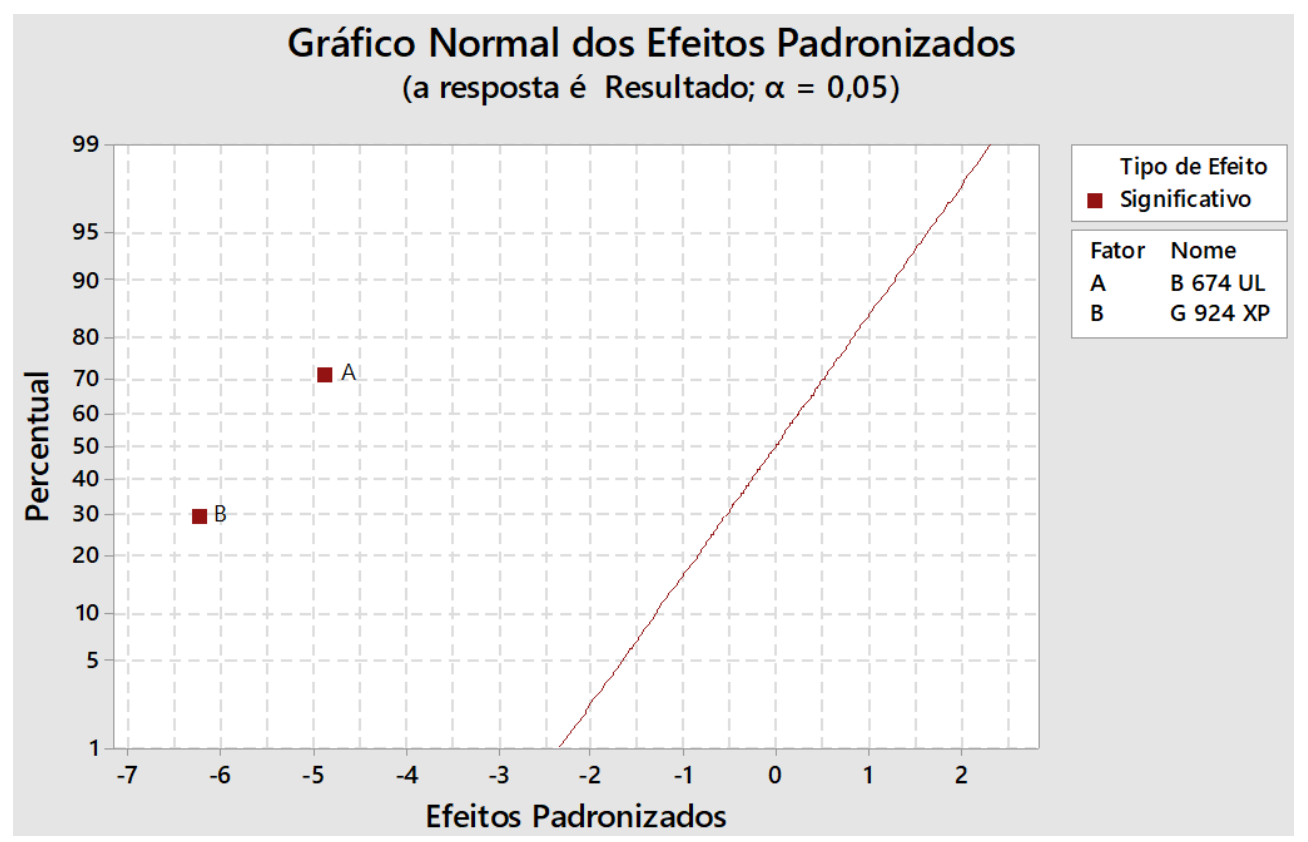

Fonte Minitab $®$

No gráfico normal dos efeitos podemos determinar a direção e significância dos efeitos. Observamos que todos os efeitos são estatisticamente significativos e também, que os teores tanto de B674UL (Fe) quanto de G924XP (Se) têm efeito padronizado negativo, ou seja, quando aumentamos esses teores, diminuímos a área sob a curva de transmitância. Observa-se também que a frita G924XP (Se) é mais significativa estatisticamente.

Os dados quantitativos gerados pelo minitab são apresentados nas tabelas 7 e 8 . Os parâmetros GL, SQ, QM, Valor-F, Valor-P, Valor-T, Coef, EP de Coef foram definidos na seção 3.1.3. 
Tabela 7- Análise de variância gerada pelo Minitab® para o grupo 1.

\begin{tabular}{lccccc}
\hline Fonte & GL & SQ $(\mathrm{Aj})$. & QM $(\mathrm{Aj})$. & Valor F & Valor-P \\
\hline Modelo & 2 & 7517604 & 3758802 & 30,14 & 0,002 \\
Linear & 2 & 7517604 & 3758802 & 30,14 & 0,002 \\
B 674 UL & 1 & 2969828 & 2969828 & 23,81 & 0,005 \\
G 924 XP & 1 & 4877354 & 4877354 & 39,11 & 0,002 \\
Erro & 5 & 623618 & 124724 & & \\
Falta de ajuste & 1 & 43183 & 43183 & 0,30 & 0,614 \\
$\quad$ Erro Puro & 4 & 580435 & 145109 & & \\
Total & 7 & 8141221 & & & \\
\hline
\end{tabular}

Fonte- Minitab®

Tabela 8-Coeficientes gerados pelo Minitab ${ }^{\circledR}$ para o grupo 1.

\begin{tabular}{lccccc}
\hline & Efeito & Coef & EP de Coef & Valor-T & Valor-P \\
\hline Constante & & 2930 & 125 & 23,47 & 0,000 \\
B 674 UL & -1260 & -630 & 129 & $-4,88$ & 0,005 \\
G 924 XP & -1582 & -791 & 126 & $-6,25$ & 0,002 \\
\hline
\end{tabular}

Fonte- Minitab®

A equação gerada para esse modelo foi:

$$
\text { Área }{ }_{(290-760)}=2930-630 *(\mathrm{~B} 674 \mathrm{UL})-791 *(\mathrm{G} 924 \mathrm{XP})
$$

Esta equação dá origem ao gráfico de contorno demonstrado na figura 25 , que permite uma melhor visualização do efeito dos teores dos elementos sobre a área abaixo da curva de transmitância.

Figura 25- Gráfico de contorno das amostras do grupo 1.

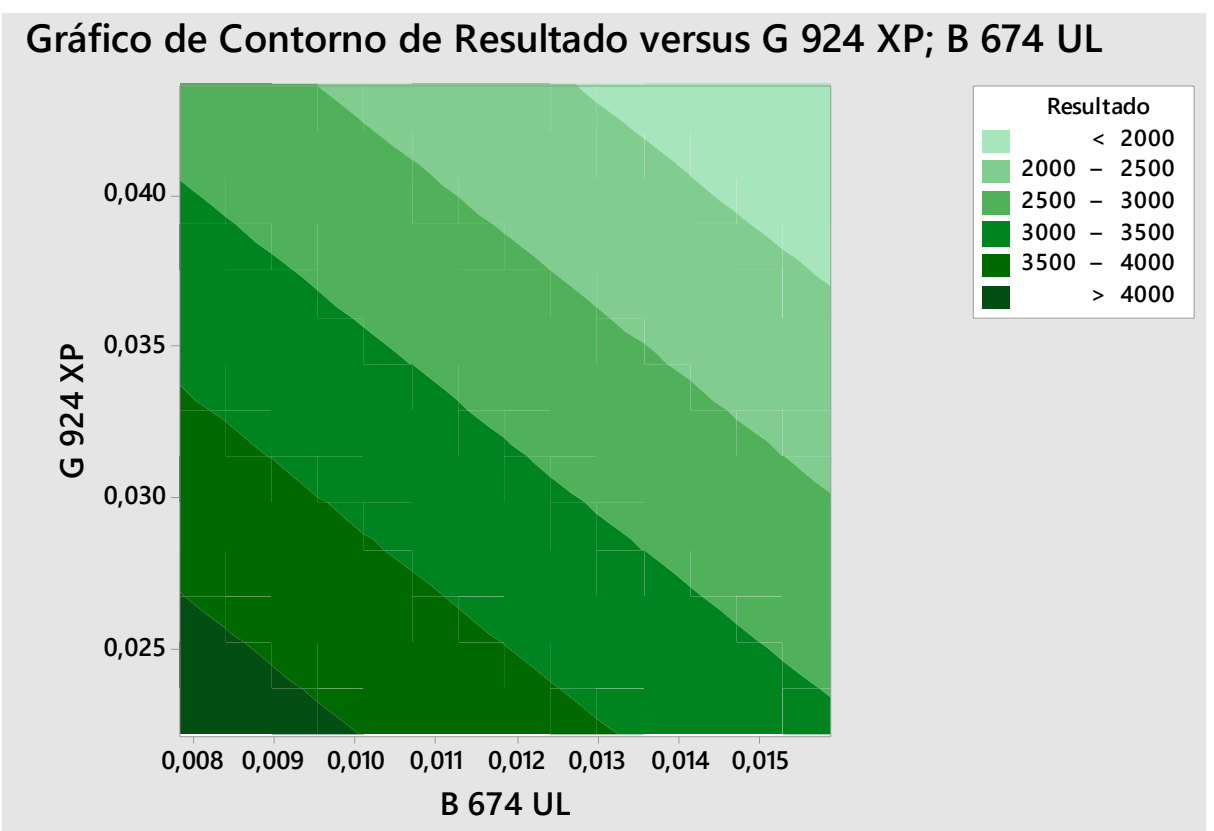


Verifica-se que, o aumento do teor de G924XP (Se), irá reduzir mais a área que o teor de B674UL (Fe), pois ele tem maior importância sobre a superfície de resposta.

JITWATCHARAKOMOL (2005), observou que em condições levemente redutoras na presença de ferro, é formado $\mathrm{Se}^{2-}$, dando origem a um cromóforo marrom avermelhado, análogo a coloração âmbar, chamado seleneto ferroso (FeSe). A formação de FeSe é devido à substituição de $\mathrm{O}^{2-}$ por $\mathrm{Se}^{2-}$ em um tetraedro de $\mathrm{Fe}-\mathrm{O}$, e é semelhante à posição do enxofre no cromofóro âmbar.

Para verificar o estado de oxidação do vidro, utilizamos a curva de concentração de enxofre retido no vidro apresentado na e explicada na seção 2.1.5. O teor de enxofre é descrito no gráfico em função do número redox, pois a condição oxidada ou reduzida determina o nível de enxofre retido no vidro, bem como a relação $\mathrm{Fe}^{2+} / \mathrm{Fe}_{\text {totalal }}$.

$\mathrm{O}$ teor de $\mathrm{SO}_{3}$, foi obtido por análise química via fluorescência de raios-X, visualizada na tabela 9 . Já a relação $\mathrm{Fe}^{2+} / \mathrm{Fe}_{\text {total }}$ é apresentada na Tabela 10 e foi obtida por espectrometria, pois o $\mathrm{Fe}^{2+}$ apresenta um pico bem definido a $1000 \mathrm{~nm}$ enquanto o $\mathrm{Fe}^{3+}$, apresenta um pico bem definido em $380 \mathrm{~nm}$. A amostra G26 foi selecionada para cálculo do estado de oxidação por ter apresentado a menor área abaixo da curva de transmitância, sendo considerada a melhor amostra do grupo.

Tabela 9- Análise química por fluorescência de Raios-X da amostra G26.

\begin{tabular}{ccccccccccc}
\hline $\mathrm{Al}_{2} \mathrm{O}_{3}$ & $\mathbf{B a O}$ & $\mathbf{C a O}$ & $\mathrm{Fe}_{2} \mathbf{O}_{3}$ & $\mathbf{K}_{2} \mathbf{O}$ & $\mathbf{M g O}$ & $\mathbf{N a}_{2} \mathbf{O}$ & $\mathrm{SiO}_{2}$ & $\mathrm{SO}_{3}$ & $\mathrm{TiO}_{2}$ & $\mathbf{S e}$ \\
1,85 & 0,13 & 10,7 & 0,863 & 0,02 & 0,71 & 14,5 & 70,9 & 0,19 & 0,0094 & 0,01 \\
\hline
\end{tabular}

Fonte- Autor

Tabela 10- Dados para calcular a relação $\mathrm{Fe}^{2+} / \mathrm{Fe}_{\text {total }}$ para inserir na curva de concentração de enxofre retido no vidro em função de $\mathrm{Fe}^{2+} / \mathrm{Fe}_{\text {total, }}$ associada ao número redox.

\begin{tabular}{cccccc}
\hline Amostra & $\mathbf{\% T}_{\mathbf{1 0 0 0 n m}}$ & $\mathbf{\% T}_{380 \mathrm{~nm}}$ & $\mathbf{\%} \mathbf{T ~ F e}_{\text {total }}$ & $\mathbf{\%} \mathbf{T ~ F e}^{2+} / \mathbf{F e}_{\text {total }}$ & $\mathbf{S O}_{\mathbf{3}}$ \\
$\mathrm{G} 26$ & 24,99 & 12,26 & 0,373 & 67 & 0,19 \\
\hline
\end{tabular}

Fonte- Autor

Observando a figura 26, podemos verificar que a amostra G26 está num estado levemente reduzido, entre o vidro oxidado, flint (número redox positivo, conforme explicado na seção 2.1.5) e o vidro âmbar, reduzido, (número redox negativo, e quanto mais negativo, mais reduzido o vidro), e, portanto, indicando que o seleneto ferroso pode ter sido formado. 
Figura 26- Curva de concentração de enxofre retido no vidro em função de $\mathrm{Fe}^{2+} / \mathrm{Fe}_{\text {total }}$, associada ao número redox, para determinação do número redox da amostra G26

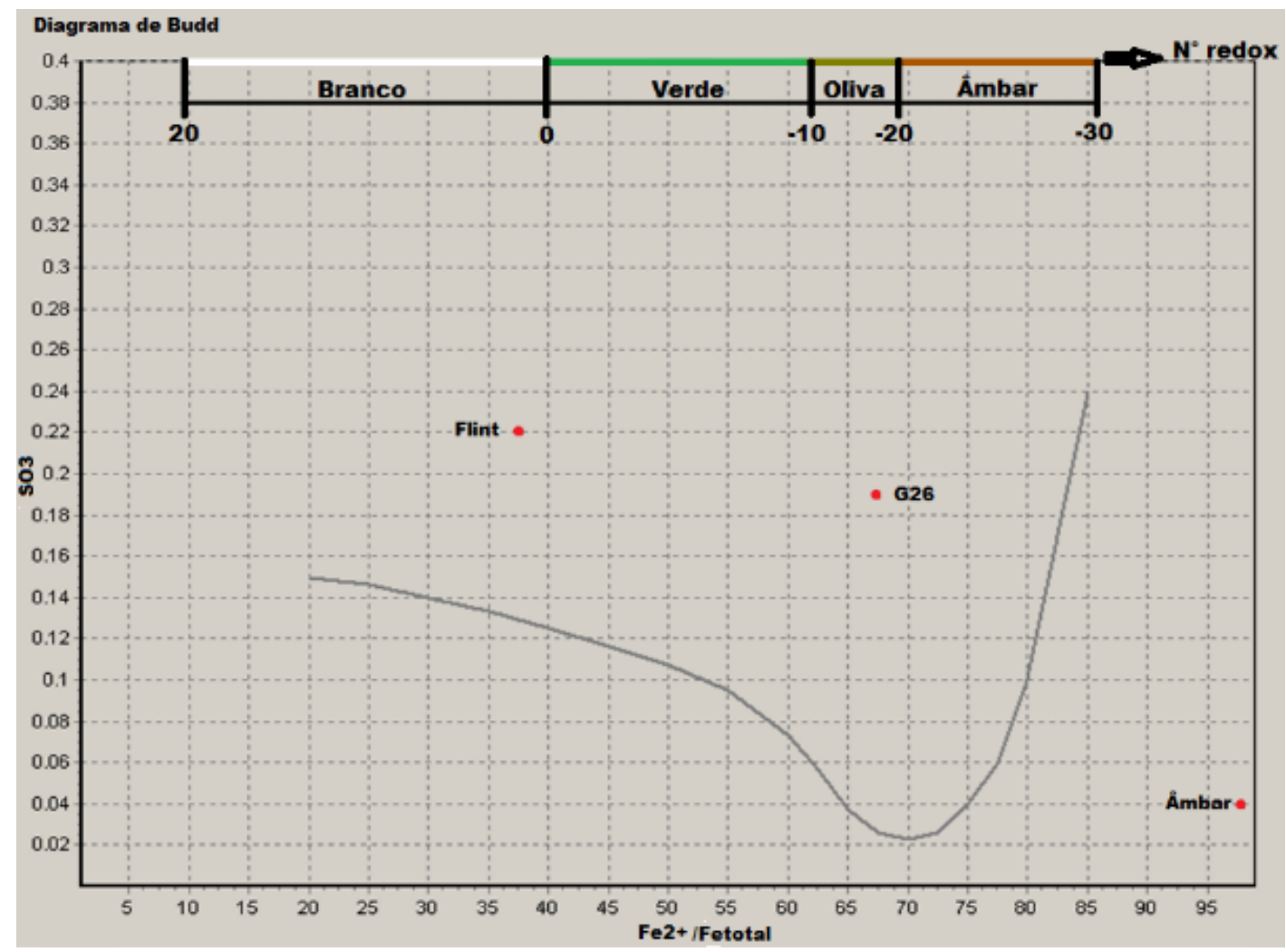

Fonte- Autor

Outro ponto a ser observado é que quanto mais longe e acima da curva o ponto estiver, maior o teor de $\mathrm{SO}_{3}$ no vidro e, portanto, maior a tendência de formação de bolhas, sendo assim, a composição de G26 possuirá tendência a formação de bolhas.

Podemos verificar também que existe relação direta entre quantidade de frita adicionada e redução da área abaixo da curva de transmitância, que pode ser visualizado na penúltima coluna da Tabela 11, onde os dados de resultado foram inseridos em ordem crescente.

Tabela 11- Soma das quantidades adicionadas de fritas para comparação com o resultado da integração das curvas das amostras do grupo 1 na faixa de 290 a 450 nm com o software Origin.

\begin{tabular}{cccccccc}
\hline Amostra & R1 & R2 & Vidro & B674UL & G924XP & $\begin{array}{c}\text { Quantidade de } \\
\text { fritas adicionada }\end{array}$ & $\begin{array}{c}\text { Resultado } \\
\text { (Área) }\end{array}$ \\
\hline G22 & 0,0165 & 0,046 & 0,9412 & 0,0155 & 0,04329 & 0,059 & $\mathbf{1 9 0 6 , 8 1}$ \\
G24 & 0,0083 & 0,046 & 0,9485 & 0,0078 & 0,04363 & 0,051 & $\mathbf{3 0 4 9 , 6 2}$ \\
G23 & 0,0165 & 0,023 & 0,962 & 0,0159 & 0,02213 & 0,038 & $\mathbf{3 1 3 6 , 9 9}$ \\
G21 & 0,0083 & 0,023 & 0,9697 & 0,008 & 0,0223 & 0,030 & $\mathbf{4 6 8 4 , 1 5}$ \\
\hline
\end{tabular}


Como as amostras não atingiram a transmitância desejada, foi calculada a espessura na qual esta seria atingida, para a composição que gerou a menor transmitância: 1,65\% B674UL (Fe) e 4,6\% G924XP (Se). O cálculo resultou em uma espessura de 4,2 mm. Portanto, com 4,2 mm a amostra de composição 1,65\% B674UL (Fe) e 4,6\% G924XP (Se) estaria dentro dos limites estabelecidos pela Farmacopeia, ou seja, teria transmitância dentro de $10 \%$ no comprimento de onda de 290 a $450 \mathrm{~nm}$.

No entanto, os frascos aplicáveis à indústria farmacêutica, que é o maior consumidor de vidro âmbar na indústria em que este trabalho foi desenvolvido, geralmente não possuem espessuras acima de $2 \mathrm{~mm}$, sendo inviável a produção nesta espessura para esta aplicação, mas pode ser considerada para outros itens em que seja desejável ter uma parede de vidro mais espessa e que apresente a retenção de raios ultravioleta.

\subsection{GRUPO 2: B674UL (Fe) + 410JS (Mn) + G924XP (Se)}

Por meio de um novo planejamento experimental, estudamos uma composição em que fosse possível a produção de todos os itens em vidro âmbar, ou seja, uma composição que atingisse a transmitância abaixo de 10\% no comprimento de onda de 290 a $450 \mathrm{~nm}$, com espessuras inferiores a $2 \mathrm{~mm}$, visto que isso não foi atingido no grupo 1 .

SALMANG (2013), observou que o óxido de manganês atua como oxidante de FeO a $\mathrm{Fe}_{2} \mathrm{O}_{3}$, o que poderia aumentar a retenção de ultravioleta. Portanto, adicionamos mais uma variável ao sistema: 410JS (Mn).

A curva de transmitância do Grupo 2 para o comprimento de onda de 290 a $760 \mathrm{~nm}$ pode ser visualizada na figura 27 . Devido ao acréscimo de uma variável ao sistema, não foram efetuadas réplicas dos experimentos, mas para garantir a confiabilidade dos dados obtidos, foi incluído um ponto central no planejamento experimental. 
Figura 27- Curva de transmitância das amostras do grupo 2 corrigidas para a espessura de $3 \mathrm{~mm}$.

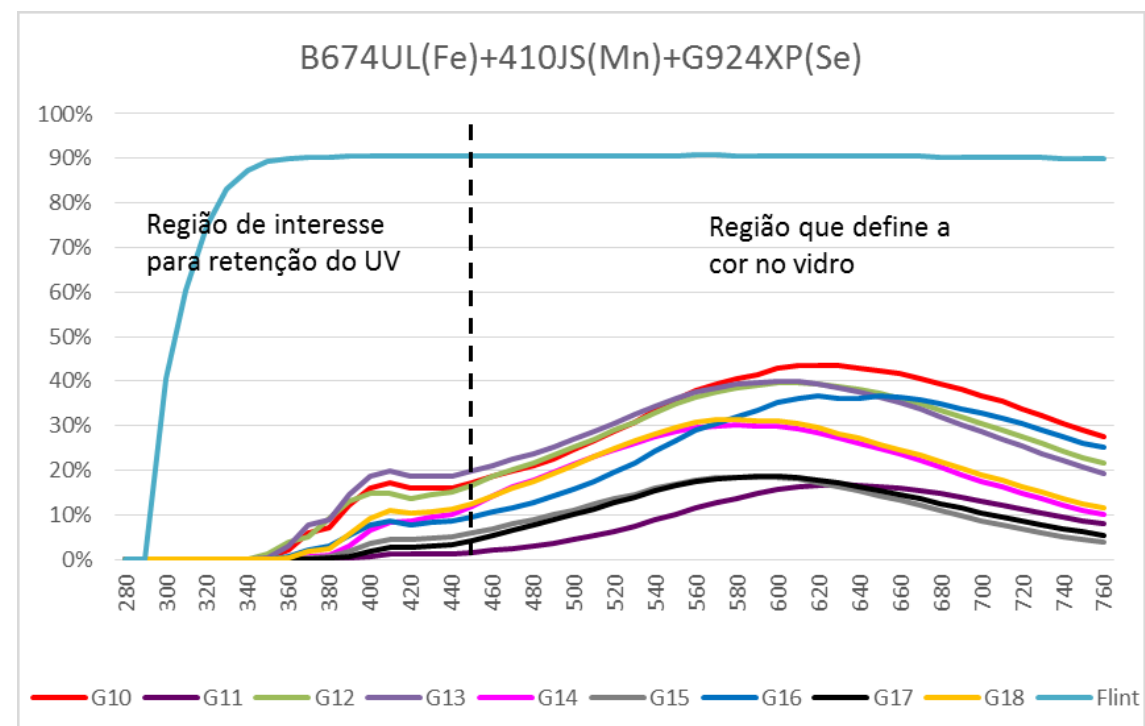

Fonte- Autor.

É possível observar que, as amostras G11, G17, G15, G16 e G14 estariam aprovadas pela Farmacopeia americana, visto que apresentaram transmitância inferior a 10\% no comprimento de onda de 290 a $450 \mathrm{~nm}$, para espessura de $3 \mathrm{~mm}$.

A posição de cada composição no diagrama de cromaticidade é mostrada na figura 28 : 
Figura 28- Coordenadas tricromáticas das amostras do grupo 2 para transmitância corrigida na espessura de $3 \mathrm{~mm}$.

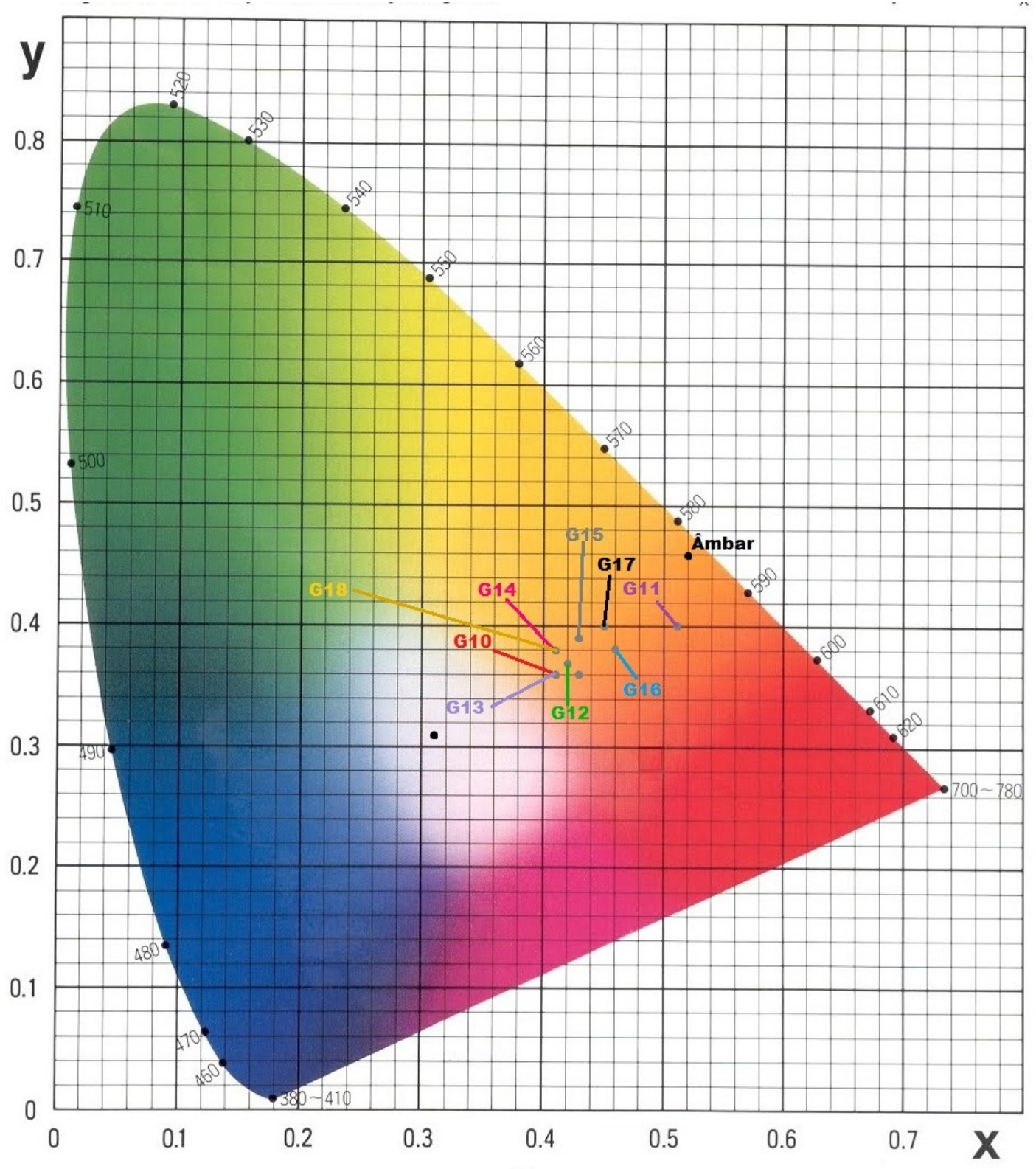

Fonte- Adaptado de HARDY, 1936

Assim como ocorreu com o sistema contendo Fe-Se, observa-se que as amostras com menor transmitância na faixa de 290 a $450 \mathrm{~nm}$ foram as mesmas que apresentaram maior proximidade com o ponto âmbar no diagrama de cromaticidade, sendo a melhor delas: G11, a qual possui o maior teor de ferro, selênio e manganês.

Para análise comparativa e estatística dos dados, feita com o Minitab ${ }^{\circledR}$, foi calculada a área abaixo de cada curva de transmitância na faixa de 290 a $450 \mathrm{~nm}$, utilizando a ferramenta de integração do software OriginLab ${ }^{\circledR}$. Os resultados podem ser visualizados na última coluna da Tabela 12. 
Tabela 12- Resultados da integração das curvas das amostras do grupo 2 na faixa de 290 a $760 \mathrm{~nm}$ com o software Origin.

\begin{tabular}{ccccccccc}
\hline Amostra & $R 1$ & $R 2$ & $R 3$ & Vidro & B674UL (Fe) & 410JS (Mn) & G924XP (Se) & Resultado(Área) \\
\hline G10 & 0,0250 & 0,0250 & 0,0250 & 0,9302 & 0,0233 & 0,0233 & 0,0233 & $\mathbf{1 1 7 4 , 8 9}$ \\
G11 & 0,0500 & 0,0500 & 0,0250 & 0,8889 & 0,0444 & 0,0444 & 0,0222 & $\mathbf{6 5 , 9}$ \\
G12 & 0,0250 & 0,0500 & 0,0125 & 0,9195 & 0,0230 & 0,0460 & 0,0115 & $\mathbf{1 1 3 6 , 1 9}$ \\
G13 & 0,0500 & 0,0250 & 0,0125 & 0,9195 & 0,0460 & 0,0230 & 0,0115 & $\mathbf{1 3 8 3 , 1 4}$ \\
G14 & 0,0250 & 0,0250 & 0,0125 & 0,9412 & 0,0235 & 0,0235 & 0,0118 & $\mathbf{5 3 7 , 3 9}$ \\
G15 & 0,0500 & 0,0250 & 0,0250 & 0,9091 & 0,0455 & 0,0227 & 0,0227 & $\mathbf{2 8 3 , 2 8}$ \\
G16 & 0,0250 & 0,0500 & 0,0250 & 0,9091 & 0,0227 & 0,0455 & 0,0227 & $\mathbf{5 5 9 , 9 6}$ \\
G17 & 0,0500 & 0,0500 & 0,0125 & 0,8989 & 0,0449 & 0,0449 & 0,0112 & $\mathbf{1 6 5 , 0 7}$ \\
G18 & 0,0375 & 0,0375 & 0,0188 & 0,9143 & 0,0343 & 0,0343 & 0,0171 & $\mathbf{6 4 8 , 7 8}$ \\
(P.central) & & & & & & & & \\
\hline
\end{tabular}

Fonte- Minitab®

O vidro âmbar não apresenta picos de transmitância até $520 \mathrm{~nm}$, portanto, a área abaixo da curva de transmitância é zero. Por este motivo, para comparação, determinamos que o melhor resultado seria aquele em que a área abaixo da curva de transmitância fosse a menor possível, já que não havia nenhum valor limite de área que pudéssemos comparar.

A melhor amostra foi a G11, de composição máxima das fritas B674UL (Fe) + 410JS $(\mathrm{Mn})+\mathrm{G} 924 \mathrm{XP}(\mathrm{Se}), 5 \%, 5 \%$ e 2,5\%, respectivamente.

Com as áreas obtidas na, foi possível a análise no Minitab ${ }^{\circledR}$, por meio da análise de experimento fatorial $2^{3}$ com ponto central, gerando o gráfico de Pareto apresentado na figura 29 . 
Figura 29- Gráfico de Pareto dos efeitos padronizados das amostras do grupo 2

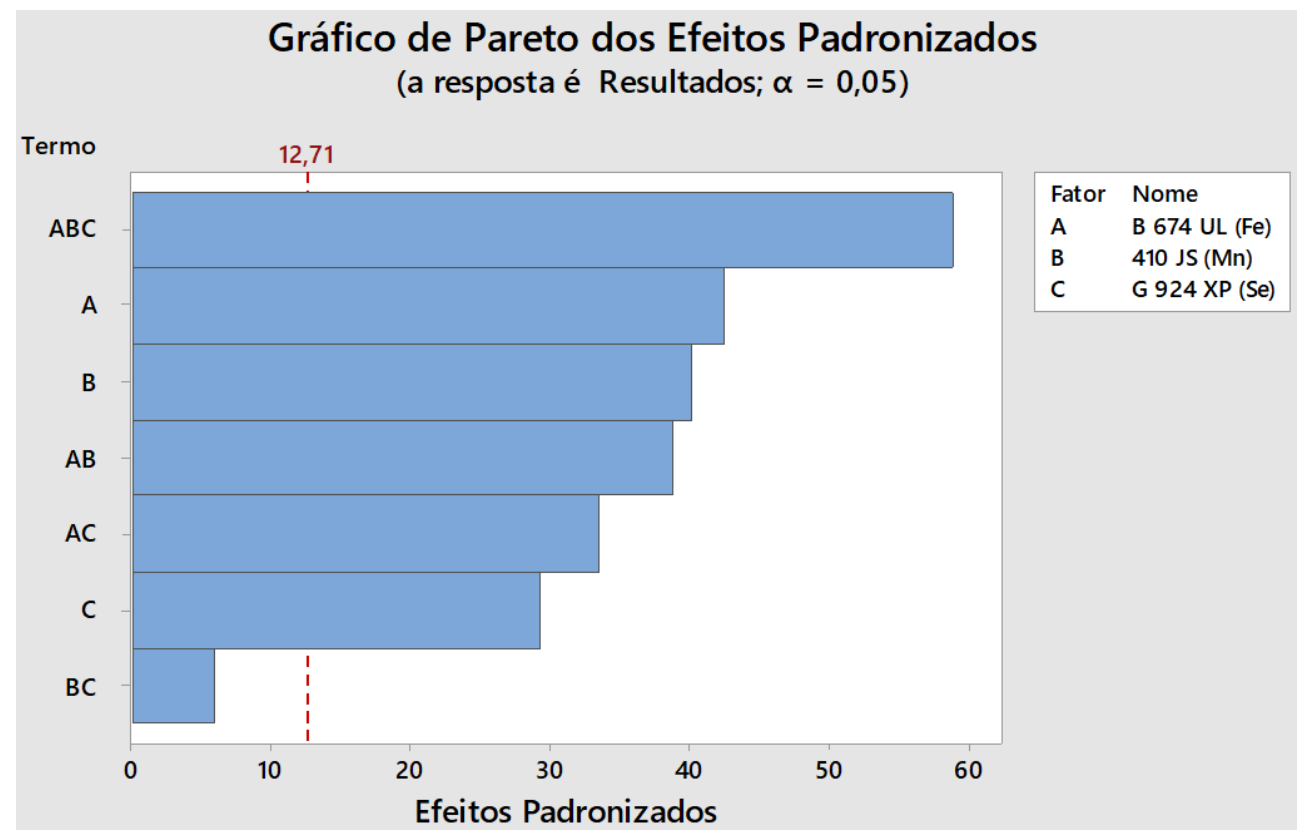

Fonte- Minitab®

O gráfico de Pareto determina importância dos efeitos de cada variável. No primeiro gráfico de Pareto gerado pelos dados obtidos, verificamos que a interação entre 410JS (Mn) e G924XP (Se), indicado como termo BC, não foi significativa, pois não ultrapassou a linha de referência para ser estatisticamente significativa. Por este motivo, foi retirada do modelo, gerando um grau de liberdade para o cálculo do erro experimental. O novo gráfico de Pareto gerado é apresentado figura 30 .

Figura 30- Gráfico de Pareto dos efeitos padronizados das amostras do grupo 2, sem o efeito da interação BC.

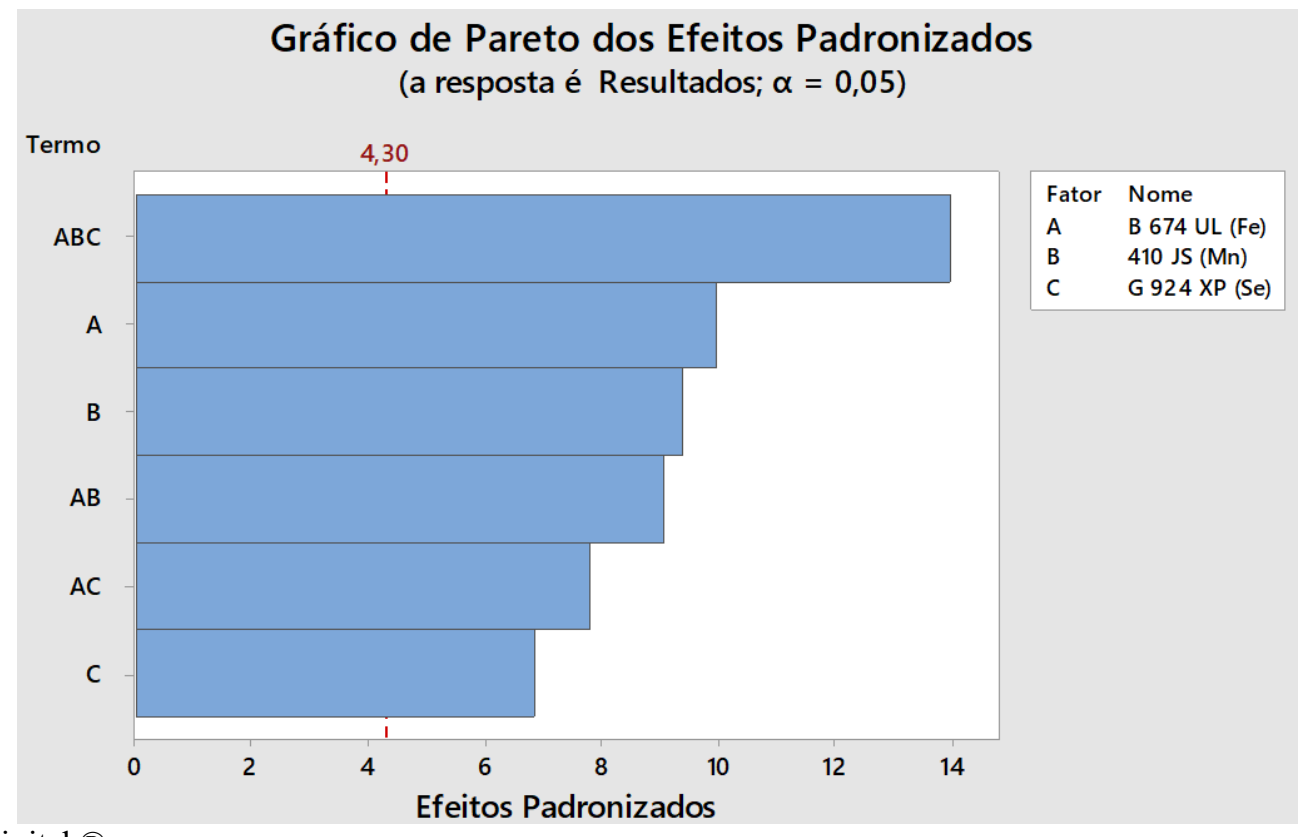


As barras que cruzam a linha de referência são estatisticamente significativas, portanto, todas as variáveis e interações apresentadas na são estatisticamente significativas. Observamos que a interação entre B674UL (Fe), 410JS (Mn) e G924XP (Se) tem maior importância, seguido pelos teores de B674UL (Fe) e 410JS (Mn). Entretanto, o gráfico de Pareto não indica se o efeito sobre a resposta é positivo ou negativo, ou seja, se aumenta ou diminui a área sob as curvas de transmitância. Este efeito é analisado através do gráfico da figura 31.

Figura 31- Gráfico de probabilidade normal dos efeitos padronizados, para o grupo 2.

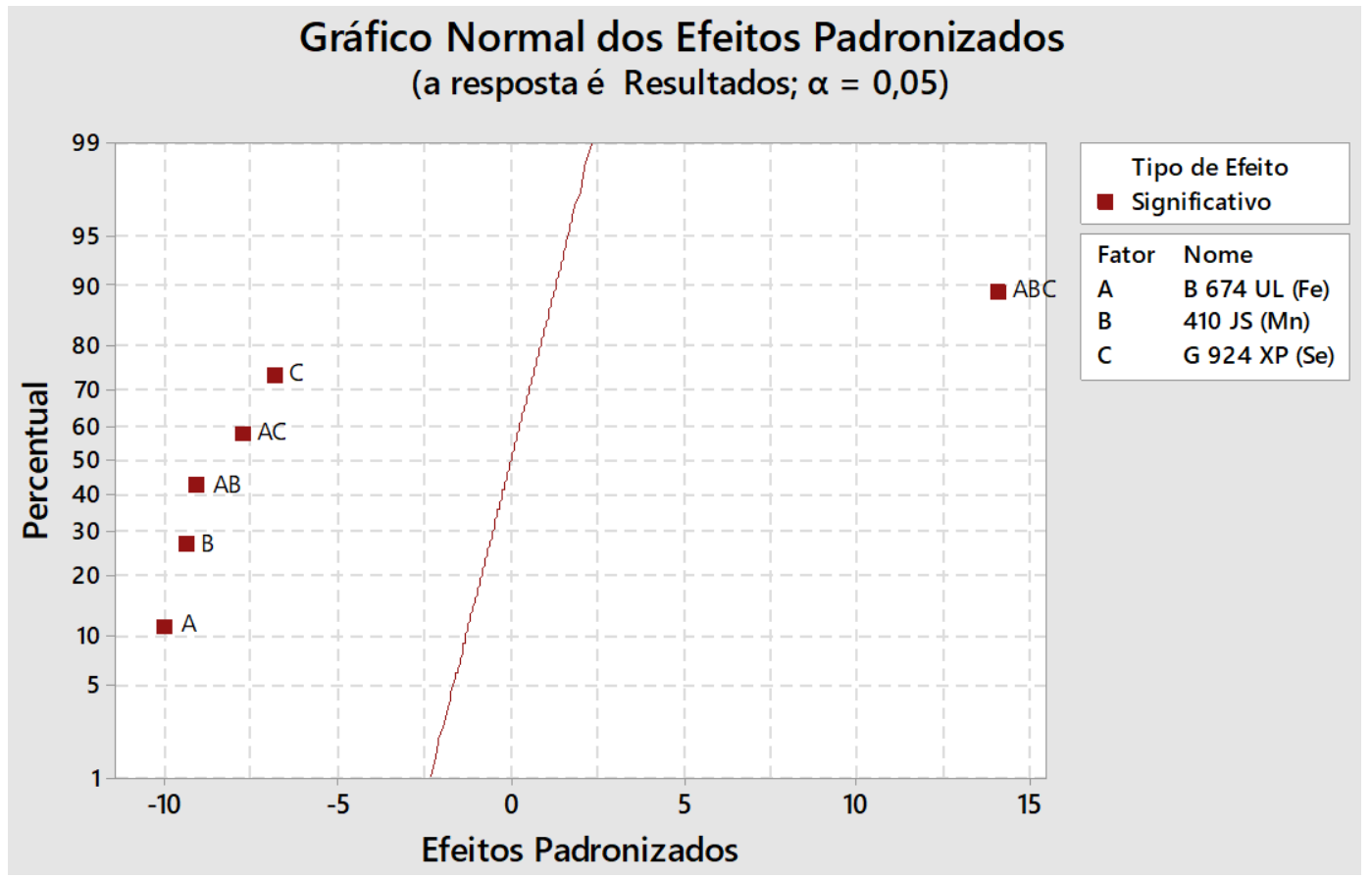

Fonte- Minitab ${ }^{\circledR}$

No gráfico de probabilidade normal dos efeitos padronizados podemos determinar a direção e a importância dos efeitos. Verifica-se que a interação entre B674UL (Fe), 410JS (Mn) e G924XP (Se), termo $\mathrm{ABC}$, tem um efeito padronizado positivo $(+14)$, que quer dizer que quanto maior a interação dos três elementos, maior será a área sob a curva de transmitância. Já os outros fatores possuem valores negativos, ou seja, causam uma redução na área sob a curva de transmitância.

Observando os dois gráficos, conseguimos afirmar que o aumento do teor de B674UL (Fe) e 410JS (Mn), bem como a interação resultante desses componentes, tem um efeito mais acentuado na redução da área abaixo da curva de transmitância, quando comparados ao teor de G924XP (Se). 
Os dados quantitativos gerados pelo Minitab ${ }^{\circledR}$ são demonstrados nas Tabela 13 e 14 . Os parâmetros GL, SQ, QM, Valor-F, Valor-P, Valor-T, Coef, EP de Coef foram definidos na seção 3.1.3.

Tabela 13- Análise de variância gerada pelo Minitab® para o grupo 2.

\begin{tabular}{lccccc}
\hline Fonte & GL & SQ (Aj.) & QM (Aj.) & Valor F & Valor-P \\
\hline Modelo & 6 & 1773682 & 295614 & 97,08 & 0,010 \\
Linear & 3 & 632353 & 210784 & 69,22 & 0,014 \\
B674UL (Fe) & 1 & 302965 & 302965 & 99,50 & 0,010 \\
410JS (Mn) & 1 & 267825 & 267825 & 87,96 & 0,011 \\
G924XP (Se) & 1 & 142238 & 142238 & 46,71 & 0,021 \\
Interações de 2 fatores & 2 & 413404 & 206702 & 67,88 & 0,015 \\
B674UL (Fe)*410JS (Mn) & 1 & 250321 & 250321 & 82,21 & 0,012 \\
B674UL (Fe)*G924XP (Se) & 1 & 184097 & 184097 & 60,46 & 0,016 \\
Interações de 3 fatores & 1 & 594474 & 594474 & 195,23 & 0,005 \\
B674UL (Fe)*410JS (Mn)*G924XP (Se) & 1 & 594474 & 594474 & 195,23 & 0,005 \\
Erro & 2 & 6090 & 3045 & & \\
Total & 8 & 1779772 & & & \\
\hline
\end{tabular}

Fonte- Minitab®

Tabela 14- Coeficientes gerados pelo Minitab® para o grupo 2.

\begin{tabular}{llllll}
\hline Termo & Efeito & Coef & $\begin{array}{l}\text { EP de } \\
\text { Coef }\end{array}$ & Valor-T & Valor-P \\
\hline Constante & & 633,2 & 18,5 & 34,28 & 0,001 \\
B674UL (Fe) & $-412,3$ & $-206,2$ & 20,7 & $-9,97$ & 0,010 \\
410JS (Mn) & $-387,4$ & $-193,7$ & 20,7 & $-9,38$ & 0,011 \\
G924XP (Se) & $-286,6$ & $-143,3$ & 21,0 & $-6,83$ & 0,021 \\
B674UL(Fe)*410JS(Mn) & $-392,5$ & $-196,3$ & 21,6 & $-9,07$ & 0,012 \\
B674UL(Fe)*G 924XP (Se) & $-342,1$ & $-171,0$ & 22,0 & $-7,78$ & 0,016 \\
B674UL(Fe)*410JS(Mn)*G 924XP (Se) & 644,8 & 322,4 & 23,1 & 13,97 & 0,005 \\
& & & & & \\
\hline
\end{tabular}

Fonte- Minitab®

A equação gerada para esse modelo a partir dos dados da Tabela 14 foi:

Área ${ }_{(280-760)}=633,2-206,2 * B 674 U L(F e)-193,7 * 410 J S(M n)-143,3 * G 924 X P(\mathrm{Se})-$ 196,3B674UL(Fe)*410JS(Mn) - $\quad$ 171,0*B674UL(Fe)*G924XP(Se) + $322,4 * \mathrm{~B} 674 \mathrm{UL}(\mathrm{Fe}) * 410 \mathrm{JS}(\mathrm{Mn}) * \mathrm{G} 924 \mathrm{XP}(\mathrm{Se})$

Considerando que o teor de selênio apresenta efeito menos significativo na redução de transmitância e que a interação $\mathrm{ABC}$ gera um efeito positivo, construiu-se o gráfico da figura 32 , fixando-se o teor de G924XP em 0,0172 que é o valor do ponto central. Este gráfico permite 
uma melhor visualização do efeito dos teores dos elementos sobre a área abaixo da curva de transmitância.

Figura 32- Gráfico de contorno para as amostras do grupo 2.

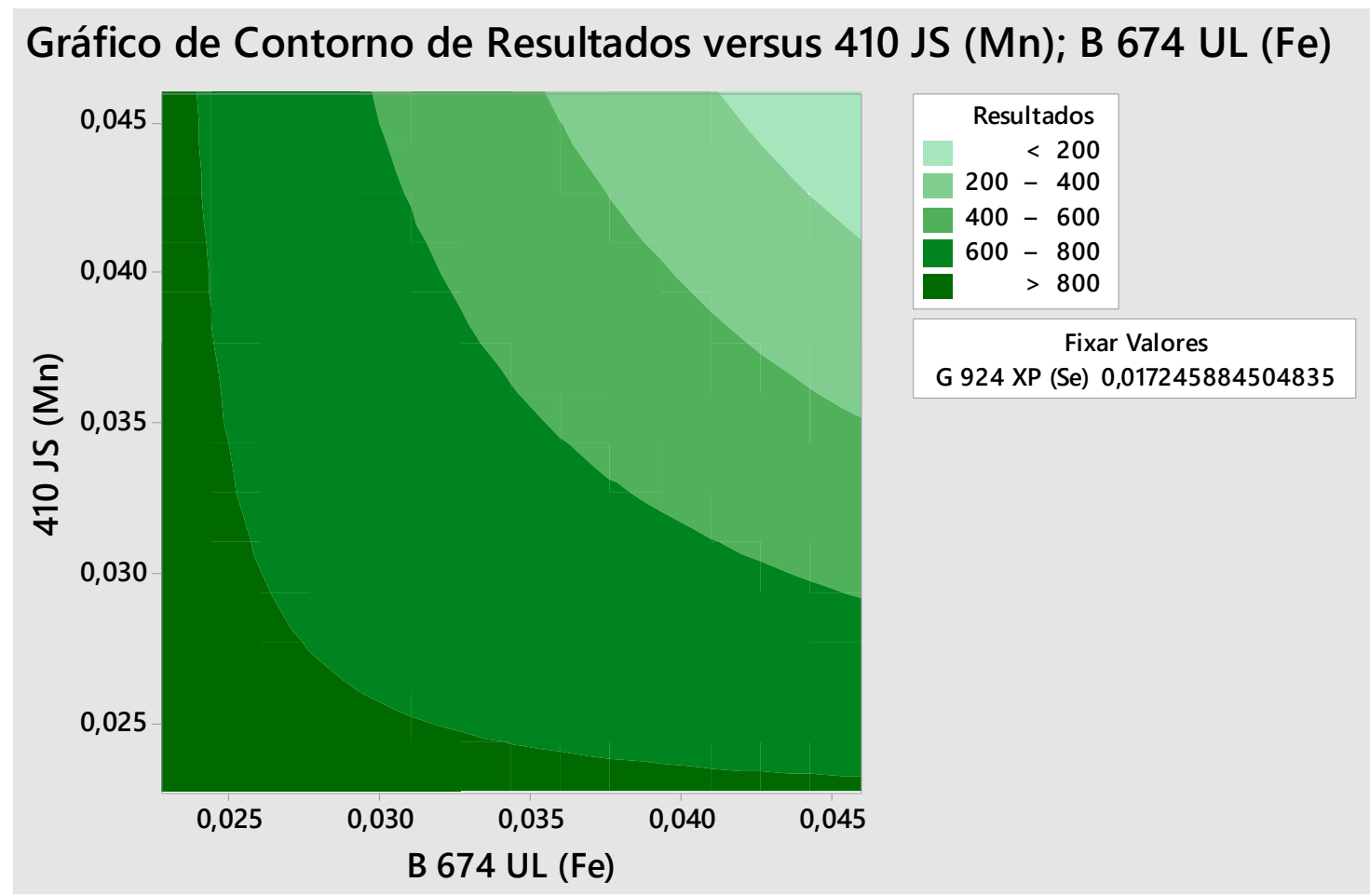

Fonte- Minitab ${ }^{\circledR}$

Observando o gráfico, conseguimos afirmar que o aumento do teor de B674UL (Fe) e de 410JS (Mn) gera uma redução na área sob a curva de transmitância na região considerada, pois ambos os componentes, bem como a interação entre eles, possuem maior importância sobre a superfície de resposta.

Esse resultado pode ser explicado pelo trabalho apresentado por SALMANG (2013), no qual observa-se que o óxido de manganês atua como oxidante de $\mathrm{FeO}$ a $\mathrm{Fe}_{2} \mathrm{O}_{3}$ durante a fusão e somente quando todo o $\mathrm{Fe}^{2+}$ é oxidado para $\mathrm{Fe}^{3+}$ é iniciado a formação de $\mathrm{Mn}^{3+}$ no vidro. Associando esta informação ao trabalho apresentado por BAMFORD (1977), que diz que $\mathrm{Fe}^{3+}$ possui forte absorção no ultravioleta, podemos inferir que houve o aumento da formação de $\mathrm{Fe}^{3+}$ devido a adição de fritas com manganês.

Para verificar o estado de oxidação do vidro, utilizamos a curva de concentração de enxofre retido no vidro apresentado na e explicada na seção 2.1.5. O teor de enxofre é descrito no gráfico em função do número redox, pois a condição oxidada ou reduzida determina o nível de enxofre retido no vidro, bem como a relação $\mathrm{Fe}^{2+} / \mathrm{Fe}_{\text {total }}$. 
$\mathrm{O}$ teor de $\mathrm{SO}_{3}$, foi obtido por análise química via fluorescência de raios $\mathrm{X}$ (Tabela 15), e a relação $\mathrm{Fe}^{2+} / \mathrm{Fe}_{\text {total }}$, foi obtida por espectrometria, visto que o $\mathrm{Fe}^{2+}$ apresenta um pico bem definido a $1000 \mathrm{~nm} \mathrm{e} \mathrm{Fe}^{3+}$, apresenta um pico bem definido em $380 \mathrm{~nm}$, conforme a Tabela 16. Tabela 15-Análise química por fluorescência da amostra G11

\begin{tabular}{ccccccccccc}
\hline $\mathbf{A l}_{2} \mathbf{O}_{3}$ & $\mathbf{B a O}$ & $\mathbf{C a O}$ & $\mathrm{Fe}_{2} \mathbf{O}_{3}$ & $\mathbf{K}_{2} \mathbf{O}$ & $\mathbf{M g O}$ & $\mathbf{N a}_{2} \mathbf{O}$ & $\mathbf{S i O}_{2}$ & $\mathbf{S O}_{3}$ & $\mathbf{T i O}_{2}$ & $\mathbf{S e}$ \\
1,7 & 0,07 & 10,1 & 2,45 & 0,43 & 0,66 & 13,6 & 70,9 & 0,18 & 0,062 & 0,008 \\
\hline
\end{tabular}

Fonte- Autor

Tabela 16- Dados para calcular a relação $\mathrm{Fe}^{2+} / \mathrm{Fe}_{\text {total }}$ para inserir na curva de concentração de enxofre retido no vidro em função de $\mathrm{Fe}^{2+} / \mathrm{Fe}_{\text {total, }}$ associada ao número redox

\begin{tabular}{cccccc}
\hline Amostra & $\boldsymbol{\%}_{\mathbf{1 0 0 0 n m}}$ & $\mathbf{\%}_{\mathbf{3 8 0 n m}}$ & $\mathbf{\%} \mathbf{T ~ F e}_{\text {total }}$ & $\mathbf{\%} \mathbf{T} \mathbf{F e}^{2+} / \mathbf{F e}_{\text {total }}$ & $\mathbf{S O}_{\mathbf{3}}$ \\
G11 & 2,01 & 0,08 & 0,021 & 96 & 0,18 \\
\hline
\end{tabular}

Fonte- Autor

Figura 33- Curva de concentração de enxofre retido no vidro em função de $\mathrm{Fe}^{2+} / \mathrm{Fe}_{\text {total}}$, associada ao número redox, para determinação do número redox da amostra G11

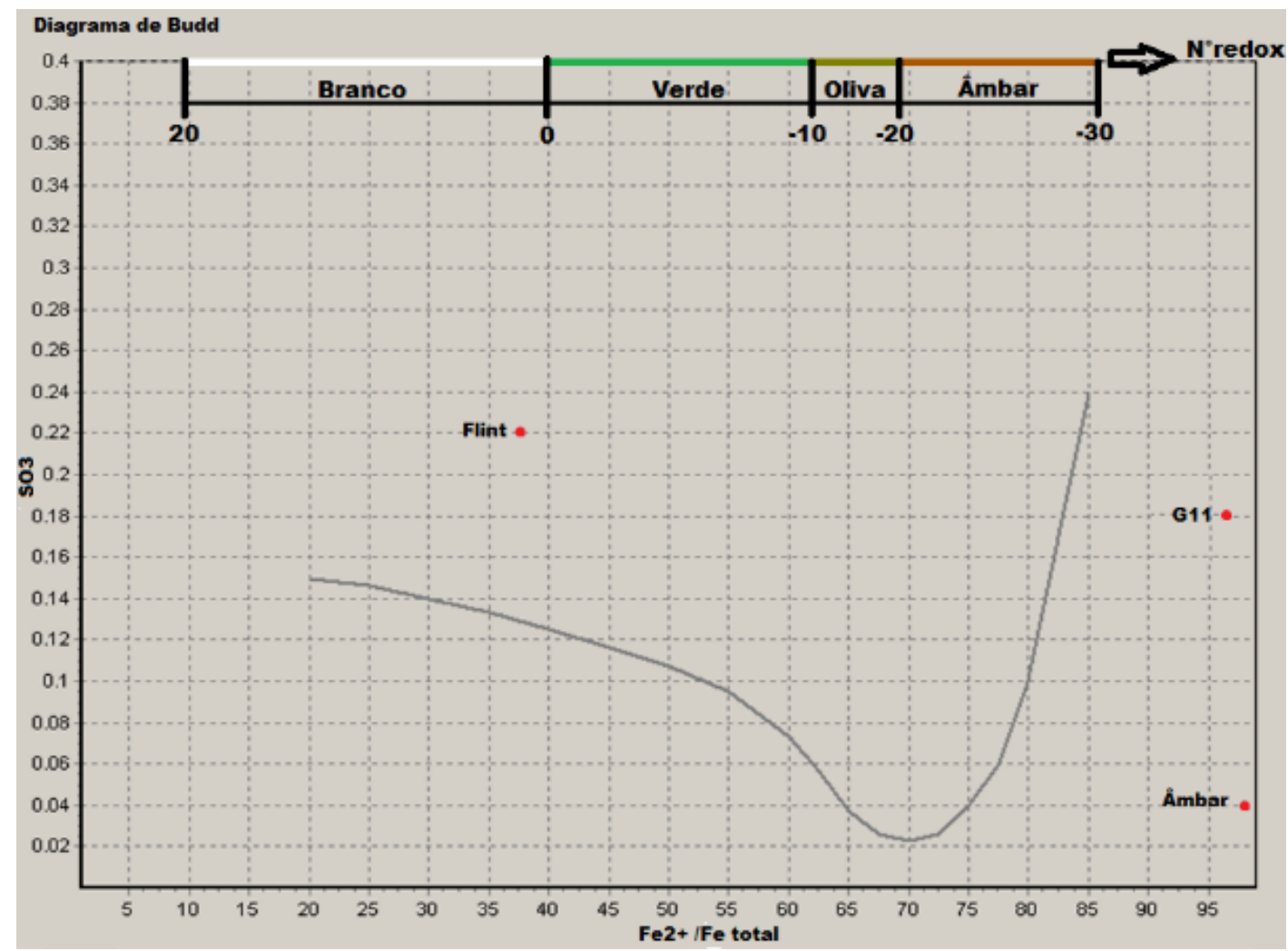

Fonte-Autor

Observando a figura 33, podemos verificar que a amostra G11 está num estado de oxidação próximo ao do vidro âmbar, portanto reduzido.

Podemos verificar também, assim como ocorreu no grupo 1, que existe relação direta entre quantidade de fritas adicionada e a redução da área abaixo da curva de transmitância, o 
que pode ser visualizado nas duas últimas colunas da Tabela 17, onde os dados foram inseridos em ordem crescente de transmitância.

Tabela 17- Soma das quantidades adicionadas de frita em cada tratamento para comparação com o resultado obtido, no grupo 2 .

\begin{tabular}{cccccccccc}
\hline Amostra & R1 & R2 & R3 & Vidro & $\begin{array}{c}\text { B674UL } \\
(\mathrm{Fe})\end{array}$ & $\begin{array}{c}410 \mathrm{JS} \\
(\mathrm{Mn})\end{array}$ & $\begin{array}{c}\text { G924XP } \\
(\mathrm{Se})\end{array}$ & $\begin{array}{c}\text { Concentração } \\
\text { de fritas } \\
\text { adicionada }\end{array}$ & $\begin{array}{c}\text { Resultado } \\
\text { (Área) }\end{array}$ \\
\hline G11 & 0,0500 & 0,0500 & 0,0250 & 0,8889 & 0,0444 & 0,0444 & 0,0222 & $\mathbf{0 , 1 1 1}$ & $\mathbf{6 5 , 9 0}$ \\
G17 & 0,0500 & 0,0500 & 0,0125 & 0,8989 & 0,0449 & 0,0449 & 0,0112 & $\mathbf{0 , 1 0 1}$ & $\mathbf{1 6 5 , 1}$ \\
G15 & 0,0500 & 0,0250 & 0,0250 & 0,9091 & 0,0455 & 0,0227 & 0,0227 & $\mathbf{0 , 0 9 1}$ & $\mathbf{2 8 3 , 3}$ \\
G14 & 0,0250 & 0,0250 & 0,0125 & 0,9412 & 0,0235 & 0,0235 & 0,0118 & $\mathbf{0 , 0 5 9}$ & $\mathbf{5 3 7 , 4}$ \\
G16 & 0,0250 & 0,0500 & 0,0250 & 0,9091 & 0,0227 & 0,0455 & 0,0227 & $\mathbf{0 , 0 9 1}$ & $\mathbf{5 6 0 , 0}$ \\
G18 & 0,0375 & 0,0375 & 0,0190 & 0,9143 & 0,0343 & 0,0343 & 0,0171 & $\mathbf{0 , 0 8 6}$ & $\mathbf{6 4 8 , 8}$ \\
(P.central) & & & & & & & & & $\mathbf{0 , 0 8 1}$ \\
G12 & 0,0250 & 0,0500 & 0,0125 & 0,9195 & 0,0230 & 0,0460 & 0,0115 & $\mathbf{0 1 3 6}$ \\
G10 & 0,0250 & 0,0250 & 0,0250 & 0,9302 & 0,0233 & 0,0233 & 0,0233 & $\mathbf{0 , 0 7 0}$ & $\mathbf{1 1 7 4}$ \\
G13 & 0,0500 & 0,0250 & 0,0125 & 0,9195 & 0,0460 & 0,0230 & 0,0115 & $\mathbf{0 , 0 8 1}$ & $\mathbf{1 3 8 3}$ \\
\hline
\end{tabular}

Fonte- Autor.

A influência da quantidade de fritas adicionada na área abaixo da curva de transmitância no comprimento de 290 a $450 \mathrm{~nm}$ é observada na figura 34 .

Figura 34- Influência da quantidade de fritas adicionadas sobre a área abaixo da curva de transmitância na faixa de comprimento de onda entre 290 e $450 \mathrm{~nm}$.

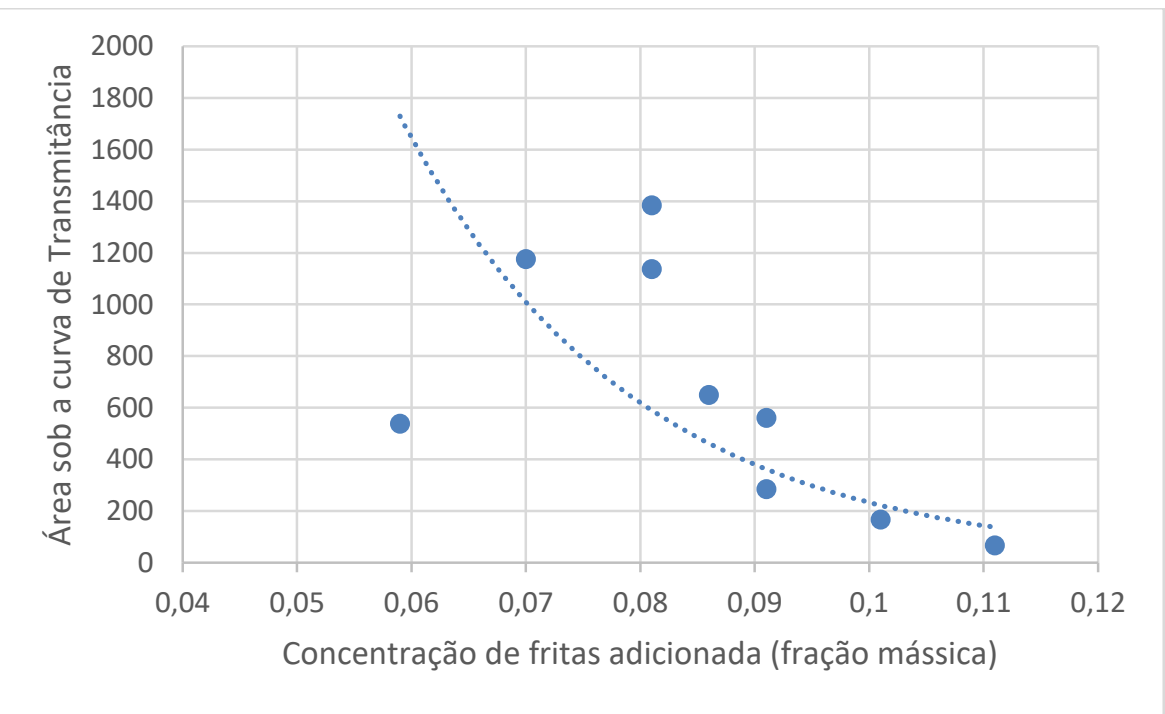

Fonte- Autor

A composição que gerou a menor transmitância, 5\% B674UL (Fe), 5\% 410JS (Mn) e 4,6\% G924XP (Se), já estaria aprovada pela Farmacopeia, visto que está dentro do limite de $10 \%$ de transmitância no comprimento de onda de 290 a $450 \mathrm{~nm}$ para uma espessura de $3 \mathrm{~mm}$. 
Entretanto, sendo a transmitância uma função também da espessura, calculamos a menor espessura de vidro que poderia ser produzido na qual ainda atenderia a Farmacopeia, resultando numa espessura de 1,6 $\mathrm{mm}$. Portanto, 1,6 $\mathrm{mm}$ é o limite mínimo no qual a amostra de composição 5\% B674UL (Fe), 5\% 410JS (Mn) e 4,6\% G924XP (Se), continuaria dentro dos limites estabelecidos pela Farmacopeia, ou seja, teria transmitância de até $10 \%$ no comprimento de onda de 290 a $450 \mathrm{~nm}$. 


\section{CONCLUSÕES}

Nos dois grupos de amostras estudados, as amostras com menor transmitância na faixa de 290 a $450 \mathrm{~nm}$ foram as que mais se aproximaram ao ponto âmbar no diagrama de cromaticidade, demonstrando haver uma relação entre a cor na faixa do espectro visível e a retenção de raios ultravioleta. Verificou-se também, para ambos os grupos, que o aumento da concentração de fritas leva a uma diminuição da área abaixo da curva de transmitância.

No grupo 1, a composição G26, que continha 1,65\% B674UL (Fe) e 4,60\% G924XP (Se), gerou a menor transmitância. Na curva de concentração total de enxofre retido no vidro

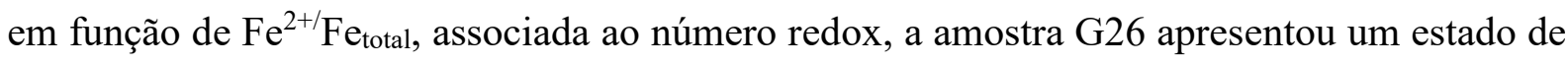
oxidação que indica a possível formação de seleneto ferroso. Entretanto, mesmo essa amostra, não atingiu a transmitância desejada na faixa de comprimento de ondas de interesse, para uma espessura de $3 \mathrm{~mm}$. A espessura mínima para atingir o limite de transmitância estabelecido pela Farmacopeia deveria ser no mínimo 4,2 mm.

No caso do grupo 2, que além de Fe e Se continha também fritas à base de Mn, a interação entre B674UL (Fe) e 410JS(Mn) foi mais significativa que a interação entre 410JS(Mn) e G924XP (Se). Entretanto, a interação entre os três componentes resultou em um efeito positivo, ou seja, aumento da área abaixo da curva de transmitância. Para este grupo, a composição G11, contendo 5,0\% B674UL (Fe), 5,0\% 410JS (Mn) x 2,5\% G924XP (Se), gerou a menor transmitância. Na curva de concentração total de enxofre em função de $\mathrm{Fe}^{2+} / \mathrm{Fe}_{\text {total, }}$ associada ao número redox, a amostra G11 apresentou um estado reduzido próximo ao do vidro âmbar, indicando que a adição de fritas com Mn contribui para transformação de $\mathrm{Fe}^{2+}$ para $\mathrm{Fe}^{3+}$.

Calculando-se, pelas equações de Fresnel e Lambert-Beer, a mínima espessura para que a amostra se mantenha abaixo do limite admissível de $10 \%$ de transmitância na faixa de 290 a $450 \mathrm{~nm}$, obteve-se um valor de 1,6 mm. Ou seja, para a composição G11, processada nas condições de laboratório, foi possível produzir vidro com retenção de UV em cor próxima ao âmbar dentro das especificações internas baseadas na Farmacopeia Americana para espessuras acima de $1,6 \mathrm{~mm}$. 


\section{SUGESTÃO PARA TRABALHOS FUTUROS}

a) Estudar composições sem o Selênio ou em quantidades menores, junto ao ferro e manganês, para reduzir a quantidade total de fritas a serem adicionadas, visto que o selênio teve menor importância nos efeitos sob a variável de resposta;

b) Analisar através da técnica de espectroscopia Raman o cromóforo formado para detectar se houve realmente a formação de Fe-Se, para as amostras do grupo 1, e se algum $\mathrm{Mn}^{3+}$ foi formado nas amostras do grupo 2, indicando que todo o $\mathrm{Fe}^{2+}$ foi convertido em $\mathrm{Fe}^{3+}$;

c) Executar o teste no canal de alimentação para verificar se a composição encontrada na escala de testes irá manter as propriedades encontradas na escala real, pois na escala real o estado é dinâmico e não estático. Podem ocorrer variações na taxa de extração, que irão influenciar no tempo de mistura. Quanto maior a taxa de extração, menor o tempo para mistura e vice-versa. 


\section{REFERÊNCIAS}

ASSOCIAÇÃO BRASILEIRA DE NORMAS TÉCNICAS. NBR 11819: Embalagens de vidro para produtos farmacêuticos - Requisitos e métodos de ensaio. Rio de Janeiro, 2004.

AKERMAN, M.. Efeito do Cobalto na Coloração de Vidros Sodo-Cálcicos Industriais. 2007. Dissertação - Escola Politécnica da Universidade de São Paulo, São Paulo.

ASKELAND, D.R.; PHULÉ, P.P.. The science and engineering of materials. 2003. EUA.

BACH, H.; NEUROTH, N.. The properties of optical glass. Springer Science \& Business Media, 2012

BAMFORD, C. R.. Colour generation and control in glass. Part of a collection of research on crystalline glazes donated (c. 1990) to CSAD by CI Brown. See Shelf 8, Boxes 5, 6, 7. Elsevier Scientific. 1977.

BEERKENS, R. G. C.; Kahl, K.. Chemistry of sulphur in soda-lime-silica glass melts. Physics and Chemistry of Glasses. v. 43. p189-198. 2002.

BEERKENS, R. G.C..Sulfate decomposition and sodium oxide activity in soda-lime-silica glass melts. Journal of the American Ceramic Society. p1893-1899. 2003.

BEERKENS, R. G.C..Amber chromophore formation in sulphur-and iron-containing sodalime-silica glasses. Glass Science and Technology. v76. p166-175. 2003.

BORTOLINI, J. Estudo de experimentos fatoriais $2 \mathrm{k}$ aplicados em um processo industrial. 2012

CALLISTER JR., William D. Ciência e engenharia de materiais: uma introdução . 5.ed. Rio de Janeiro: LTC, 2002

CHOUDHURY, A. K. R., Principles of Colour and Appearance Measurement. Elsevier Science, 2014.

DE ARAÚJO, T. S.; DE SOUZA, S. O. Protetores solares e os efeitos da radiação ultravioleta. Scientia plena, v. 4, n. 11, 2008.

DIBELLO, P. M. Controlling the oxidation state of a glass as a means of optimising sulphate usage in melting and refining. Glass technology, v. 30, n. 5, p. 160-165, 1989.

DUFFY, J. A.. Redox equilibria in glass. Journal of Non-Crystalline Solids. v196. p45-50. 1996.

GALDÁMEZ, E.V.C.. Aplicação das técnicas de planejamento e análise de experimentos na melhoria da qualidade de um processo de fabricação de produtos plásticos. Dissertação, Universidade de São Paulo. 2002.

HARDY, A. C. Handbook of Colorimetry, The Technology Press, Massachusetts Institute of Technology, Cambridge, Massachusetts, 1936 
Handbook, IES Lightning. "Application Volume Illuminating Engineering Society of North America." New York .1987.

JITWATCHARAKOMOL, T. Optimization and control of selenium chemistry and color in flint glass melts. Diss. Bibliothek der RWTH Aachen, 2005.

MAGNIEN, V., et al. Kinetics and mechanisms of iron redox reactions in silicate melts: The effects of temperature and alkali cations. Geochimica et Cosmochimica Acta. v72. p21572168. 2008.

MORSI, M.M., EL-SHERBINY, S.I; MOHAMED, K.M.. Spectroscopic investigation of amber color silicate glasses and factors affecting the amber related absorption bands. Spectrochimica Acta Part A: Molecular and Biomolecular Spectroscopy, v145, p.376-383. 2015.

MONTGOMERY, D.C. Design and Analysis of Experiments. 7th edition. John Wiley \& Sons, Inc, Toronto, CA, 2009.

NAROTTAM P. BANSAL and R.H. DOREMUS, Handbook of Glass Properties, Academic Press, San Diego, 1986.

RAO, K. J..Structural chemistry of glasses. Amsterdam: Elsevier.2002

REA, M. S..The IESNA lighting handbook: reference \& application. 2000.

RYAN TA. Normal probability plots and tests for normality. Statistics Department The Pennsylvania State University; 1974.

SHELBY, J. E.. Introduction to glass science and technology. Cambridge: Royal Society of Chemistry. 2005.

SALMANG, H., Die physikalischen und chemischen Grundlagen der Glasfabrikation. Springer-Verlag, 2013.

SOUZA, J. N. de.. Estudo de estabilidade: fatores que influenciam na estabilidade do medicamento. Especialização. Rio de Janeiro: Instituto de Tecnologia em Fármacos/Farmanguinhos, Fundação Oswaldo Cruz, 2014.

TEÓFILO, R. F. et al.. Quimiometria II: planilhas eletrônicas para cálculos de planejamentos experimentais, um tutorial. Química Nova, 2006.

THE UNITED STATES PHARMACOPOEIA. 31th.ed. Rockville: United States Pharmacopeial Convention; 2008. Containers - Performance testing. Part 671, 10 p.

ZANOTTO, Edgar D.; MAURO, John, 2017. The glassy state of matter: Its definition and ultimate fate. Journal of Non-Crystalline Solids. v. 471. p 490-495. 2017. 


\section{ANEXO 1}

TABLE A-10. Determination from Spectrophotometric Curve of I.C.I. Co-ordinates for a Surface Illuminated by Illuminant $\mathbf{C}$

\begin{tabular}{|c|c|c|c|c|c|c|c|}
\hline \multirow{2}{*}{$\begin{array}{c}\text { I } \\
\text { WAVE- } \\
\text { LENGTH } \\
\text { (microns) }\end{array}$} & \multirow{2}{*}{$\begin{array}{c}\text { II } \\
\text { REFLECT- } \\
\text { ANCE R } \mathbf{4} / 14 \\
\text { n } \\
\text { (from Fig. } \\
\text { 4-9) }\end{array}$} & \multicolumn{3}{|c|}{$\begin{array}{l}\text { III } \\
\text { I.C I.DATA FOR } \\
\text { ILLUMINANT C } \\
\text { (from Tatle A-11) }\end{array}$} & \multicolumn{3}{|c|}{$\stackrel{\text { IV }}{\times}$ III) } \\
\hline & & $\bar{z} P$ & $f^{P}$ & ${ }_{i 2} P$ & $\bar{x} P \eta_{\lambda}$ & $\hat{y} P_{\lambda}$ & $\bar{z} P_{\lambda}$ \\
\hline $\begin{array}{r}0.380 \\
.390\end{array}$ & $\begin{array}{r}0.051 \\
.051\end{array}$ & $\begin{array}{r}4 \\
19\end{array}$ & & $\begin{array}{l}20 \\
89\end{array}$ & 1 & & $\begin{array}{l}1 \\
5\end{array}$ \\
\hline $\begin{array}{l}.400 \\
.410 \\
.420 \\
.430 \\
.440\end{array}$ & $\begin{array}{l}.051 \\
.051 \\
.050 \\
.050 \\
.050\end{array}$ & $\begin{array}{r}85 \\
329 \\
1,238 \\
2,997 \\
3,975\end{array}$ & $\begin{array}{c}2 \\
9 \\
37 \\
122 \\
262\end{array}$ & $\begin{array}{r}404 \\
1,570 \\
5,949 \\
14,628 \\
19,938\end{array}$ & $\begin{array}{r}4 \\
17 \\
62 \\
150 \\
199\end{array}$ & $\begin{array}{l}2 \\
6 \\
13\end{array}$ & $\begin{array}{r}21 \\
80 \\
297 \\
731 \\
997\end{array}$ \\
\hline $\begin{array}{l}.450 \\
.460 \\
.470 \\
.480 \\
.490\end{array}$ & $\begin{array}{l}.047 \\
.045 \\
.044 \\
.043 \\
.041\end{array}$ & $\begin{array}{l}3,915 \\
3,362 \\
2,272 \\
1,112 \\
363\end{array}$ & $\begin{array}{r}443 \\
694 \\
1,058 \\
1,618 \\
2,358\end{array}$ & $\begin{array}{r}20,638 \\
19,299 \\
14,972 \\
9,461 \\
5,274\end{array}$ & $\begin{array}{r}184 \\
151 \\
100 \\
48 \\
15\end{array}$ & $\begin{array}{l}21 \\
31 \\
47 \\
70 \\
97\end{array}$ & $\begin{array}{l}970 \\
868 \\
659 \\
407 \\
216\end{array}$ \\
\hline $\begin{array}{l}.500 \\
.510 \\
.520 \\
.530 \\
.540\end{array}$ & $\begin{array}{l}.041 \\
.041 \\
.041 \\
.041 \\
.041\end{array}$ & $\begin{array}{r}52 \\
89 \\
576 \\
1,523 \\
2,785\end{array}$ & $\begin{array}{l}3,401 \\
4,833 \\
6,462 \\
7,934 \\
9,149\end{array}$ & $\begin{array}{r}2,864 \\
1,520 \\
712 \\
388 \\
195\end{array}$ & $\begin{array}{r}2 \\
4 \\
24 \\
62 \\
114\end{array}$ & $\begin{array}{l}139 \\
198 \\
265 \\
325 \\
375\end{array}$ & $\begin{array}{r}117 \\
62 \\
29 \\
16 \\
8\end{array}$ \\
\hline $\begin{array}{l}.550 \\
.560 \\
.570 \\
.580 \\
.590\end{array}$ & $\begin{array}{l}.042 \\
.043 \\
.050 \\
.075 \\
.145\end{array}$ & $\begin{array}{l}4,282 \\
5,880 \\
7,322 \\
8,417 \\
8,984\end{array}$ & $\begin{array}{l}9,832 \\
9,841 \\
9,147 \\
7,992 \\
6,627\end{array}$ & $\begin{array}{l}86 \\
39 \\
20 \\
16 \\
10\end{array}$ & $\begin{array}{r}180 \\
253 \\
366 \\
631 \\
1,303\end{array}$ & $\begin{array}{l}413 \\
423 \\
457 \\
599 \\
961\end{array}$ & $\begin{array}{l}4 \\
2 \\
1 \\
1 \\
1\end{array}$ \\
\hline $\begin{array}{l}.600 \\
.610 \\
.620 \\
.630 \\
.640\end{array}$ & $\begin{array}{l}.290 \\
.465 \\
.575 \\
.623 \\
.648\end{array}$ & $\begin{array}{l}8,949 \\
8,325 \\
7,070 \\
5,309 \\
3,693\end{array}$ & $\begin{array}{l}5,316 \\
4,176 \\
3,153 \\
2,190 \\
1,443\end{array}$ & $\begin{array}{l}7 \\
2 \\
2\end{array}$ & $\begin{array}{l}2,595 \\
3,871 \\
4,065 \\
3,308 \\
2,393\end{array}$ & $\begin{array}{r}1,542 \\
1,942 \\
1,813 \\
1,364 \\
935\end{array}$ & $\begin{array}{l}2 \\
1 \\
1\end{array}$ \\
\hline $\begin{array}{l}.650 \\
.660 \\
.670 \\
.680 \\
.690\end{array}$ & $\begin{array}{l}.667 \\
.683 \\
.699 \\
.713 \\
.725\end{array}$ & $\begin{array}{r}2,349 \\
1,361 \\
708 \\
369 \\
171\end{array}$ & $\begin{array}{r}886 \\
504 \\
259 \\
134 \\
62\end{array}$ & & $\begin{array}{r}1,567 \\
930 \\
495 \\
263 \\
124\end{array}$ & $\begin{array}{r}591 \\
344 \\
181 \\
96 \\
45\end{array}$ & \\
\hline $\begin{array}{l}.700 \\
.710 \\
.720 \\
.730 \\
.740 \\
.750 \\
.760\end{array}$ & $\begin{array}{l}.739 \\
.749 \\
.762 \\
.775 \\
.785 \\
.791 \\
.795\end{array}$ & $\begin{array}{r}82 \\
39 \\
19 \\
8 \\
4 \\
2 \\
1\end{array}$ & $\begin{array}{r}29 \\
14 \\
6 \\
3 \\
2 \\
1 \\
1\end{array}$ & & $\begin{array}{r}61 \\
29 \\
14 \\
6 \\
3 \\
2 \\
1\end{array}$ & $\begin{array}{r}21 \\
10 \\
5 \\
2 \\
2 \\
1 \\
1\end{array}$ & \\
\hline ums.. & . & 98,040 & 100,000 & 118,103 & $X=23,597$ & $Y=13,337$ & $Z=5,497$ \\
\hline
\end{tabular}

Dados utilizados para cálculo das coordenadas tricromáticas das amostras. Extraído de HANDBOOK, IES Lightning. Illuminating Engineering Society of North America. New York, 1987. 